\title{
U.S. FOOD AND NUTRITION PROGRAMS
}

\author{
Hilary W. Hoynes \\ Diane Whitmore Schanzenbach \\ Working Paper 21057 \\ http://www.nber.org/papers/w21057 \\ NATIONAL BUREAU OF ECONOMIC RESEARCH \\ 1050 Massachusetts Avenue \\ Cambridge, MA 02138 \\ March 2015
}

We thank Dorian Carloni, Elora Ditton and Andrea Kwan for excellent research assistance. We appreciate comments provided by Marianne Bitler, Jeffrey Liebman, Robert Moffitt, Zoe Neuberger, Dottie Rosenbaum, and James Ziliak. The views expressed herein are those of the authors and do not necessarily reflect the views of the National Bureau of Economic Research.

NBER working papers are circulated for discussion and comment purposes. They have not been peerreviewed or been subject to the review by the NBER Board of Directors that accompanies official NBER publications.

(C) 2015 by Hilary W. Hoynes and Diane Whitmore Schanzenbach. All rights reserved. Short sections of text, not to exceed two paragraphs, may be quoted without explicit permission provided that full credit, including $(\mathcal{C}$ notice, is given to the source. 
U.S. Food and Nutrition Programs

Hilary W. Hoynes and Diane Whitmore Schanzenbach

NBER Working Paper No. 21057

March 2015, Revised September 2015

JEL No. H53,I3

\begin{abstract}
$\underline{\text { ABSTRACT }}$
This chapter provides an overview of the patchwork of U.S. food and nutrition programs, with detailed discussions of SNAP (formerly the Food Stamp Program), WIC, and the school breakfast and lunch programs. Building on Currie's (2003) review, we document the history and goals of the programs, and describe the current program rules. We also provide program statistics and how participation and costs have changed over time. The programs vary along how "in-kind" the benefits are, and we describe economic frameworks through which each can be analyzed. We then review the recent research on each program, focusing on studies that employ techniques that can isolate causal impacts. We conclude by highlighting gaps in current knowledge and promising areas for future research.
\end{abstract}

Hilary W. Hoynes

Richard \& Rhoda Goldman School of Public Policy

University of California, Berkeley

2607 Hearst Avenue

Berkeley, CA 94720-7320

and NBER

hoynes@berkeley.edu

Diane Whitmore Schanzenbach

School of Education and Social Policy

Northwestern University

Annenberg Hall, Room 205

2120 Campus Drive

Evanston, IL 60208

and NBER

dws@northwestern.edu 
Concerns about adequate nutrition figure prominently in discussions of the health and wellbeing of America's disadvantaged populations. In 2014, 15.4 percent of persons and 20.9 percent of children lived in households reported as food insecure - meaning conditions such as worrying about whether food would run out, food not lasting, not being able to afford balanced meals, skipping meals, not eating enough (Coleman-Jensen et al. 2015). At the same time, Americans' diet quality has been persistently low and unchanging over time (Wang et al. 2014) and more than a third of adults and 17 percent of children are obese (Ogden et al. 2014).

To address these problems, a range of U.S. food and nutrition programs are provided by the U.S. Department of Agriculture. Spending on the top eight programs totaled $\$ 99$ billion in 2014; by comparison the Earned Income Tax Credit cost $\$ 64$ billion (in 2012). In this survey, we focus on the four largest of these programs, including Supplemental Nutrition Access Program (SNAP, previously known as Food Stamps), Special Supplemental Nutrition Program for Women Infants and Children (WIC), the National School Lunch Program (NSLP) and the School Breakfast Program (SBP).

There are many features that are common to the four food and nutrition programs. The programs are all means tested, that is they are limited to individuals living in households with limited income (and sometimes limited assets). The programs share the goal of assuring adequate nutrition. Notably, while much of the U.S. social safety net is provided at the state or local level, food and nutrition programs are federal, thus providing a basic floor for protecting individuals and families that is similar across all states.

However, there are also important ways in which the programs differ. First, the programs vary in their targeted populations, from near-universal eligibility for SNAP to the narrowly defined age groups eligible for WIC. Second, the income cutoffs for eligibility vary across the programs with higher income limits (185 percent of the federal poverty line) for WIC compared to SNAP (130 percent of the federal poverty line). Third, the programs also vary by the degree to which the benefits are provided "in-kind," from largely unrestricted vouchers in SNAP, to moretargeted vouchers in WIC, to direct provision of meals that are required to conform to nutrition guidelines in the school feeding programs. Fourth, the programs vary by whether they phase out gradually (SNAP) or abruptly as income increases (the others). Together, these factors affect how the programs impact the family's budget, and as we describe in section 3 below, how they are to be modeled in the canonical means-tested program budget constraint framework. Notably, the programs also layer on top of each other so that a family may be receiving benefits from multiple programs at once, and also may lose access to one or more of them abruptly (e.g. during school vacations, or when a child ages out of WIC).

We begin our survey with a description of these four central food and nutrition programs, their history, the rules under which they operate, as well as providing program statistics. SNAP is by far the largest program at a cost of $\$ 74.2$ billion in 2014. Nearly 1 in 7 Americans participated in SNAP in 2014, and the program lifted 4.7 million people including 2.1 million children out of poverty in 2014 (Short 2015). SNAP is the most universal of the programs, in that is there is no additional targeting to specific groups beyond income and asset eligibility criteria. Additionally, SNAP is the most unrestricted as the program provides vouchers that can be used to purchase most foods at grocery stores or other authorized retailers. Average monthly benefits in 2014 
amounted to $\$ 257$ per household, or $\$ 125$ per person. This translates to benefits worth about $\$ 4.11$ per person per day.

WIC is more narrowly targeted in terms of both population served and types of goods that can be purchased with benefits. $\$ 6.2$ billion was spent on WIC in 2014. As the name implies, benefits are targeted to infants, young children, and pregnant and postpartum women. WIC benefits can be used to purchase infant formula and other specific food items such as milk, cereal and juice as specified in the WIC bundle. Additionally WIC provides nutrition education and referrals to health care and other social services. Over half of U.S. infants receive WIC benefits.

The school breakfast and lunch programs (SBP and NSLP) provide free or low-cost meals to low-income children. Students from higher-income families may also participate in the program through the purchase of meals, and these meals receive subsidies (though much smaller ones) as well. Forty percent of school children receive free or reduced price lunches and 56.6 percent of school children overall participate in the NSLP. The combined cost of these programs in 2014 totaled 15 billion.

We go on, in section 3, to discuss the theoretical issues around these programs. Each of the food and nutrition programs can be analyzed through standard economic frameworks to explore predicted effects on food consumption and labor supply. The applicable frameworks and predictions differ somewhat due to the design of the programs - such as how "in-kind" the benefits are and whether they are phased out gradually or are all or nothing. We pay particular attention to the difference in incentives for programs with "value vouchers" (as in SNAP) versus those with "quantity vouchers" (as in WIC). An important distinction of programs with quantity vouchers is the lack of sensitivity to price, leading to incentives for firm markup and increases in program costs. More generally, as with other means-tested transfer programs, these programs face the usual tradeoff in balancing the protective aspects of the programs to improve dietary intake and reduce food insecurity against their distorting incentives such as reduced labor supply.

In Section 4 we provide a comprehensive summary of the research on these programs, with particular emphasis on the work published since Currie (2003). We begin by discussing the challenges for identification and an overview of the different empirical approaches taken in the literature. A central challenge for evaluation of the effects of food and nutrition programs is that commonly used quasi-experimental approaches, relying on variation across states and reforms over time, are not easily applied. This stems from the federal structure of these programs and the relatively limited changes over time. Further, a comparison of participants to nonparticipants is problematic due to selection into the program and its relationship to poverty and disadvantage. Additionally, with respect to the food stamp program, the universal nature of the program means there are no ineligible groups to serve as controls, which is another common approach in the quasi-experimental literature. Nonetheless, researchers have found sources of variation - such as exploiting geographic variation in access, sharp differences in eligibility, and program rule changes - to credibly identify program impacts in some cases. We provide a summary of the literature on our four central food and nutrition programs, focusing on studies with credible, design based approaches. Throughout our review, we pay particular attention to studies that examine the impact and relevance of these programs for the nonelderly population. 
Overall our review of SNAP studies shows that macroeconomic conditions are a key determinant for tracking caseloads and expenditures over time, with less role for changes in program policies. Additionally, studies have investigated the impacts of SNAP on a wide range of economic and health outcomes, including their impacts on food insecurity, dietary quality, consumption patterns, obesity, and labor market participation. In general, the studies with the most credible designs have found results on take-up and consumption that are consistent with economic theory predictions. SNAP increases family resources and studies show that the program leads to increases in food and nonfood spending. Furthermore, the increases in food spending from the relatively unrestricted SNAP benefit appear to be similar to if the program was provided as cash. Studies consistently show that SNAP reduces food insecurity and increases health at birth and greater exposure to SNAP in early life leads to improvements in medium term and long term health. The evidence for effects of SNAP on contemporaneous health for children and adults is more mixed, however.

The literature on WIC is primarily aimed at estimating the effects of the program on health at birth. The most credible design-based studies show consistent evidence that WIC leads to improvements in outcomes such as average birthweight, the incidence of low birth weight and maternal weight gain. There is much less evidence about how the program affects outcomes for children, who are eligible for benefits through age 5. Recent work on firm incentives explores interesting and important issues arising due to the quantity voucher nature of the program.

Most research on the NSLP has focused on how the program impacts dietary intake, and also obesity rates. The results have been somewhat mixed, with generally more positive impacts for lower-income students. The research on the SBP has increased dramatically over the past 20 years, in part taking advantage of the expansion of the program during this time first to schools that previously did not offer the program, and then by expanding access within schools to a wider range of students. The former generally shows positive program impacts, while the latter finds strong improvements in participation but more mixed effects on dietary quality and student outcomes.

We conclude by discussing new developments and current policy discussions. We identify areas that are unexplored and discuss areas that are ripe for future research.

\section{History of the programs and rules}

Table 1.1 provides a brief overview of the four food and nutrition programs that we study in this chapter: SNAP (formerly the Food Stamp Program), Supplemental Nutrition Program for Women, Infants and Children (WIC), National School Lunch Program, and School Breakfast Program. While all of the programs share the goal of assuring adequate nutritional intake among at risk populations and each is means tested, the programs differ in terms of the population served, and the nature of the program provided. SNAP is the largest program, reaching an average of 46.5 million persons at a total annual cost of $\$ 74.2$ billion in 2014 . It is the most unrestricted, providing a debit card to facilitate purchases of most food items in the grocery store and extending benefits to the broadest population. WIC, on the other hand, is highly prescribed 
benefit, largely consisting of "quantity" vouchers to purchase very specific bundles. Additionally, the program is highly targeted, extending benefits only to pregnant and postpartum women, infants and children under age five. In 2014, WIC served just under 2 million women and 6.3 million children at a cost of $\$ 6.3$ billion. The school lunch and breakfast programs provide free and reduced-price meals to eligible school-aged children. In 2014, the lunch program served 21.7 million low-income children at a cost of $\$ 9.6$ billion and the breakfast program served 11.6 million low-income children at a total cost of $\$ 3.6$ billion. ${ }^{1}$

\subsection{Program History and Rules: SNAP}

\subsubsection{Overview of Program}

SNAP has features consistent with traditional means-tested transfer programs. Eligible households must satisfy income and asset tests. Maximum benefits are assigned based on household size, and actual benefits received are reduced as income increases based on the benefit reduction rate (or tax rate) calculated through the benefits formula. The similarities with other U.S. means-tested programs end there.

Unlike virtually all means tested programs in the U.S., SNAP eligibility is not limited to certain targeted groups such as families with children, aged, and the disabled. ${ }^{2}$ Second, SNAP is a federal program with all funding (except 50 percent of administrative costs) provided by the federal government, eligibility and benefit rules determined federally, and comparably few rules set by the states (particularly prior to welfare reform). ${ }^{3}$ Third, the income eligibility threshold and benefits are adjusted for changes in prices each year. ${ }^{4}$ Fourth, the benefit reduction rate is $30 \%$ of net income (lower than AFDC/TANF) and the program serves both the working and nonworking poor. Its universal eligibility (i.e., eligibility depends only on need) combined with the fact that benefits and caseloads rise freely with need (i.e., it expands during recessions, since the program is an entitlement and expenditures are not capped) have elevated SNAP to its status as the fundamental safety net program in the U.S.

Benefits take the form of "value vouchers" in that they provide a dollar amount that can be used to purchase most foods from grocery stores that are foods designed to be taken home and prepared. In other words, most grocery store foods can be purchased with the exceptions of goods such as hot foods intended for immediate consumption, vitamins, paper products, pet foods, alcohol and tobacco. Starting in the late 1980s and completed by 2004, states transitioned to delivery of benefits by Electronic Benefit Transfer (EBT) cards, eliminating the use of paper vouchers. In 2008, the program name was changed from the Food Stamp Program to the

\footnotetext{
${ }^{1}$ These costs only include spending on free and reduced-price meals. Total spending, including paid meals, in 2014 was $\$ 11.4$ and $\$ 3.7$ billion for lunch and breakfast, respectively.

${ }^{2}$ The program is not quite universal: notably undocumented immigrants are not eligible for SNAP. Additionally, as discussed below, there are restrictions on receipt for able bodied adults 18-49 without dependents.

${ }^{3}$ In other public assistance programs such as TANF and Medicaid, states determine fundamental parameters such as the income eligibility cutoffs and (for TANF) benefit levels.

${ }^{4}$ Benefits are tied to the cost of a "market basked of foods which if prepared and consumed at home, would provide a complete, nutritious diet at minimal cost", the so-called Thrifty Food Plan, and then indexed for increases in prices.
} 
Supplemental Nutrition Assistance Program (SNAP). Some states have different names for the program, such as California's "CalFresh".

\subsubsection{Eligibility and Benefits}

SNAP, like other safety net programs, is designed to insure a basic level of consumption in low-income families. Consequently, a traditional income support program will feature a "guarantee" - that is, a benefit level if the family has no income. As earnings or income increases, benefits are reduced resulting in an implicit tax rate on earnings (called the benefit reduction rate or BRR).

Unlike most means-tested benefit programs in the U.S., SNAP is broadly available to almost all households with low incomes. The eligibility rules and benefit levels vary little within the U.S., and are largely set at the federal level. Eligible households must meet three criteria: gross monthly income does not exceed 130 percent of the poverty line, net income (income after deductions) does not exceed the poverty line, and "countable" assets do not exceed $\$ 2,250$ (or $\$ 3,250$ for elderly, disabled). ${ }^{5}$ Additionally, most non-working, non-disabled childless adults aged 18 to 49 (referred to as able bodied adults without dependents or ABAWD) are limited to three months of benefits within a three-year period. The eligibility unit is the "household unit" and consists of people who purchase and prepare food together. After initial eligibility, households must be recertified every 6 to 24 months.

A stylized version of the benefit formula is presented in Figure 1.1 for a family of a fixed size. A key parameter of the formula is the cost of food under the USDA's Thrifty Food Plan, which we also term the "needs standard." The maximum SNAP benefit amount (represented as the horizontal line in the figure) is typically set equal to the needs standard. ${ }^{6}$ SNAP is designed to fill the gap between the needs standard and the cash resources available to a family to purchase food. A family with no income receives the maximum benefit amount, and is expected to contribute nothing out-of-pocket to food purchases. Total food spending, depicted by the upward-sloping line labeled "hypothetical food spending" increases with income since food is a normal good. ${ }^{7}$ Total food spending thus equals the maximum benefit level for a family with no other income source. As a family's income increases, they are expected to be able to spend more of their own cash on food purchases, and SNAP benefits are reduced accordingly. The slope of the SNAP benefits line in Figure 1.1 is the BRR, which is currently set at 0.3 . The benefit formula is thus as follows:

$$
\text { Benefits }=\text { Max_Benefit }-0.3 *(\text { Net_Income }) \text {. }
$$

\footnotetext{
${ }^{5}$ As described below, the gross income test rules have recently been relaxed through expansions in categorical eligibility. For SNAP, countable assets exclude homes and retirement plans, and the extent to which vehicles are counted varies across states. SNAP recipients who receive SSI or TANF are excluded from the SNAP asset test. ${ }^{6}$ Congress can set maximum benefits equal to some multiple of the needs standard. For example, the American Recovery and Reinvestment Act of 2009 temporarily raised maximum benefits to be 113.6 percent of the needs standard.

${ }^{7}$ As drawn here, we assume the marginal propensity to consume food out of income is lower than the marginal tax rate, and we assume that SNAP is valued the same as cash for food purchases.
} 
The SNAP benefit level as a function of net family income is represented by the downward-sloping line in the figure. Finally, the family's out-of-pocket spending on food is the vertical distance between the SNAP benefits line and the food spending line.

Net income is calculated as cash pre-tax income less the following deductions: a standard deduction, a $20 \%$ deduction from earned income, an excess shelter cost deduction, a deduction for childcare costs associated with working/training, and a medical cost deduction that is available only to the elderly and disabled. Because of these deductions, in practice the benefit reduction rate (the effective tax rate) out of gross income is lower than 0.3 (we present data on this below). Notably, the income measures used for SNAP eligibility use a cash, pre-tax measure and therefore do not include in-kind benefits (e.g. housing assistance) or tax credits including the EITC or the Child Tax Credit. Net income does include cash transfers such as social security, disability income, unemployment insurance and TANF.

Central policy issues include whether the needs standard is set at an appropriate level, and whether the benefit reduction rate is appropriate (Institute of Medicine 2013). It is worth pointing out that this 0.3 (statutory) benefit reduction rate is substantially lower than that experienced by other safety net programs such as disability and TANF.

\subsubsection{History, Reforms, and Policy Changes}

Currie (2003) provides a detailed history of the Food Stamp Program. We briefly touch on some of the important elements of the history and discuss more recent policy changes.

The modern Food Stamp Program began with President Kennedy's 1961 initiation of pilot food stamp programs in eight impoverished counties. ${ }^{8}$ The pilot programs were later expanded to 43 counties in 1962 and 1963. The success with these pilot programs led to the Food Stamp Act of 1964, which gave local areas the authority to start up the Food Stamp Program in their county. As it remains today, the program was federally funded and benefits were redeemable at approved retail food stores. In the period following the passage of the Food Stamp Act, there was a steady stream of counties initiating Food Stamp Programs and Federal spending on the FSP more than doubled between 1967 and 1969. Support for requiring counties to participate in FSP grew due to a national spotlight on hunger (Berry 1984). This interest culminated in passage of 1973 Amendments to the Food Stamp Act, which mandated that all counties offer FSP by $1975 .{ }^{9}$

Figure 1.2 plots the population weighted percent of counties with a FSP from 1960 to 1975. ${ }^{10}$ During the pilot phase (1961-1964), FSP coverage increased slowly. Beginning in 1964, Program growth accelerated; coverage expanded at a steady pace until all counties were covered

\footnotetext{
${ }^{8}$ A more detailed history timeline can be found here: http://www.fns.usda.gov/sites/default/files/timeline.pdf.

${ }^{9}$ Prior to the Food Stamp program, some counties provided food aid through the Commodity Distribution Program (CDP). The main goal of the CDP was to support farm prices and farm income by removing surplus commodities from the market. The CDP was far from a universal program. It never reached all counties. The food basket contained a limited range of products, the distribution was infrequent, and distribution centers were difficult to reach.

${ }^{10}$ Counties are weighted by their 1970 population. Note this is not the food stamp caseload, but represents the percent of the U.S. population that lived in a county with a FSP.
} 
in 1974. There was substantial heterogeneity in timing of adoption of the FSP, both within and across states. The map in Figure 1.3 shades counties according to date of FSP adoption (with darker shading denoting a later start-up date).

Compared to the dramatic reforms (AFDC) and expansions (EITC) of income support programs that have characterized the last two decades, the programmatic aspects of Food Stamps have remained fairly stable over time. A major change took place in the 1977 Food Stamp Act reauthorization with the elimination of the purchase requirement. Prior to this law change, families were required to make cash payment upfront (the "purchase requirement") to receive their food stamp benefits. The presence of (or elimination of) this feature did not change the net value of the benefits a family received yet food stamp caseloads increased substantially after the removal of the purchase requirement. ${ }^{11}$

The 1996 welfare-reform legislation left the core structure of the Food Stamp Program relatively unaffected but did limit benefits for legal immigrants (who were deemed ineligible until they accumulated 10 years of work history) and able-bodied adults without dependents 1849 (who were typically limited to 3 months of benefits in a 3 year period) and eliminated benefits for convicted drug felons. ${ }^{12,13}$ The legislation included a temporary waiver of the time limits in places with high unemployment rates or "insufficient jobs". A 1998 agriculture bill restored food stamp eligibility to some legal immigrant children, disabled persons, the blind, and the elderly (those who had arrived in the U.S. prior to welfare reform). Later, the 2002 Farm Bill restored food stamp eligibility to all legal immigrant children and disabled persons, regardless of their time of residence in U.S., and to legal immigrant adults in the country for five or more years. Additionally, welfare reform reduced the maximum benefit, froze many deductions used in calculating net income, and mandated that states adopt Electronic Benefit Transfer.

Beginning with regulatory changes in 1999 and continuing with the 2002 Farm Bill, the USDA has allowed states to implement policies aimed at improving access to benefits, particularly for working families. This came from the observation that the process of signing up for Food Stamps takes considerable time and, in particular for working families, getting to the benefits office can be a significant barrier to access to the program. This has led to redesigning income reporting requirements (increasing the time between re-certifications, reducing income reporting between re-certifications), moving away from in-person meetings for determining

\footnotetext{
${ }^{11}$ That is, if the family was deemed able to afford to spend $\$ 60$ on food, but the cost of the thrifty food plan was $\$ 80$, the family could purchase $\$ 80$ in food stamps for the cash price of $\$ 60$. Under today's program, a similar family would receive simply receive $\$ 20$ in food stamps and would not have to outlay any cash.

${ }^{12}$ The CBO estimated that welfare reform's changes to food stamps that did not address immigrants would reduce spending on food stamps by $\$ 23$ billion over 1997-2002. Most of the savings came from imposing the work requirement, reducing maximum benefits across the board, and changing allowable deductions when calculating net income. See http://www.cbo.gov/sites/default/files/1996doc32.pdf.

${ }^{13}$ As discussed in Bitler and Hoynes (2013), prior to welfare reform, there was a "bright line" that distinguished between legal immigrants and unauthorized residents in determining eligibility for safety net programs. Legal immigrants were eligible for most safety net programs on the same terms as citizens while unauthorized immigrants were not. There were exceptions: unauthorized immigrants maintained eligibility for free and reduced price School Lunch and Breakfast, WIC, emergency Medicaid, and state funded emergency programs. In addition, refugees and asylum seekers also sometimes faced different rules than others. Finally, in response to the post-welfare reform reductions in immigrant eligibility for food stamps, some states chose to maintain coverage for legal immigrants with state-funded replacement coverage (known as "fill in" programs).
} 
eligibility (instead using call centers and online applications) as well as relaxing of asset limits (such as vehicle ownership). Additionally, during this time states also expanded "broad based categorical eligibility" (U.S. GAO 2007) whereby states extend SNAP eligibility to households whose gross income is above 130 percent of poverty (above gross income test) but with disposable income is below the poverty line (meet the net income test). They also can relax the asset limits. However, the benefit formula remained fixed (as the maximum benefit less $30 \%$ of net income); this implies that any expanded eligibility would be for those with large deductions to gross income (such as families with high child care and shelter costs).

In 2008, the Food Stamp Program was renamed the Supplemental Nutrition Assistance Program (SNAP). Legislative reforms at that time also included excluding certain tax-preferred education savings and retirement accounts from the calculation of the asset test, and indexing of the asset limits to inflation.

The American Recovery and Reinvestment Act of 2009 (federal stimulus or ARRA) increased the maximum SNAP benefit by 13.6 percent. Due to ordinary SNAP nominal benefit changes and additional legislation, the benefit increase was sunset in October 2013. In addition, because unemployment rates rose to high levels during the Great Recession, in most states the threemonth time limit on able-bodied childless adults was temporarily suspended as allowed at state option during periods of high unemployment under the rules adopted with welfare reform.

\subsection{Program History and Rules: WIC}

\subsubsection{Overview of Program}

The goal of the Supplemental Nutrition Program for Women, Infants, and Children (WIC) is to improve the nutritional well-being of low-income pregnant and postpartum women, infants, and children under the age of five who are at nutritional risk by providing nutritious foods to supplement diets, nutrition education, and referrals to health care and social services. More specifically the program aims to improve birth outcomes, support the growth and development of infants and children, and promote long-term health in all WIC participants. WIC also provides nutritional services and education.

\subsubsection{Eligibility and Benefits}

Eligibility for WIC requires satisfying categorical eligibility and income eligibility requirements. Five types of individuals are categorically eligible for WIC: pregnant women, post-partum women for six months after birth, breastfeeding women with an infant under 12 months, infants, and children under age five. Benefits are assigned separately for each group, so for example an income-eligible family consisting of a pregnant woman, infant and child under age 5 would receive three WIC benefits. Income eligibility dictates that participants must live in households with family incomes below 185 percent of the poverty line or become eligible through participation in another welfare program (with income eligibility below 185 percent of poverty) such as TANF or SNAP. Under the federal rules, immigrants are eligible for WIC under 
the same circumstances as natives. ${ }^{14}$ Additionally, participants must be deemed to be at nutritional risk; risk factors include low maternal weight gain, inadequate growth in children, anemia, dietary deficiencies, heavy weight, and other nutrition-related medical conditions. ${ }^{15}$ However, virtually all financially eligible persons appear to satisfy this requirement (Ver Ploeg and Betson 2003). After initial eligibility, recertification is generally required every 6 months. Like SNAP, WIC benefits take the form of vouchers and many states currently use (or are in planning stages to use) debit cards for distributing benefits. The vast majority of WIC participants access the food packages by redeeming vouchers or using EBT at participating retail outlets. ${ }^{16}$

WIC benefits differ from Food Stamp benefits in two key ways. First, the WIC benefit does not vary with countable income, and thus there is no "benefit reduction rate" that reduces the benefit as countable income rises. Instead, as with programs such as Medicaid, recipients who are income and categorically eligible receive the full WIC benefit (an "all or nothing" benefit package). Second, the WIC bundle is restricted to specific items; the WIC approved foods are chosen because they contain substantial amounts of protein, calcium, iron, or Vitamins A or C. The approved foods include juice, fortified cereal, eggs, cheese, milk, dried legumes or peanut butter, and canned fish. Table 1.2 summarizes the current elements of the food package and the specified maximum monthly allowance of WIC foods (separately for each eligibility group). For example, children ages one to four receive vouchers for juice (128 fluid ounces), milk (16 quarts), breakfast cereal (36 ounces), eggs (one dozen), whole wheat bread (2 pounds), and legumes/peanut butter. Infants are eligible for formula (if not exclusively breast fed), infant cereal and baby food. Post-partum women have access to breastfeeding services. In addition, in 2009 WIC added a "cash value voucher" (CVV) here shown as \$8 (\$10) for fruits and vegetables for children (women).

This discussion makes clear that WIC then is primarily a "quantity" voucher and thus households do not face price incentives for these goods (the exception is the CVV for fruits and vegetables). In part to address this, an increasing number of states require participants to limit purchases to the cheapest available items or store brands in the authorized grocery outlet. More generally, WIC purchases may be limited by product type, product size, and brand. An important special case of this is for infant formula, which is a large part of WIC food costs. In 2010, spending on formula for WIC totaled almost $\$ 1$ billion out of a total program food cost of $\$ 4.6$ billion (FNS 2013). Under current regulations, state WIC agencies typically award a contract to a single manufacturer of infant formula in exchange for a rebate for each can of infant formula purchased by WIC participants. These rebates are very high, ranging from 77 to 98 percent of the wholesale price. The formula market is highly concentrated - with only three firms - and more than half of all formula sold in the U.S. goes to WIC participants (Oliveira et al. 2013).

In addition to the food benefits, WIC provides participants with health screenings, nutrition education, and referrals to other social services.

\footnotetext{
${ }^{14}$ States have the discretion to deny benefits to immigrants, though as of this writing none have implemented explicit restrictions (http://www.fns.usda.gov/sites/default/files/wic/WICRegulations-7CFR246.pdf).

${ }^{15}$ Risk factors can also include homelessness and migrancy, drug abuse and alcoholism.

${ }^{16}$ Alternatively, a few state agencies purchase the items in bulk and make available through distribution centers or through home delivery.
} 
Importantly WIC is not an entitlement program; SNAP on the other hand has been a fully funded entitlement since the program went national in 1975. Congress makes appropriations for WIC, which in principle could lead to shortfalls in the number of people that can be served. In recent times (since 1997), these allocations have been sufficient to meet demand for the program and thus in practice it has operated as an entitlement program.

WIC has an unusual administrative structure that operates at the Federal, State and local levels. The program is federally funded and operated through the USDA. The USDA provides grants to support food benefits, nutrition services, and administration to 90 WIC agencies (covering the 50 states, Washington DC, U.S. territories, and Indian Tribal Organizations). The State agencies then contract with local WIC sponsoring agencies located primarily in State and county health departments. These local sponsoring agencies then provide benefits directly or through local services sites at community health centers, hospitals, schools, mobile vans, and other locations.

\subsubsection{History, Reforms, and Policy Changes}

Currie (2003) provides a detailed history of WIC. We briefly touch on some of the important elements of the history and discuss more recent policy changes. ${ }^{17}$

The WIC program was first established as a pilot program in 1972 as an amendment to the Child Nutrition Act of 1966. The program was developed in direct response to policy recommendations highlighting health deficits among low-income individuals that might be reduced by improving their access to food. It was further recognized that, by providing food at "critical times of development" to pregnant and lactating women and young children, it might be possible to prevent a variety of health problems (Oliveira et al. 2002). The program became permanent in 1975. WIC was intended to provide targeted benefits to its eligible population, and was not intended to replace food stamp benefits for them. The authorizing legislation specifically did not preclude a person from WIC participation if they were already receiving food stamps.

WIC sites were established in different counties between 1972 and 1979, with legislation requiring that the program be implemented first in "areas most in need of special supplemental food" (Oliveira et al. 2002). The first WIC program office was established in January 1974 in Kentucky, and had expanded to include counties in 45 states by the end of that year. ${ }^{18}$ Figure 1.4 shows the population weighted percent of counties with WIC programs in place. The graph shows steady expansion in the program between the years of 1974-1978.

The Child Nutrition and WIC Reauthorization Act of 1989 established automatic eligibility for WIC for families participating in Food Stamps, Medicaid or Aid to Families with Dependent Children. At this time, the WIC income eligibility limits exceeded the limits in these other programs. The policy change led to an expansion of WIC and in some ways turned it into a

\footnotetext{
${ }^{17}$ Much of this section is drawn from Oliveira et al. (2002).

${ }^{18}$ Participation in the commodity distribution program, however, disqualified individuals from WIC participation (Oliveira et al. 2002). But the CDP was being phased out during the 1970s as the FSP expanded to a national program.
} 
"gateway program through which many low-income households enter the public health system" (Macro International 1995). Additionally, the Act required WIC agencies to use competitive bidding or other cost containment policies to reduce costs of infant formula. Finally, the Act required USDA to promote breastfeeding.

For the first 30 plus years of the program, there was little change in the WIC food package. The food packages throughout this period included a very limited number of items: juice, infant cereal, milk, cheese, eggs, dried beans, and peanut butter. The only major change to the food package in this period was in 1992 with the addition of an enhanced WIC food package including canned tuna and carrots for fully breastfeeding mothers, which was part of a growing desire to encourage breastfeeding among the WIC population.

In the late 1990s and early 2000s there was a growing view that this very narrow food package did not adequately meet current dietary guidelines (which are updated every 5 years). Additionally, concerns grew about significant changes in the food supply at grocery outlets (such as the increased availability of low-cost, energy-dense foods), the growing prevalence of obesity, and whether WIC foods were culturally appropriate for all participants. The USDA's Food and Nutrition Service set a goal to determine cost-neutral changes to WIC food packages based on information about the nutrition needs of WIC participants. This led to a report by the Institute of Medicine (IOM 2005), with new food packages introduced in 2009 and adopted in 2014. The IOM report identified that WIC packages should increase their coverage of nutrients such as iron, vitamin E, potassium, and fiber, and also provide more access to fruits and vegetables. Particular attention was aimed at encouraging breastfeeding through expanding the food package for breastfeeding mothers. The modified rules added flexible vouchers for fruit and vegetables (e.g. $\$ 8.00$ per month for a child, $\$ 10.00$ for pregnant and breastfeeding women), decreased juice and milk allotments, and added milk alternatives (cheese, yogurt, tofu) and whole grains. Table 1.2 , as presented above, describes this recently adopted WIC food bundle. The Institute of Medicine is now reviewing the WIC food package to update it to reflect the latest nutrition science and Dietary Guidelines for Americans.

\subsection{Program History and Rules: National School Lunch Program}

\subsubsection{Overview of Program}

The school lunch program provides Federal cash and commodity support for meals served to children at public and private schools, and other qualifying institutions. There is a three-tiered system based on a child's household income that determines the level of Federal payments made to schools. Unless the school has adopted a universal free meals plan, this system also typically determines the student's price category (free, reduced-price, or paid).

Schools receive both cash and in-kind payments for meals served. In 2014-15, schools received Federal cash subsidies equal to $\$ 2.98$ per free lunch, $\$ 2.58$ per reduced-price lunch, and $\$ 0.28$ per paid lunch. ${ }^{19}$ If the share of free or reduced-price lunches served at the school exceeds 60 percent (in a base year two years prior to the current year), then per-meal cash subsidies are

\footnotetext{
${ }^{19}$ Payment levels are higher in Alaska and Hawaii.
} 
increased by 2 cents per meal. ${ }^{20}$ As described below, schools are eligible for additional payments of 6 cents per meal if they document that their lunches meet nutritional guidelines. In addition, schools receive commodity foods worth $\$ 0.2475$ for each lunch served, regardless of the price category. Schools may also receive bonus commodities from USDA's purchase of surplus commodities if they are available.

\subsubsection{Benefits and Eligibility}

Under traditional eligibility, children from households with incomes less than 130 percent of the federal poverty line receive lunches free of charge, while those from households with incomes between 130 percent and 185 percent of the federal poverty line are eligible for reduced-price meals, which have a maximum allowable price charged to students of $\$ 0.40$. Children from households with incomes above 185 percent of the federal poverty line may purchase so-called "paid meals." Individual school districts have discretion to set their own prices for paid lunches, which are priced on average less than $\$ 2.50$ per meal. Some children are additionally eligible for free meals based on categorical eligibility criteria, or if their school has adopted a universal free meal program. Regardless of household income, children are deemed to be categorically eligible for free meals if their family receives benefits through SNAP or the Food Distribution Program on Indian Reservations (FDPIR), TANF, if the child is a foster, homeless, runaway or migrant, or if the child is in Head Start. Students are offered the same components of school lunch regardless of their price category, and are allowed some choice to refuse components they are offered.

In recent years, there has been expansion in the use of direct certification of students for free meals using other data sources instead of requiring families to fill out application forms at schools. Direct certification can take the form of data matching or, in the case of homeless, migrant, runaway or foster children, using a list provided to the school meals program by an appropriate official. States are required to conduct direct certification using SNAP data, but are not required to conduct direct certification using other sources (e.g. TANF or FDPIR rolls). ${ }^{21}$ The 2010 Healthy, Hunger-Free Kids Act provides incentives to states that show "outstanding performance" or "substantial improvement" in directly certifying students for free meals through these methods. In addition, as described below, students who are not income-eligible or categorically eligible for free meals may receive them for free if their school has adopted a universal free lunch program.

\subsubsection{History, Reforms, and Policy Changes}

Predecessors to the National School Lunch Program (NSLP) date back to the Great Depression, when the government began to distribute surplus farm commodities to schools with large populations of malnourished students. In 1946 Congress passed the National School Lunch Act (Gunderson 1971, see also Table 1.3). The act's statement of purpose indicates that a nonprofit school lunch program should be established "as a measure of national security" with the dual purposes "to safeguard the health and well-being of the Nation's children and to

\footnotetext{
${ }^{20}$ Some states provide additional supplementary funding.

${ }^{21}$ Under USDA demonstration projects, a few states are allowed to use Medicaid data for direct certification, but only if the household's income is at or below 133\% of the federal poverty line (Levin and Neuberger, 2014).
} 
encourage the domestic consumption of nutritious agricultural commodities and other food..." Under the Act, commodities were distributed and cash payments were made to states according to a formula that was a function of per-capita income and population. The NSLP was significantly amended in 1962 to adjust the funding formula to become a function of both the program participation rate and the "assistance need rate" that was a function of the state's average per capita income (Hinrichs 2010).

In recent years there have been legislative changes both regarding payment formulas and nutrition standards. In terms of payment formulas, there have been several recent efforts to reduce administrative costs for the payment process. Under the typical approach to eligibility, families are required to apply for the lunch subsidy, and then schools must track daily meal participation by price category. The alternative reimbursement provisions save schools the administrative costs of both processing applications and also daily tracking of meals served by price category. One such provision available to schools is the Community Eligibility Provision (CEP), which was phased-in starting in 2011 and became available nationally in the 2014-15 school year. This policy allows schools to provide free meals to all of its students if they can document that at least 40 percent of their students are categorically eligible for free meals. If a school opts for the CEP, the Federal government reimburses X percent of school meals at the free rate, where $\mathrm{X}$ equals 1.6 times the share of students who are categorically eligible at the school. Remaining meals served are reimbursed at the paid-lunch rate, and schools must cover any shortfall between costs and reimbursements with non-federal funds. Under the CEP, a school must provide both breakfast and lunch free to all students.

Two alternatives (referred to as "Provision 2" and "Provision 3") allow schools to serve free meals to all students enrolled at the school, while only requiring the collection of applications for free or reduced-price eligibility every four years. Provision 2 allows a school to determine the fraction of meals it serves at each price tier during one base year, then applies the same ratio of reimbursement rates to all meals served for the following three years. Under the Provision 3 option, a school counts meals served by type during the base year, and then may receive the same level of cash payments and commodities in the subsequent three years regardless of the number of meals served. Under these provisions, a school may decide to provide lunch, breakfast, or both meals for free to all students. Likely in part due to these administrative alternatives, the share of schools offering universal free lunches has increased.

The 2010 Healthy, Hunger-Free Kids Act made major changes to nutrition standards for school lunches, as shown in Table 1.4. Under prior nutrient standards, schools were required to serve at least a minimum number of calories per meal, and the standard varied by student age from 633 calories in grades K-3 to 785 calories in grades 4-12. Schools were also required to insure that no more than 10 percent of calories came from saturated fats. There were also requirements for minimum levels of daily fruits and vegetables, meats, grains, and milk. Updated program rules have imposed new calorie guidelines, imposing both minimum and maximum calorie rules. For many grades, the new maximum allowable calories were set below the previous calorie floor (see Table 1.5). The new rules also include stronger requirements for daily and weekly food group servings, including weekly requirements for a variety of vegetables (such as dark green, red/orange, and starchy), restrictions on the fat content of milk, and a phased-in requirement to use only whole grain rich grains. Schools that meet these enhanced nutrition 
requirements receive an additional 6-cent payment per meal. In addition, the Act gave the USDA authority to set nutritional standards for all foods sold in school during the school day, including in vending machines, school stores, and a la carte lunch items. The research literature evaluating the impacts of the policy changes on participation in the program at the individual or school level is sparse to date.

\subsection{Program History and Rules: School Breakfast Program}

\subsubsection{Overview of Program}

The school breakfast operates in a similar manner to the lunch program, though participation is lower. The SBP provides Federal cash support (but, unlike the NSLP, no additional commodity support) for meals served to children at public and private schools, and other qualifying institutions. The same approach is employed as in the NSLP, in which a threetiered system based on a child's household income determines the level of Federal payments made to schools, and typically also determines the student's price category.

In 2014-15, schools received Federal cash subsidies equal to $\$ 1.62$ per free breakfast, $\$ 1.32$ per reduced-price breakfast, and $\$ 0.28$ per paid breakfast. ${ }^{22}$ If the share of free or reducedprice breakfasts served at the school exceeds 40 percent (in a base year two years prior to the current year), then the school is eligibility for "severe need" payments, which increase the permeal cash subsidies by 31 cents per meal for free and reduced-price meals. About three-quarters of breakfasts served in the SBP receive this "severe need" payment.

\subsubsection{Benefits and Eligibility}

The eligibility rules are the same for breakfast and lunch, and a single eligibility determination is made for each child that covers both meals. The current maximum allowable price for reduced-price breakfast is $\$ 0.30$. Children from households with incomes above 185 percent of the federal poverty line may purchase so-called "paid meals." The categorical eligibility criteria (whereby participation in selected means tested transfers automatically confer eligibility for SBP) are the same as they are for the school lunch program.

\subsubsection{History, Reforms, and Policy Changes}

The SBP was established in 1966 as a two-year pilot program. It originally provided categorical grants to provide payments to schools that served breakfast to "nutritionally needy" students. In 1973, the program was amended to replace the categorical grant with the per-meal payment system used today. It was permanently authorized in 1975.

New program rules adopted after the 2010 Healthy, Hunger-Free Kids Act made substantial changes to breakfast standards. Under prior nutrient standards, schools were required to serve at least at least 554 calories at breakfast. Under the new standards, breakfast calories were required to fall within a specified range, from 350-500 for grades K-5 to 450-600 for high school students. Similar to the changes made to the lunch nutrient standards, new rules required

${ }^{22}$ Reimbursements are higher in Alaska and Hawaii. 
more fruits and vegetables, a switch to whole grains, and imposed restrictions on the fat content of milk. The Act also authorized grants that can be used to establish or expand school breakfast programs.

\subsection{Other Food and Nutrition Programs}

There are four other child nutrition programs (see Table 1.1), and together they comprise about 4 percent of spending on food and nutrition programs overall or about one quarter of the total Federal spending on child nutrition programs). These programs provide meals for children and other vulnerable groups outside of school and during the summer, or provide additional food items to children.

The Child and Adult Care Food Program (CACFP) provides meals and snacks to children in day care facilities, as well as to functionally impaired adults receiving care in non-residential adult day care centers and to the elderly (e.g. through Meals on Wheels). Participation in 2014 totaled 3.9 million children and adults, and total Federal spending was \$3.1 billion. The Summer Food Service Program (SFSP) supports meals and snacks served to children at schools, camps and other organizations during the summer when school is not in session. In 2014 the program served 160 million meals to 2.7 million children (measured in July, the peak participation month) at a cost of $\$ 465.6$ million. The Fresh Fruit and Vegetable Program (FFVP) provides resources for elementary schools to serve fresh fruits and vegetables as snacks outside of regular lunch and breakfast times. Schools apply to participate in the program, which is targeted to schools with high enrollments of free- and reduced-price meal eligible students. Participating schools receive an annual allotment of $\$ 50$ to $\$ 75$ per student. In 2014-15, the FFVP had \$153 million in spending. The Special Milk Program (SMP) provides subsidized milk, primarily to schools, childcare institutions, and camps that do not participate in other federally subsidized child nutrition programs. The cost in 2014 was $\$ 10.5$ million.

\section{Program Statistics and Recipient Characteristics}

\subsection{Program Statistics: SNAP}

In 2014, SNAP expenditures totaled $\$ 74.2$ billion and served 46.5 million persons (or 22.7 million households). This translates to participation by more than one out of seven Americans. The average monthly benefit in 2014 amounted to $\$ 257$ per household, $\$ 125$ per person, or $\$ 4.11$ per person per day. Overall, SNAP is the largest cash or near-cash means-tested, safety net program in the United States.

Table 2.1 presents data on SNAP participation and expenditures over time. Total expenditures (in real 2014 dollars) increased from \$28.0 billion in 1990 to \$74.2 billion in 2014 . Average monthly participation follows a similar path, moving from 20 million persons in 1990 to 46.5 million in 2014. The bottom of the table presents SNAP participants as a percent of the total U.S. population - it has ranged from 8.1 percent in 1990 down to 6.2 percent in 2000, to 14.8 percent in 2014. 
The take-up rate of SNAP, calculated as the fraction of the eligible population that is participating in the program, is fairly high at 79 percent in 2011 (Cunnyngham 2014). The takeup rates vary significantly across groups, with elderly individuals having considerably lower take-up rates than other groups. The take-up rates also vary substantially across states in the U.S. with higher rates in New England, the upper Midwest and the Pacific Northwest and lower rates in the Mountain Plains, the Far West and Texas (Cunnyngham 2014). Take-up rates have varied substantially over time: from 75 percent in 1994, down to 59 percent after federal welfare reform (in 2000), to 54 percent in 2002, then increasing to 67 percent in 2006 and 79 percent in 2011 (Cunnyngham 2002, 2010, Cunnyngham et al. 2014).

Figure 2.1 plots annual SNAP expenditures from 1980 to 2014, in real 2014 dollars. We normalize by the total U.S. population in each year, thereby generating real per capita (not per recipient) expenditures. The figure also includes the annual U.S. unemployment rate. During this period, per capita real spending on SNAP was relatively flat in the 1980s, increased in the early 1990s and then fell dramatically through the late 1990s. Since that time, spending has increased steadily. Overall the program shows a countercyclical pattern, increasing in the recessions in the early 1990s, early 2000s, and especially notable, in the Great Recession.

Table 2.2 presents summary characteristics for SNAP recipient units and how they vary over time. The top panel of the table relates to all SNAP recipients and the bottom panel limits to SNAP recipient units without any elderly (age 60 or more) individuals. These tabulations are based on administrative data from the USDA, the Quality Control (QC) files. In 2012, about 45 percent of SNAP recipient units included children, down from about 60 percent in 1996. Femaleheaded households with children as a share of the total caseload are also falling over time, from 39 percent in 1996 to 24 percent in 2012 . About 17 percent contain an elderly individual, and that share has not changed much over time. The share with no children, elderly or disabled persons (a proxy for the able bodied adults without dependents) has increased from 15 percent in 1996 to 25 percent in 2012. An increasing share of the caseload combines benefit receipt with employment. About 31 percent of households currently have earned income, a rate that is up 8 percentage points since 1996. On the other hand, some 20 percent have no cash income, up from 10 percent in 1996 (for an in-depth analysis of this issue see Peterson et al. 2014). 38 percent of households have no net income (income after allowable deductions) up from 25 percent in 1996.

At the bottom of the bottom panel of Table 2.2, we present the effective tax rates faced by (non-elderly) SNAP recipients. These are calculated using the QC data and follow the methods used in Ziliak (2008). The effective tax rate is the average of the marginal tax rates faced by SNAP households - marginal because it is calculated on their observed income amounts, and average because it is averaged over households. Table 2.2 shows that effective tax rate on earned income is 15 percent in 2012, down slightly from 18 percent in 1996. The tax rate on unearned income is somewhat higher at 16 percent in 2012. In light of the discussion above, it is important to point out that this is the tax rate within SNAP only (as opposed to the cumulative tax rate experienced across multiple programs). To the extent that SNAP recipients have children and very low earnings, then the negative marginal tax rates in the EITC will reduce the cumulative tax rates below the SNAP effective tax rate. On the other hand, those with higher earnings (e.g., perhaps in the phase-out of the EITC) would experience cumulative tax rates in 
excess of the SNAP effective tax rate. See Moffitt (2014) for further discussion of multiple participation rates.

Given the patchwork of U.S. means-tested programs, it is of interest to examine the propensity to participate in multiple programs, especially in light of concerns about cumulative work disincentives (Congressional Budget Office 2012, Mulligan 2012). ${ }^{23}$ It is also interesting to examine this over time given welfare reform and the many changes in the safety net. The food stamp quality control data (Table 2.2) track all resources that count as income for determining SNAP benefits, practically this translates to cash income programs. In 2012, only 7 percent of SNAP recipients have income from TANF, down from 37 percent in 1996 on the eve of welfare reform. The share with income from SSI and social security has stayed relatively steady; in 2012 20 and 23 percent of SNAP units received SSI and social security, respectively. If you limit to recipient units without elderly individuals, the share with "social security" (which we interpret as likely including SSDI) has increased, from 9 percent in 1996 to 14 percent in 2012. Few food stamp recipients have income from UI ( 5 percent), general assistance ( 3 percent) or veteran's payments (1 percent). Although receipt of UI among SNAP recipients units is low, the data show a notable increase in the Great Recession (from 2 percent in 2005 to 7 percent in 2010). While the QC data are valuable, they are limited because they only track sources of income relevant for determining SNAP benefits. Moffitt (2014) uses the Survey of Income and Program Participation and studies multiple program participation across a wider range of programs. He finds that (in 2008) 30 percent of non-disabled, non-elderly SNAP families receive WIC, more than half receive the EITC and 21 percent receive subsidized housing.

Table 2.3 presents maximum monthly SNAP benefits by household size for 2014 . A household of four has a maximum monthly benefit of $\$ 649$ while a household of size two has a maximum benefit of $\$ 357$. Annualizing these amounts, maximum benefits correspond to between 27 and 33 percent of the federal poverty line.

As discussed above in section 1.1, the SNAP benefit formula has changed little over time, other than adjusting for annual changes in the price of food. Interest in the adequacy of the SNAP benefit has increased over time and led to a recent Institute of Medicine report (IOM 2013). Hoynes, McGranahan and Schanzenbach (2015) explore SNAP benefit adequacy by examining the food spending patterns across families of differing income and composition. They argue that the maximum benefit level is inappropriate on at least two fronts: the Thrifty Food Plan (TFP) is based on outdated assumptions, and the family size adjustment does not reflect differences in spending patterns. First, consider the TFP, which is set at $\$ 632$ per month for a typical family of 4 in 2013. Recall that maximum benefits are set based on the TFP, and the program aims to ensure that households have adequate resources to purchase this "target" spending level. Based on an analysis of the Consumer Expenditure Survey, they show that over the past 20 years, the majority of families with incomes below $200 \%$ poverty spent more than the TFP amount. They argue this is in part due to the fact that the TFP is based on assumptions regarding how much cooking is done from scratch that are increasingly unrealistic and out of line with time use data. Second, they show that differences in actual spending patterns across family

\footnotetext{
${ }^{23}$ As discussed in Moffitt (2014), Parrott and Greenstein (2014) and elsewhere, in many analyses citing high cumulative marginal tax rates, the calculations assume that families are participating in all programs. This, as we discuss below, it not consistent with the data.
} 
size are much steeper than are accounted for by the benefit multipliers. Since the average SNAP household size is 2.3 , this suggests that many families are receiving benefits based on a formula that under-states their needs.

\subsection{Program Statistics: WIC}

In 2014, WIC expenditures totaled $\$ 6.2$ billion and served 8.3 million persons. The costs break down into $\$ 4.3$ billion for food and $\$ 1.9$ billion for nutrition services and administration. ${ }^{24}$ Average monthly federal food cost per person in 2014 amounted to $\$ 43.65$, or $\$ 1.44$ per person per day. The WIC caseload breaks down to be 10 percent pregnant women, 13 percent postpartum or breastfeeding women, 24 percent infants and 53 percent children (USDA 2014). The average cost per recipient varies little across groups, from $\$ 49.36$ per infant, to $\$ 49.16$ per breastfeeding woman, to $\$ 36.94$ per child (USDA 2014). A given family may have multiple members with WIC benefits (for example a pregnant mother, her infant and her child age 3 would have three WIC packages) and the total value of the WIC package to a family accumulates across individuals.

Table 2.1 presents data on WIC participation and expenditures over time. The WIC program has increased over this period from 4.5 million recipients in 1990 to 8.3 million in 2014 . The total cost increased from 3.8 billion (2014\$) in 1990 to 6.2 billion in 2014. The growth seems to be fairly similar across the subgroups of women, infants and children. The bottom of Table 2.1 presents program participation rates, where we express the number of participants as a percent of the relevant demographic group. So for example, the WIC infant (child) caseload is a percent of all persons less than 1 (between 1 and 4). ${ }^{25}$ We express the women caseload as a share of women ages 18-44. Both infant and child caseloads have increased over this period. Fully 26.9 percent of children aged 1-4 receive WIC in 2014, up from 13.5 percent in 1990. Participation is higher for infants, likely due to the high cost of infant formula, more than half of infants in the U.S. in 2014 received WIC benefits. In 2014, 3.5 percent of women aged 18-44 received WIC, though this figure is an underestimate of potential participation since we do not condition on pregnant, postpartum or breastfeeding women in the denominator.

Figure 2.2 plots the real spending on WIC annually from 1980 to 2013. Again, we normalize by the total U.S. population to create a per capita (not per participant) measure. WIC expenditures exhibit a fairly steady rise in the 1990s consistent with the expansions in the 1989 WIC reauthorization act. Costs slowed in the late 1990s perhaps due to welfare reform (and the overall "chilling" effect that followed) as well as the strong labor market. After a relatively flat period, a countercyclical pattern with the Great Recession and recovery is evident at the end of the period.

Table 2.4 presents summary characteristics for WIC recipient units in 2012 (the most recent year available) and, for comparison, 1994. Despite the income-threshold of 185 percent of poverty (higher than SNAP for example), fully 37 percent of WIC recipients have income below 50 percent of poverty ("extreme poverty"). 73 percent have incomes below 100 percent poverty

\footnotetext{
${ }^{24}$ We omit additional WIC spending on items other than food and nutrition services, including program evaluation, special projects and infrastructure.

${ }^{25}$ These are participation rates not takeup rates because they do not condition on income eligibility.
} 
and 92 have income below 150 percent poverty. The distribution of recipients by income has not changed much between 1994 and 2012. One notable change in the caseloads is the rise of breastfeeding women as a share of all women on the program, which has increased from 17 percent in 1994 to 29 percent in 2012. We also explore the extent of multiple program participation among WIC recipients. In 2012, only 9 percent of WIC recipients have income from TANF, down from 29 percent in 1992 (prior to welfare reform). The share with income from SNAP has been relatively steady; in 2012, 37 percent of WIC units received SNAP compared to 40 percent in 1992. Participation in Medicaid among WIC recipients was very high at 72 percent in 2012, up from 58 percent in 1992, reflecting the substantial expansions in Medicaid for pregnant women and children.

\subsection{Program Statistics: NSLP}

The National School Lunch Program (NSLP) serves lunch to almost 30 million students 56 percent of the total student population (see Table 2.1). Almost all public schools offer the NSLP, which in 2014 cost \$11.4 billion with average participation of 19.2 million children in free, 2.5 children in reduced-price, and 8.8 million in paid lunch. Overall, including the free, reduced-price and paid categories, over 5 billion lunches were served. As shown in the bottom of table 2.1, 40 percent of all school aged children received free or reduced price lunch in 2014, up from 25 percent in 1990. The share of students receiving school lunch for free (among those eating school lunch) has grown over time from 41 percent in 1990 to 63.6 percent in 2014. Overall, participation (free, reduced-price or paid as share of all school aged children) has edged down somewhat in the last few years from its historic peak of 59 percent in 2010.

After adjusting for inflation, spending on NSLP has almost doubled since 1990. This reflects an increase in the number of school-aged children, an increase in spending per lunch, and a trend toward increased participation rates. The increased spending per lunch has been driven by a combination of increased costs and policy changes. Per-meal spending on child nutrition programs increases annually because payment levels are indexed according to the Food Away from Home series of the CPI-U. Commodity payments are inflated according to the Price Index of Foods used in Schools and Institutions. (Payments are legislated not to decrease, so if food prices decline in a year, there is no adjustment to these costs). In recent years, the price index for food away from home has grown more quickly than overall inflation (measured by the price index for Personal Consumption Expenditures). In addition, the 2010 Healthy, Hunger-Free Kids Act increased cash payments by 6 cents per meal for schools that meet the new, more stringent nutrition requirements.

\subsection{Program Statistics: SBP}

There have been recent - and highly successful - attempts to expand access to the SBP. As shown in Table 2.1, between 1990 and 2014 the total number of students receiving the SBP more than tripled (compared to a 27 percent increase in the number of NSLP participants). At the same time, the share of school-aged children receiving free or reduced-price breakfast also increased sharply, from 7.6 percent in 1990 to 21.3 percent of children in 2014. Some of this has been driven by increases in participation rates of schools in the program in 2014. Schanzenbach and Zaki (2014) calculate from the NHANES that in 2009-10 almost three-quarters of children 
attended a school that offered the SBP, up from approximately half of students in the 1988-94 wave. An additional portion has been driven by policies to expand take-up by students, including providing breakfast for free to all students before school or introducing Breakfast in the Classroom programs. In 2014, 85 percent of participants received the SBP either for free or at reduced price.

\subsection{Summary measures across programs}

Figure 2.3 summarizes the programs, presenting the total program costs and total program recipients in 2014. Considering our four central food and nutrition programs (SNAP, WIC, NSLP, and SBP) as well as the other smaller programs in Table 1.1, total spending amounted to about 100 billion dollars in 2014 and about 95 million total participants benefited from these programs. (Given multiple program participation, the total unique recipients would be less than 95 million.) Considering the programs together, Figure 2.3 shows that SNAP is clearly the largest program - in terms of both people reached and program cost. In 2014, expenditures on SNAP were over 6 times as large as the NSLP and almost 12 times as large as WIC. The number of SNAP recipients was about 2 times those receiving free or reduced-price NSLP and over 5 times WIC. However, these comparisons ignore the fact that SNAP is universal, while NSLP and WIC are targeted on specific demographic groups. Using this lens, the figures in the bottom of Table 2.1 show that SNAP has the smallest reach among the programs. Half of all infants and almost 30 percent of children 1-4 receive WIC, over 20 percent of school-aged children receive free or reduced-price breakfast and 40 percent receive free or reduced-price lunch. SNAP, by contrast, is received by 15 percent of the population.

Figure 2.4 shows how program participation for the food and nutrition programs varies by income level. In particular, the figure plots household participation in SNAP, NSLP and WIC (alongside EITC as a comparison) as a function of household private income to poverty level (truncating at eight times income to poverty). ${ }^{26}$ The figure is based on tabulations of the 2014 Current Population Survey corresponding to data for calendar year 2013, and is limited to households with children headed by a nonelderly person. Overall, SNAP and NSLP have the highest household participation rates, with lower household participation rates for WIC. Of course, this lower WIC participation rate reflects the fact that eligibility is limited to pregnant women and children through age 4. SNAP participation is most concentrated at the lower income levels, reflecting its lower income eligibility limits. WIC has a much flatter profile with respect to income, reflecting the higher income eligibility limits.

Figure 2.5 compares anti-poverty effects of the programs. The calculations are based on the Supplemental Poverty Measure (SPM), first released by the Census in 2011 (Short 2011). The SPM provides an alternative to the official poverty measure and is based on a comprehensive after tax and transfer income resource measure that includes the value of noncash government transfers. Here we use the 2014 SPM (Short 2015) and plot the number of children removed from poverty for all government tax and transfer programs tracked in the SPM. This is a static calculation, essentially zeroing out the income source and recalculating family income and poverty status assuming all else (e.g. earnings, other income sources) remain constant.

\footnotetext{
${ }^{26}$ The figure is adopted using the approach in Bitler and Hoynes (2015). See that paper for details on the sample and
} measurement. 
SNAP removes 2.1 million children from poverty, second only to the combined effects of the EITC and Child Tax Credit that together remove 5.2 million children from poverty. By comparison, the NSLP removes 0.8 million children from poverty and WIC removes 0.2 million children from poverty. ${ }^{27}$ Although not shown here, calculations for the entire population show that SNAP removes a total of 4.7 million people from poverty, making SNAP the third largest U.S. anti-poverty program after Social Security and the Earned Income Tax Credit.

\section{Review of the issues surrounding the programs}

Each of the food and nutrition programs can be analyzed through standard economic frameworks. The applicable frameworks differ somewhat, though, because the programs differ in terms of the degree to which the benefits are provided in-kind. Closest to cash, SNAP takes the form of a "value voucher" and can be used to purchase most foods, while the more targeted WIC takes the form of a "quantity voucher" limited to specific foods and the school meals programs offer meals directly. As with other means-tested transfer programs, these programs face the usual tradeoff in balancing the protective aspects of the programs to improve dietary intake and reduce hunger and food insecurity against their distorting incentives such as reduced labor supply. We start by discussing SNAP, because it is the largest program and has been most researched, and follow with discussions of the other programs and how the basic economic framework can be adapted to analyze them.

\subsection{Effects of in-kind benefits on food consumption}

We begin by presenting the neoclassical model of consumer choice and use this to discuss predictions for the effects of SNAP on family spending patterns. ${ }^{28}$ Figure $3.1 \mathrm{~A}$ presents the standard Southworth (1945) model, in which a consumer chooses to allocate a fixed budget between food and all other goods. The slope of the budget line is the relative price of food to other goods. In the absence of SNAP, the budget constraint is represented by the line AB. When SNAP is introduced, it shifts the budget constraint out by the food stamp benefit (divided by food price) $\mathrm{B}_{\mathrm{F}} / \mathrm{P}_{\mathrm{F}}$ to the new budget line labeled $\mathrm{ACD}$. The first, and most important, prediction of the neoclassical model is that the presence of, or increase in the generosity of, the SNAP transfer leads to a shift out in the budget constraint. The transfer does not alter the relative prices of different goods, so can be analyzed as a pure income effect, and predicts an increase in the consumption level of all normal goods. Thus, the central prediction is that food stamps, like an increase in disposable income or a cash transfer, will increase both food spending and non-food spending.

However, SNAP benefits are provided as a voucher that only can be used toward food purchases. Canonical economic theory predicts that in-kind transfers like SNAP are treated as if they are cash as long as their value is no larger than the amount that a consumer would spend on the good if she had the same total income in cash. Returning to Figure 3.1A, there is a portion of the budget set that is not attainable with SNAP that would be attainable with the cash-equivalent

\footnotetext{
${ }^{27}$ With underreporting of SNAP and other food and nutrition programs, these are underestimates of the total antipoverty effects (Tiehen, Jolliffe, Smeeding 2013)

${ }^{28}$ See also Currie and Gahvari (2008) for an excellent overview of the economics of in-kind transfer programs.
} 
value income transfer. (We are assuming that the resale of these vouchers is not possible.) In other words, because the benefits $\mathrm{B}_{\mathrm{F}}$ are provided in the form of a food voucher, this amount is not available to purchase other goods, and thus we would expect a consumer to purchase at least $\mathrm{B}_{\mathrm{F}}$ amount of food. Thus paying benefits in the form of a food voucher leads to a budget constraint with a kink point.

Figure 3.1B illustrates how consumption responds to the receipt of SNAP benefits. In the absence of SNAP, a typical consumer purchases some mix of food and non-food goods, choosing the bundle that maximizes her utility and exhausts her budget constraint. This is represented as point $\mathrm{A}_{0}$ *, with the consumer purchasing food in the amount $\mathrm{F}_{0}$. After SNAP is introduced, the budget constraint shifts outwards and the consumer chooses the consumption bundle represented by point $A_{1}{ }^{*}$. Note that consumption of both goods increases, and food consumption goes up by less than the full SNAP benefit amount. Such a consumer is termed "infra-marginal" and the canonical model predicts that SNAP will increase food spending the same amount as if the SNAP benefits were paid in cash. As discussed further below, the predicted impacts of proposed policy changes, such as calls to restrict purchases of certain goods with SNAP benefits, hinges on what proportion of recipients are inframarginal.

There are two important exceptions to the SNAP-as-cash model, though. The first is for consumers that prefer relatively little food consumption. In the absence of SNAP, such a consumer may choose the consumption bundle labeled $\mathrm{B}_{0} *$ in Panel $\mathrm{B}$. When SNAP is introduced, this consumer spends only his benefit amount on food, preferring to use all available cash resources to purchase other goods as represented at point $\mathrm{B}_{1} *$. If benefits were paid in cash instead of as a food voucher, the consumer would opt to purchase less food and could obtain a higher level of utility. As a result, for this type of consumer, the canonical model predicts that SNAP will increase food spending by more than an equivalent cash transfer would. Another exception to the standard model comes from behavioral economics and predicts that SNAP may not be equivalent to cash if households use a mental accounting framework that puts the benefits in a separate "category". 29

We can extend this approach to consider the effects of the WIC program. There are two important distinctions. First, WIC is a "quantity" voucher, not a "value" voucher. So while SNAP would award, for example, \$100 to purchase food, WIC instead gives a voucher for 16 quarts of milk (and other items). Second, there are specified goods that are provided by the voucher (this can also include a restriction on the allowable "package sizes" in the WIC package). We present the WIC budget constraint in Figure 3.2 and adapt the SNAP graph by putting "targeted subsidized goods" (e.g. items in table 1.2) on the $\mathrm{x}$ axis and all other goods (which also includes much of the food budget as well as non-food goods) on the y axis. The no program budget constraint again is $\mathrm{AB}$, and the budget set shifts out by the WIC quantity

\footnotetext{
${ }^{29}$ There are other reasons that may explain why SNAP leads to different effects on food consumption compared to ordinary case income. It is possible that the family member with control over food stamp benefits may be different from the person that controls earnings and other cash income. If the person with control over food stamps has greater preferences for food, then we may find that food stamps leads to larger increases in food consumption compared to cash income. Alternatively, families may perceive that food stamp benefits are a more permanent source of income compared to earnings. Finally, Shapiro (2005) finds evidence of a "food stamp cycle" whereby daily caloric and nutritional intake declines with weeks since their food stamp payment suggests a significant preference for immediate consumption.
} 
voucher Qw. Note the contrast to SNAP where the value voucher shifts out the budget constraint by $\mathrm{B}_{\mathrm{F}} / \mathrm{P}_{\mathrm{F}}$. Thus, for SNAP, the recipient faces price incentives: choosing lower priced goods increases the value of the SNAP benefit. In contrast, with WIC recipients are price insensitive; their budget constraint (and potential increase in utility due to the program) is affected only by the quantity $\mathrm{Q}_{\mathrm{w}}$, regardless of the price of those goods $\mathrm{P}_{\mathrm{W}}$.

As with SNAP, there is a region that would be attainable with a cash transfer that is not attainable with WIC, and there are inframarginal consumers and constrained consumers. However, because WIC is such a specified bundle, we expect that a larger share of WIC participants (compared to SNAP recipients) will be constrained and at point $\mathrm{C}$.

Additionally, as discussed in Meckel (2014), vendors face incentives to charge WIC recipients a mark-up on the WIC packages (because of recipients' price inelasticity). This would amount to fraud and could be sanctioned if caught. Vendors may also choose to compete on products (quantity and diversity) to gain market share given that price competition is not available (McLaughlin 2014).

School lunch and breakfast programs are even more specified. We model these as "take it or leave it" benefits - if you are eligible for a free lunch then you have the choice to consume the lunch or use private resources for lunch. ${ }^{30}$ This is illustrated in Figure 3.3 with the targeted subsidized good (e.g. school lunch) on the $\mathrm{x}$ axis and all other goods on the $\mathrm{y}$ axis. We represent the school lunch option as a single point, and as the quality of the lunch increases the point shifts out. Some consumers will chose the private option, others will chose the public option. As the quality of the public option increases, more will switch into the lunch program.

Unlike SNAP, the WIC and school feeding programs are explicitly targeted at certain groups (pregnant women, infants, children age 1-4, school aged children). In the context of families, it is possible - perhaps likely - that the program will have spillover benefits to other family members who are not explicit recipients. This could happen with WIC because the goods purchased with the vouchers could be shared with the family. Additionally, since the programs shift out the family's total budget constraint, this "income effect" could lead to an increase in consumption of other foods or other goods that benefit the family more broadly. Additionally, WIC's nutrition education component may lead to changes in the composition of food consumption for the entire family.

\subsection{Effects of FNP on food insecurity, diet and health}

As discussed above, SNAP and the other food and nutrition programs increase household resources. If health is a normal good, then increases in resources due to food and nutrition programs should increase health. With this framing, an increase in resources could lead to changes in health through many channels. One obvious channel is through improvements in nutrition. The income effect, in principle, could also encourage behaviors that could harm health,

\footnotetext{
${ }^{30}$ In their chapter on housing programs in this volume, Ellen and Ludwig discuss the possibility that a take-it-orleave-it benefit will reduce consumption of the targeted good. While theoretically possible in the case of food consumption, we think this is not likely. Food consumption is more straightforward to top up (e.g. snacks, supplemental lunch foods brought from home or purchased) than housing is.
} 
such as smoking or drinking. ${ }^{31}$ Health improvements may work through other channels as well, for instance improving nutrition education, increasing services (for WIC) and reducing stress (e.g., financial stress).

There also may be linkages between access to food and nutrition programs in utero and in childhood and later life health and human capital outcomes. Causal mechanisms by which early childhood events affect later-life are best understood for nutrition. For example, undernourished children may suffer from anemia and listlessness. This may reduce their ability to invest in learning during childhood and may harm their long-run earnings and other outcomes. Poor early life nutrition may also directly harm long-run outcomes through altering the body's developmental trajectory. There is an emerging scientific consensus that describes critical periods of development during early life that "program" the body's long-term survival outcomes (Barker, 1992; Gluckman and Hanson 2004). During development, the fetus (and post-natally the child) may take cues from the current environment to predict the type of environment it is expected to face in the long run and in some cases adapts its formation to better thrive in the expected environment (Gluckman and Hanson 2004). A problem arises, however, when the realized environment differs substantially from the predicted environment. For example, if nutrients are scarce during the pre-natal (or early post-natal) period, the developing body therefore predicts that the future will also be nutritionally deprived. The body may then invoke (difficult-to-reverse) biological mechanisms to adapt to the predicted future environment. For example, the metabolic system may adapt in a manner that will allow the individual to survive in an environment with chronic food shortages. This pattern is termed the "thrifty phenotype" and is sometimes referred to as the Barker hypothesis. The "problem" arises if in fact there is not a long-run food shortage, and nutrition is plentiful. In that case, the early-life metabolic adaptations are a bad match to the actual environment and will increase the likelihood that the individual develops a metabolic disorder, which can include high blood pressure (hypertension), type II diabetes, obesity and cardiovascular disease. To summarize, a lack of nutrition in early life leads to higher incidence of metabolic syndrome, thus greater access to food and nutrition programs in early life and childhood may reduce metabolic syndrome in adulthood.

\subsection{Effects on Labor Supply}

We begin by considering the effect of SNAP on labor supply. As discussed above, SNAP benefits have the structure of a traditional income support program, with a guaranteed income benefit that is reduced with family income at the legislated benefit reduction rate. Recipients are allotted a benefit amount $B$ equal to the difference between the federally defined maximum benefit level for a given family size (i.e. $G$, the guarantee amount) and the amount that the family is deemed to be able to afford to pay for food on its own according to the benefits formula (30 percent of cash income, less deductions). We illustrate the labor-leisure tradeoff with and without food stamps in Figure 3.4. Like other means-tested programs, SNAP alters the household's labor-leisure tradeoff increasing after tax and transfer income at earnings up to the breakeven point. SNAP benefits are largest at zero hours of work, and benefits are reduced as income and earnings are increased leading to an implicit tax rate on earned income. The benefit reduction rate in the food stamp program is 30 percent.

\footnotetext{
${ }^{31}$ Even though recipients cannot purchase cigarettes directly with FSP benefits, the increase in resources to the household may increase cigarette consumption.
} 
In Figure 3.4, the $\mathrm{x}$ axis measures the amount of leisure consumed, and the $\mathrm{y}$ axis measures total income including the SNAP benefit. ${ }^{32}$ The "no benefit" budget constraint is a straight line with a slope equal to the individual's wage $w$. The individual has a certain amount of unearned income $(U)$, and the budget constraint is represented by the line $C A L$. The simple static labor supply model states that an individual maximizes her utility subject to this budget constraint, and assuming a positive labor supply choice, chooses some combination of consumption of goods and leisure at points illustrated for consumers with different preferences by $A^{\sim}$ and $A^{\wedge}$. If her offer wage is below her reservation wage (the slope of the indifference curve at zero hours of work) then it will be optimal to remain out of the labor force, as illustrated by point $A$ (at maximum leisure choice $L$, or hours $=0$ ).

Adding SNAP alters the budget constraint to line $C A$ ' $L$ by adding non-labor income $G$ (the maximum benefit level or the "guarantee"), and rotating the slope of the budget constraint to $\mathrm{w}(1-t)$ where $t$ is the benefit reduction rate (that is, the tax rate on benefits) as income increases $(\mathrm{t}=0.3)$. For the individual supplying zero hours of work and consuming only leisure, consumption opportunities increase by the SNAP "guarantee" amount $G$. At the income eligibility threshold (labeled on the y axis) you earn enough such that benefits have been fully taxed away.

As is well known, this combination of a guaranteed income and benefit reduction rate leads unambiguously to predictions of reductions in the intensive and extensive margins of labor supply. In this case, both the income effect of the benefit as well as the income and substitution effect from the benefit reduction rate leads, unambiguously, to a predicted decline in employment (extensive margin), hours worked (intensive margin), and (if wages are fixed) earnings. In addition, family cash income (which as measured does not include food stamp benefits) would also be predicted to fall. Of course, family total after transfer income including food stamps is likely to increase.

Referring back to Figure 3.4, our representative individual who was, prior to the introduction of the food stamp program, in the labor force and consuming at point $A^{\sim}$, is predicted to increase their leisure (reduce their hours worked) choosing a consumption bundle $A^{\sim}$. Alternatively, it is possible that the combination of the negative income and substitution effects can push them out of labor market to point $A^{\prime}$.

Figure 3.5 adapts the labor-leisure diagram to model WIC and the school feeding programs. For these programs a household receives a fixed benefit B for all income levels up to the eligibility limit (e.g., 185\% poverty for WIC). Thus the budget set shifts out by a constant amount and creates a "notch" or cliff where the household reaches the eligibility limit. The qualitative predictions for labor supply are the same as for SNAP -- reductions in the intensive and extensive margins of labor supply. In this case, many households face a pure income effect while higher income households face the incentive to reduce their labor supply to obtain eligibility.

\footnotetext{
${ }^{32}$ By shifting out the budget constraint by the full SNAP benefit we assume households treat the benefit as cash. We also assume, for simplicity, that there are no other welfare programs in place.
} 
Additionally, as discussed in Currie and Ghavari (2008), in-kind programs such as SNAP or WIC might increase labor supply, depending on the degree of complementarity between the subsidized good (here food and nutrition) and labor supply. This has had limited testing in the empirical literature.

\section{Review of Results of Research on the Programs}

\subsection{Challenges for identification and overview of empirical approaches}

A central challenge for evaluation of the effects of food and nutrition programs is that commonly used quasi-experimental approaches are not easily applied. First, food and nutrition programs are federal and exhibit little variation across states such as been used in the analysis of AFDC and TANF. Second, the programs have not seen repeated reform or expansions such as has been used in analysis of the Earned Income Tax Credit. Finally, with respect to the food stamp program, the universal nature of the program means there are no ineligible groups to serve as controls, which is another common approach in the quasi-experimental literature.

Early studies use comparisons between participants and non-participants to estimate the effect of food and nutrition programs. Many researchers (Bitler 2015; Currie, 2003; Bitler and Currie, 2005; Ludwig and Miller 2005) have drawn attention to the fact that selection into participation in these programs is non-random. If program recipients are healthier, more motivated, or generally positively selected, then comparisons between the participants and nonparticipants could produce positive program estimates even if the true effect is zero. Conversely, if program participants are more disadvantaged, or generally negatively selected, than nonrecipients, such comparisons may understate the program's impact.

Bitler (2015) provides a recent analysis to examine the selectivity of SNAP recipients. She examines detailed health data from NHANES and NHIS and shows that SNAP recipients have worse diets and nutritional intake, higher levels of obesity and underweight, worse child health and adult health when compared to all non-recipients or income eligible non-recipients. Thus, it seems clear that SNAP recipients are negatively selected. Bitler and Currie (2005) provide evidence that WIC recipients are negatively selected among a sample of Medicaid recipients, in terms of their education, marital status, smoking behavior, obesity, labor market, and program participation.

There are several approaches to solving this fundamental identification problem. First, some studies make use of the limited policy variation across areas. For SNAP, this includes variation due to welfare reform (especially for examining immigrants versus natives) and state SNAP policies (length of recertification periods, fingerprinting, vehicle asset exemptions and broad based categorical eligibility). In some cases, these state policy rules may not change much from year to year, which limits their suitability as instruments. This approach is used in instrumental variable settings, essentially providing instrument-driven variation in program participation. Policy variation is also used in reduced form approaches. 
Second, other studies take an historical approach and use program introduction, relying on variation across areas during the rollout years of the program. As discussed above, both the Food Stamp Program and WIC were introduced at different points across counties in the U.S. This allows for an event study or difference in difference approach to evaluate the programs, essentially using untreated counties as controls for treated counties. The validity of this approach relies on the exogeneity of the timing of the rollout across areas. ${ }^{33}$

A third approach is to use longitudinal data and control for family, person, or sibling fixed effects. This approach nets out time-invariant effects. For example, in an analysis of siblings, family fixed effects generate estimates by comparing outcomes among siblings who participated in the program compared to outcomes among those who did not. There are drawbacks to this approach. Between-birth changes in economic or health conditions of other family members may be correlated with between sibling differences in program participation. Additionally within-family comparisons are likely to exacerbate measurement-error problems that bias estimates towards zero (Griliches 1979). There also may be spillover effects from the participating sibling to the non-participating sibling, which will lead to underestimates of the program's true effect. In such cases, selection biases will not be eliminated. Another longitudinal differencing approach uses an individual fixed effects estimator, which compares outcomes for those who switch (into or out of) program participation. Of course, there could be some third factor that affects both transitions into (or out of) program participation and outcomes.

Fourth, some studies use regression discontinuity approaches, comparing those in a small band above the eligibility threshold to those in a small band below the eligibility threshold. The validity of the approach requires a sharp change in participation at the discontinuity that is not correlated with other changing variables. This approach can be applied to income eligibility for WIC and school feeding programs where a recipient is either eligible or not eligible for the entire bundle of benefits. This approach would not be generally be appropriate for SNAP because, empirically, participation smoothly falls as income rises (the benefit falls as income rises). It also can be applied to age discontinuities in eligibility for the other food and nutrition programs. In practice, regression discontinuity studies based on differences across income-based eligibility criteria may not be valid given that income can be manipulated, which invalidates the RD approach (one no longer has randomness across the threshold).

Fifth, randomized experiments could in principle capture the effect of food and nutrition programs (or more likely, changes in program policies). In practice, in the past decades there is not much such evidence, with notable exceptions in the Healthy Incentives Pilot (Bartlett et al. 2014) and School Breakfast Program Pilot Project (Bernstein et al. 2004), both further described below. Finally, another approach uses matching methods to control for selection, essentially relying on "selection on observables".

In order to focus our review of the literature on the studies with the most credible evidence, we limit our discussion below to papers that use of the "design based" approaches

\footnotetext{
${ }^{33}$ This approach has also been used to analyze many other aspects of the Great Society and Civil Rights era (Ludwig and Miller, 2007; Finkelstein and McKnight, 2008; Bailey 2012; Cascio, Gordon, Lewis and Reber 2010; Almond, Chay and Greenstone 2006; Goodman-Bacon 2014).
} 
discussed above. The most common study that would not pass this criterion would be simple comparisons, either with or without regression controls, of FNP recipients and nonrecipients.

\subsection{Research on Food Stamp Program}

\subsubsection{SNAP Participation}

As we showed in Table 2.1 and Figure 2.1, participation in and expenditures on SNAP have varied significantly over time. One consistent strand in the literature seeks to understand the determinants of these changes in the program (Table 4.1 provides a catalog of the papers we review.) The literature has explored the role of the macroeconomy, changes in SNAP policies, changes in related program policies (especially welfare reform), and changes in demographics. The papers in this area typically leverage variation across states and over time in labor market conditions (e.g. unemployment rates, employment-to-population ratios) and program polices. As outlined above, SNAP is primarily a federal program and has less variation across states than other parts of the U.S. means tested safety net (such as Medicaid or TANF). The available state varying policies for SNAP include length between required recertification, immigrant eligibility following welfare reform, presence or absence of restrictions for ABAWD, and the broad based categorical eligibility expansions of the 2000 s.

Overall, the macroeconomy consistently ranks as the largest contributor to changes in SNAP caseloads. However, SNAP and welfare policies have also played a role. Welfare reform and reductions in SNAP certification periods led to reductions in SNAP caseloads in the 1990s (Currie and Grogger 2001, Kabbani and Wilde 2003, Ziliak et al. 2003, Figlio et al. 2000). Additionally, changes in immigrant access to safety net during the welfare reform period also led to reductions in SNAP participation (Borjas 2004, Haider et al. 2004, Kaestner and Kaushal 2005, Bitler and Hoynes 2013).

Ganong and Liebman (2013) examine the large increase in SNAP caseloads in the Great Recession and find that local economic conditions explain about two-thirds of the increase in SNAP with a much smaller role for SNAP policy changes (e.g., expansions for broad based categorical eligibility). ${ }^{34}$ Ziliak (2015) finds a larger role for policy, perhaps accounting for 30\% of the caseload change. Bitler and Hoynes (2015) find that the countercyclical effect of SNAP as measured by the effect of the unemployment rate on the SNAP caseload was larger in the Great Recession compared to the early 1980s recession (although the difference was not statistically significant).

\subsubsection{SNAP and Consumption}

The first order prediction is that SNAP, by shifting out the budget set, should lead to an increase in food (and nonfood) spending. This is confirmed in the empirical literature. The model also predicts that for inframarginal households, SNAP should lead to a similar increase in food spending compared to equal sized cash transfer. There was significant attention to this question in the 1980s and 1990s, typically using observational approaches (comparing recipients to

\footnotetext{
${ }^{34}$ When examining the earlier period, especially the Bush expansions in the early 2000s, Ganong and Liebman (2013) find more of a role for policy changes in explaining the growth of food stamp caseloads.
} 
nonrecipients) and suffering from the biases due to selection discussed above. Overall, many of these early papers found that SNAP recipients consume more food out of SNAP than they would with an equivalent cash transfer (Currie 2003).

More recent papers, however, based on research designs that are able to isolate causality have found evidence more consistent with the canonical model. As reviewed in Currie, RCTs on "cashout" experiments in the 1990s found little difference in food spending between the group receiving benefits in cash versus in food vouchers. The reanalysis by Schanzenbach (2007) finds that the mean treatment effect is a combination of no difference in food spending among inframarginal recipients, and a substantial shift in consumption toward food for the relatively small group of stamp recipients who are constrained. Overall, these experiments provide evidence on the difference between cash and vouchers, but do not provide estimates for the broader question of how providing SNAP benefits (by increasing family disposable income) affects food spending or consumption more broadly.

Hoynes and Schanzenbach (2009) use the initial rollout of the food stamp program to quasi-experimentally examine the effects on food spending. As discussed above, the program's introduction took place across the approximately 3,000 U.S. counties between 1961 and 1975. Consistent with the theoretical predictions discussed in 3.1, they find that the introduction of FSP leads to a decrease in out-of-pocket food spending and an increase in overall food expenditures. They estimate a marginal propensity to consume food out of food stamps of 0.16 for all nonelderly and 0.30 for female-headed households. The estimated marginal propensity to consume food out of food stamp income is close to the marginal propensity to consume out of cash income. In addition, consistent with economy theory those predicted to be constrained (at the kink in the food/nonfood budget set) experience larger increases in food spending with the introduction of food stamps.

Several recent studies have used the changes in SNAP benefits from the economic stimulus (ARRA) whereby benefits were temporarily increased between April 2009 and October 2013. Beatty and Tuttle (2012) use a difference-in-difference approach and using non-recipients as controls (with matching methods), they find using the Consumer Expenditure Survey that the 13.6 percent increase in benefits leads to a 6 percent increase in food at home. Kim (2014) uses the same approach and data and finds that, consistent with the theoretical predictions, the increase in SNAP benefits leads to increases in food spending and increases in spending on nonfood (housing, transportation, entertainment). Bruich (2014) uses grocery store level scanner data and a difference-indifference model (using variation in SNAP share at the stores) to examine the expiration of the ARRA increase in SNAP benefits. On average, SNAP households lost \$17 dollars in benefits (per month) and Bruich's estimates imply a marginal propensity to consume food out of food stamps of 0.30 .

A second set of studies examines the effects of food stamps on consumption, with the focus on estimating the insurance effects of the program. Blundell and Pistaferri (2003) use longitudinal data from the PSID to examine how SNAP mitigates the effect of shocks to permanent income on consumption and income volatility. Gundersen and Ziliak (2003) use an IV approach to examine how log income changes affect log consumption. Both studies show that SNAP provides important consumption protection. Gundersen and Ziliak find that SNAP receipt 
reduced income volatility by $12 \%$ and food consumption volatility by $14 \%$. Blundell and Pistaferri find that the effect of permanent income shocks decline by about one-third with SNAP.

\subsubsection{SNAP and Food Insecurity}

Food hardship measures were developed by the USDA in response to the National Nutrition Monitoring and Related Research Act of 1990 with an interest in "access at all times to enough food for an active, healthy life" (Coleman-Jensen et al. 2012). The first measures were released in 1995 and currently a household's "food security" (or insecurity) status is determined through a battery of questions asked during the December CPS as part of the Food Security Supplement (CPS-FSS). There are 10 questions asked of all households, and an additional 8 questions asked of households with children. There are four kinds of questions: those that capture anxiety or perception that the food budget or supply is inadequate in quantity. There are also questions that capture whether food is perceived to be inadequate in quality. A group of questions are more quantitative in nature, asking about instances where food intake was reduced or weight loss occurred associated with reduced food intake. One set of these questions pertains to adults and the other to children in the household. Answering more of these questions affirmatively indicates a more severe degree of food insecurity. For example, a household is considered to have "very low food security among children" if 5 or more of the 8 child-centered food security questions are answered affirmatively (Nord 2009).

There are several existing reviews of the literature of SNAP and food insecurity [FI] (e.g., Currie 2003, Gregory, Rabbitt and Ribar 2015). Here we focus on the research since Currie's review that meets our research design criteria.

One set of studies use instrumental variable approaches, typically using state SNAP policies as instruments (Yen et al. 2008, Mykerezi and Mills 2010, Shaefer and Gutierrez 2013, Ratcliffe et al. 2011). A commonly employed instrument is the state's SNAP certification length, and while it is not a very strong instrument it may be valid on excludability grounds. A second instrument leverages variation in state policies towards immigrant SNAP coverage or overall immigrant participation in the program. This is more powerful but less likely to be excludable. The results vary across studies, typically finding that SNAP participation leads to decreases in FI (that is, they improve outcomes) but many are not statistically significant.

Two studies use IV approaches but broaden the analysis to examine effects of public assistance (rather than only SNAP). Borjas (2004) uses welfare reform and the relatively large reduction in program participation among immigrants in a triple difference IV, essentially using state by year by citizenship status as the instrument. Schmidt, Shore-Sheppard and Watson (2013) use a simulated program benefit (using detailed benefit calculators) as an instrument for actual benefits to identify the effects of benefit income on FI. Both studies find that program participation (or benefits) leads to reductions in FI.

A second approach uses a household fixed effects and longitudinal data, essentially identifying the effects of SNAP on FI using switchers into and out of SNAP (Depolt et al. 2009, Wilde and Nord 2005). This approach may not be credible, given that transitions into SNAP may be correlated with other factors that negatively affect FI. Compared to the IV approach, these 
studies are more likely to find a positive association between SNAP and FI. A final approach uses propensity score matching (e.g., Gibson-Davis and Foster 2006) often finding a positive association between SNAP and FI.

Overall, the literature on SNAP and FI finds a wide range of results, some finding positive association, some negative and some insignificant. This range is well illustrated in the recent review and replication work in Gregory et al. (2015) showing a range of estimates for propensity score matching, longitudinal and IV approaches in one sample. The range of estimates illustrates well the challenge for causal identification in evaluating the effects of food and nutrition programs.

\subsubsection{SNAP and Child and Adult Health}

The literature on child and adult health takes a similar path to the literature on food insecurity. Studies use family and child fixed effects, instrumental variables, and propensity score matching. In this setting there are also studies that leverage the historical rollout of SNAP. As above, we review the studies since Currie (2003) that meet our research design criteria. The recent review by Meyerhoefer and Yang (2011) is also a useful reference.

Studies of the effect of SNAP on child BMI find varying effects, depending to some degree on the estimation approach. Gibson (2004) uses child and family fixed effects and finds SNAP leads to a reduction in overweight for boys but an increase for girls. Vartanian and Houser (2012) use a similar approach but relate childhood exposure to adult BMI, finding a beneficial effect of SNAP. Schmeiser (2012) uses an IV approach, with state SNAP policies (recertification period, fingerprinting, vehicle asset exemptions) as instruments, and finds that SNAP reduces BMI for most gender-age groups. Kreider et al. (2012) address selection into and measurement error of SNAP using a bounding approach and find quite substantial bounds that generally cannot rule out positive or negative effects of SNAP on BMI.

Similar approaches are used to examine effects on adult health. Gibson (2003) uses an individual fixed effects approach and finds SNAP participation increased obesity among women, though as noted above the fixed effects approach may not be credible if transitions into SNAP are correlated with other factors that directly affect health. Fan (2010) extends this approach and adds propensity score matching and finds no significant effect of SNAP on obesity, overweight or BMI. Meyerhoefer and Pylypchuk (2008) combine individual fixed effects and IV and find SNAP leads to increases in obesity for women but no significant effects for men. Their instruments - state SNAP policies - do not vary over time so these effects could be capturing state cross sectional correlations. Kaushal (2007) extends Borjas's (2004) study and uses welfare reform as an instrument for SNAP; she finds insignificant effects of SNAP on obesity of immigrants.

There is a small set of studies that examine the effect of SNAP on birth outcomes; thereby examining the effects of SNAP on pregnant women. Currie and Moretti (2008) use the county roll out of FSP in California and find that FSP introduction was associated with a reduction in birth weight, driven particularly by first births among teens and by changes for Los Angeles County. Almond, Hoynes and Schanzenbach (2011) extend that work and examine the 
effects of the program rollout across all counties in the U.S., finding that infant outcomes improve with FSP introduction. Changes in mean birth weight were small, but impacts were larger at the bottom of the birth weight distribution, reducing the incidence of low birth weight among the treated by 7 percent for whites and between 3 percent for blacks. They also find that the FSP introduction leads to a reduction in neonatal infant mortality, although these results rarely reach statistical significance. East (2015a) utilizes changes in immigrants' eligibility across states and over time as the result beginning with 1996 welfare reform and extending through subsequent legislation in the early 2000s. She finds that parental access to SNAP in utero improves health at birth. Additionally, she finds that increases in SNAP access between conception and age five improves parent-reported health at ages 6-16 (with suggestive evidence of reductions in school days missed, doctor visits and hospitalizations at ages 6-16).

Hoynes, Schanzenbach and Almond (2015) extend their SNAP rollout design and estimation approach to estimate the relationship between childhood access to the Food Stamp Program and adult health and human capital outcomes. They find that access to the FSP in utero and in early childhood leads to a large and statistically significant reduction in the incidence of "metabolic syndrome" (obesity, high blood pressure, heart disease, diabetes) as well as an increase in reporting to be in good health. The results show little additional protection beyond the age of 4, consistent with the importance of early life in the development of metabolic system. They also find for women, but not men, that access to food stamps in early childhood leads to an increase in economic self-sufficiency.

Overall, we have more confidence in the approaches using instruments based on state policies and the quasi-experimental estimates from program rollouts, and these studies tend to find positive or null impacts of SNAP on health. The estimates relying on within-family or within-individual variation in SNAP participation are more likely to find harmful estimates, and are subject to the concern that changes in unobservables are simultaneously driving SNAP participation and negative health outcomes.

\subsubsection{SNAP and Labor Supply}

Hoynes and Schanzenbach (2012) use county variation in the rollout of food stamps to identify the impact of food stamps on labor supply. Using the PSID, they use a difference in difference approach (using counties without food stamps as controls) and find no significant impacts on the overall sample but among single-parent households with a female head - a group much more likely to participate in the program - they find a significant intent-to-treat estimate of a reduction of 183 annual hours (treatment-on-the-treated reduction of 505 annual hours). They find no significant impacts of the FSP on earnings or family income, though the estimates are imprecise.

Using variation across states and over time in immigrants' eligibility for SNAP, East (2015b) studies the effect on the labor supply of foreign-born single women and married couples, who both participate in the program at high rates. She finds individuals reduce labor supply when eligible: the largest effects are among married and single women who reduce employment, whereas the effects for married men are smaller and are concentrated along the intensive margin (hours of work). Other than East (2015b), to our knowledge, there is no other study that meets 
our research design criteria that estimates the impact of SNAP on labor supply in the era after welfare reform and the expansion of EITC.

\subsection{Research on WIC}

Given the targeted nature of WIC, the literature naturally focuses on the impact of WIC on birth outcomes, breastfeeding, and nutritional intake. (See Table 4.2 for the catalog of the WIC studies we review.) There is also attention on the health of pregnant women and children less than 5. In the earlier volume, Currie (2003) reviews the literature and it generally concludes that women who participate in WIC give birth to healthier infants than non-participants. Here, we update the literature since the Currie review, again limiting to studies that meet our research design criteria.

\subsubsection{WIC Participation}

We begin our review with studies on the determinants of WIC participation. As with the early SNAP literature, the early WIC literature often relied on comparisons of the birth outcomes of women participating in WIC versus not participating. To explore the validity of this approach, several studies explore the characteristics of WIC participants. Bitler and Currie (2005) found that WIC participants (among women with Medicaid funded births) are negatively selected revealed through measures of education, age, marital status, presence of father, smoking, obesity, employment, and housing characteristics. ${ }^{35}$ Currie and Rajani (2014) extend this analysis and examine the characteristics of WIC participation among mothers who switched WIC participation status between births. They found that women receive WIC when they are younger, unemployed or unmarried. Identifying these changes are important for evaluating the validity of the maternal fixed effects design. Rossin-Slater (2013), examining variation due to the openings and closings of WIC clinics, finds evidence that participation increases with proximity to a clinic. Two studies examine the cyclicality of WIC participation, finding little relationship between state unemployment and poverty and state WIC caseloads (Bitler et al. 2003, Corsetto 2012).

\subsubsection{WIC and Health Outcomes}

The next panel reviews the literature on pregnancy and birth outcomes. Recent studies have used several different approaches to address the fundamental selection problem. One approach taken is to compare outcomes among more narrowly defined treatment and control groups (e.g., Bitler and Currie 2005, Joyce et al. 2005, 2008, and Figlio et al. 2009). Bitler and Currie (2005) create a control group based on Medicaid funded births and find that WIC leads to higher average birth weight and reduction in small for gestational age. Figlio, Hamersma, and Roth (2009) identify groups marginally eligible versus marginally ineligible for WIC (obtained by matching birth records to older sibling free and reduced price lunch records). They find WIC reduces the incidence of low birth weight but has no effect on average birth weight, gestational age, or premature birth.

\footnotetext{
${ }^{35}$ Women eligible for Medicaid are categorically eligible for WIC. Limiting to Medicaid funded births identifies a sample where all women are eligible for WIC.
} 
Another approach employs maternal fixed effects models, controlling for unobserved family background characteristics by comparing outcomes among siblings who participated in WIC to outcomes among those who did not. Currie and Rajani (2014) use a maternal fixed effects model applied to administrative data from NYC from 1994-2004 and find that WIC leads to reductions in low birth weight and being small for gestational age, but an increase in medical care use.

Joyce et al. (2008) discuss the possibility of a gestational age bias in this literature. They point out that women whose pregnancies last longer have more opportunity to enroll in WIC. If this is true (which they demonstrate using administrative data) then it leads to a mechanical relationship between WIC participation and longer gestation, biasing the results toward a positive effect of WIC. Currie and Rajani (2014) address this concern by estimating results on the subsample of full term births; they find smaller effects but still conclude that WIC improves birth outcomes.

An alternative approach is to use the introduction of WIC in the 1970s. Hoynes, Page and Stevens (2011) use differences in the timing of roll out by county to examine impacts of WIC on infant health. Using a difference-in-differences analysis, where the control counties have not yet adopted WIC, they find that roll out of the WIC program led to an increase birth weight and a decline in low birth weight. Rossin-Slater (2013) extends this analysis by combining geographic access with a maternal fixed effects approach. In particular, she uses administrative data from Texas combined with detailed information about the opening and closing of WIC clinics over 2005-2009; her approach is identified across mothers who had varying access to WIC clinics across births. She finds WIC improves pregnancy weight gain, birth weight, and breastfeeding initiation.

There are few studies that leverage variation in WIC policy changes. This is in large part due to the minimal variation across states and over time in the program rules. Bitler and Currie (2005) find lower takeup for states in which proof of income is required (prior to the federal mandate) and higher takeup for states with higher WIC package prices. However, they find these to be relatively weak instruments. With the more recent changes to WIC, it might be reasonable to reexamine the potential for using state policy variation to identify the effects of WIC.

The studies above are all focused on pregnant women and outcomes at birth. Yet pregnant women account for less than a quarter of WIC participants (Table 2.4), half are children 1-4 and another quarter are infants. There are many outcomes of interest here, notably rates of breastfeeding, nutritional intake, food security, child weight gain, and general health. However, there is a dearth of studies that use credible designs to evaluate WIC on children. Reflecting on the designs used in the analysis of birth outcomes (e.g., maternal fixed effects, geographic and time variation in presence of WIC clinics), it appears possible to apply similar approaches to examine child health. However, this would likely require rich administrative data, combining child health records, linked across siblings, and family WIC participation. The birth records data, with fine geographic identifiers, and WIC participation data, with the ability to link births across mothers, provide this information. But it is much less common to have these linkages for child health data. Any analysis of the effects of WIC on child health would have to grapple with the interesting question as to the possibility of spillovers to other non-covered family members. This 
could occur either though the sharing of WIC bundle or an income effect of WIC benefit. It could also possibly work through the nutritional education component of the program.

\subsubsection{WIC and Market Factors}

The supply side of the WIC market is less developed in the literature. There is a small literature on the infant formula market that starts with the stunning fact that over half of all U.S. infant formula is purchased through the WIC program (Oliveira, Frazao, and Smallwood 2010). Further, because WIC is a "quantity-voucher" benefit, recipients are not sensitive to price. This creates clear incentives for producers to price above marginal cost, especially in this highly concentrated market. Amid concerns about the rising costs of formula, the WIC program moved to a system whereby manufacturers bid on the contract to be the formula provider for the state. In exchange for the right, manufacturers pay a rebate on the formula; in practice the rebates are large, averaging $85-90 \%$ of wholesale price. Recent studies find that market shares increase substantially for firms that land the state contract (Huang and Perloff 2014, Oliveira, Franzao and Smallwood 2011), and Davis (2012) finds that the winning firm sees its share of the sales to nonWIC customers increase by $50 \%-60 \%$.

Meckel (2014) examines the incentives for vendor fraud with WIC. Because WIC recipients are price insensitive, vendors face incentives to price discriminate by charging higher prices to WIC recipients. She uses the rollout of EBT in WIC across Texas counties and finds that with EBT (which makes it harder to engage in fraud), prices charged to non-WIC recipients increase. Additionally, EBT sparks a decline in both vendor participation and individual participation in WIC. McLaughlin (2014) explores vendor competition given that they cannot compete on price (due to price insensitivity of WIC participants). Using a sample of WIC vendors in California, he finds that vendors compete on products (brand profile, range and diversity of products) as well as choosing locations consistent with Hotelling-like incentives.

Another aspect to the supply side has to do with the nature of foods available in stores where WIC recipients shop. Andreyava (2012) provides an interesting case study analysis of how product stock changed in WIC-authorized grocery and convenience stores after the recent alteration of the WIC packages. There was a substantial increase in stocking of healthy foods; for example $8 \%$ of WIC-authorized convenience and grocery stores had any whole wheat/whole grain bread at baseline, while $81 \%$ did so after the revisions took effect (over the same time, nonWIC stores increased whole wheat/whole grain bread from $25 \%$ to $35 \%$ ).

\subsection{Research on NSLP}

Most research on the National School Lunch Program has focused on how the program impacts dietary intake, and also obesity rates. Because the NSLP is virtually universally available, and most policy changes are implemented at the Federal level, there are relatively few examples of credible quasi-experiments in the literature. Most of the research employs differences-in-differences between siblings, or across periods when the NSLP is or is not

available. It is worth noting that none of the studies reviewed in this section have used data collected after the 2012-13 implementation of the Healthy, Hunger-Free Kids Act which 
dramatically overhauled nutrition standards for school meals. Table 4.3 catalogs the studies we review.

\subsubsection{NSLP and Dietary Quality}

Gleason and Suitor (2003) compare observations of dietary intake for an individual across multiple days that vary by whether the student does or does not receive a school lunch, and find mixed evidence on nutrition intake. They find that NSLP increases the consumption of fat, protein, and six types of vitamins and minerals, but that it has no overall impact on total calories eaten at lunch or over a 24-hour period. Nord and Romig (2006) compare intake during the summer vs. the school year for families with school-age vs. preschool-age children, and find that NSLP availability significantly reduces the rate of food insecurity.

\subsubsection{NLSP and Child Health and Education Outcomes}

Several papers have investigated the relationship between NSLP participation and childhood obesity. The results are estimated at different ages and at different points on the income distribution, and find mixed results. Schanzenbach (2009) finds that children ineligible for a free or reduced-price lunch who go on to consume school lunch enter kindergarten with similar body weights when compared to children who do not consume school lunch, but that NSLP participants become comparatively heavier as their exposure to school lunch increases. In addition, she uses the income cutoff for receipt of reduced-price lunch and finds that both NSLP participation and body weight discretely increase at the cutoff. Millimet, Tchernis, and Husain (2010) find similar results using the same data.

On the other hand, Gundersen, Kreider and Pepper (2012) use a Manski-style partial identification approach and find that receipt of free or reduced-price lunch improves child health and substantially reduces obesity rates. Mirtcheva and Powell (2013) use children who change their participation in NSLP between waves in the PSID, and find that NSLP has no effect on body weight in either direction.

Dunifon and Kowaleski-Jones (2003) compare siblings who differ in their NSLP participation decisions. In the OLS, NSLP participation predicts more behavioral problems, increased health limitations, and lower math test scores. When sibling comparisons are employed, the coefficients decline in magnitude and are no longer statistically significant, suggesting the OLS correlations in part reflect unobserved family characteristics.

In the spirit of the program rollout literature described in the SNAP section above, Hinrichs (2010) leverages changes in NSLP funding formulas during the early years of the program to estimate the long-run impacts of the expansion of the program. He finds that increasing NSLP exposure in a state by 10 percentage points increases completed education by nearly 1 year for males, and one-third of a year for females. On the other hand, NSLP did not appear to have long-term health impacts.

\subsection{Research on SBP}


As shown in Table 2.1, participation in the SBP has increased dramatically over the past 20 years. In particular, many more schools have adopted the program during this time period, or have adopted policies aimed at increasing availability and take-up of the program. The literature has been active in recent years, and Table 4.4 lists the studies we review.

Bhattacharya, Currie and Haider (2006) use variation in school participation in the SBP prior to the recent increase in participation to identify the impacts of the program on children and their families. Using a difference-in-differences setup, they compare students observed during the school year vs. when they are on school vacation, by whether or not their school offered the SBP. They find that SBP does not impact the number of calories consumed nor the likelihood that a student eats breakfast, but it does improve dietary quality as measured by the Healthy Eating Index and in blood serum. The income transfer implied by the SBP does not appear to spill over and improve dietary quality for other household members, however. Modeling school selection into the SBP and bounding the potential for individual-level unobservables to confound the effect, Millimet, Tchernis and Husain (2010) find that the SBP reduces childhood obesity.

Some states have statutes requiring participation in the SBP for schools that meet at least some threshold (which varies across states, typically between 10 and 40 percent) of eligibility for free or reduced-price meals. Frisvold (2012) uses these thresholds to construct difference-indifferences and RD estimates of the impact of SBP for schools near the thresholds. He finds that SBP improves achievement in math and reading, and that participation improves the nutritional content of breakfast.

Evidence on the SBP has increased recently as researchers have used policy changes aimed at expanding the program to identify its impacts. In particular, to address (perceived) stigma associated with participation in the school breakfast program and in response to incentives from the USDA, some districts have begun (or stopped) offering universal free school breakfast instead of the standard program that provides free breakfast only to students who are income-eligible for a subsidy. There is substantial evidence that universal free breakfast (UFB) has increased participation rates. Leos-Urbel, Schwartz, Weinstein and Corcoran (2013) find that expansion of the UFB program in New York City schools increased participation rates for those previously ineligible for breakfast subsidies, and also for free-breakfast students. This suggests that the UFB program may also reduce stigma associated with participation. They find small positive impacts of the program on attendance rates, but no impact on test scores. Ribar and Haldeman (2013) use the termination of UFB in some schools but not others in a North Carolina district, and find a decline in participation that was largest for students who were not incomeeligible for free breakfasts.

The USDA sponsored a large randomized-controlled trial of UFB, and collected information on impacts on participation, dietary intake, health, behavior and achievement. Crepinsek et al. (2006) analyze the experimental data and find that students who attend a school randomly assigned to receive UFB are more likely to consume a nutritionally substantive breakfast, the program has no impact on 24-hour dietary intakes or on the rate of breakfast skipping. 
While UFB increases take-up rates, the limitation remains that in order to participate in the breakfast program a student generally has to arrive at school prior to the start of classes. To remove this barrier, another recent policy innovation has been to serve breakfast in the classroom (BIC) during the first few minutes of the school day. BIC eliminates the need for students to arrive to school early to participate in the school breakfast program, and dramatically increases participation in the SBP. This program has recently gained momentum, with major expansions in cities such as Washington, D.C., Houston, New York City, Chicago, San Diego and Memphis, and a flurry of research studies on the impacts of the program.

Imberman and Kugler (2014) investigate the very short-term impacts of the introduction of a BIC program in a large urban school district in the southwestern United States. The program was introduced on a rolling basis across schools, and the earliest-adopting schools had the program in place for up to 9 weeks before the state's annual standardized test was administered. They find increases in reading and math test scores on the order of 0.06 and 0.09 standard deviations, respectively, but no impact on grades or attendance. Additionally, there was no difference in impact on test scores between those schools that had adopted the program for only one week vs. those that had the program for a longer time. The pattern in the results led the authors to speculate that the test score impacts were driven by short-term cognitive gains on the day of the test due to eating breakfast and not underlying learning gains.

Schanzenbach and Zaki (2014) re-analyze the USDA's experimental data described above to separately investigate the impact of the BIC program. They find few positive impacts on measures of dietary quality, and no positive impacts on behavior, health or achievement measured after 1 to 3 years of treatment. They find some evidence of health and behavior improvements among specific subpopulations. Dotter (2012), on the other hand, finds stronger impacts of the staggered introduction of a BIC program in elementary schools in San Diego. Using a difference-in-differences approach based on the introduction of the program, he finds that $\mathrm{BIC}$ increases test scores in math and reading by 0.15 and 0.10 standard deviations, respectively. He finds no test score impacts on schools that previously had universal free breakfast, and no impacts on attendance rates.

\section{Conclusions and Future Directions}

A pressing concern for policy makers is whether food and nutrition programs are doing an adequate job enhancing and protecting the nutrition status of Americans. Despite the patchwork of nutrition programs available, many recipients either suffer food insecurity, consume diets that fall short of dietary guidelines, or both. There are many holes in the research literature, and better answers to these unresolved questions could give policy makers guidance on ways to potentially improve the programs. We conclude this chapter with our thoughts on open research questions. We organize these comments into three categories: programs and policy (basic program impacts), the role of market incentives, and potential insights from behavioral economics to enhance the effectiveness of the programs.

\subsection{Programs and Policy}


As described in the sections above, while there have been recent strides in our understanding of the causal impacts of food and nutrition programs, there are many holes to be filled in terms of our knowledge about what food and nutrition programs do. For example, although over three quarters of WIC participants are infants and children, little is known about the health impacts of WIC these populations. In addition, little is known about the effects of the $\$ 388$ million in nutrition education or $\$ 100$ million in employment and training programs in SNAP (figures from CBO, 2012). Recent policy changes also need evaluation, for example the impacts of stricter nutrition standards for school meals adopted under the Healthy, Hunger-Free Kids Act on participation and outcomes are yet to be understood. The Act also imposed restrictions on "competitive foods" sold in schools that could have important impacts on participation, child health, and educational outcomes. Similarly, the impacts of the recent change in the WIC food basket on take-up and participant outcomes need study. In addition, the impacts of the relaxation of the gross income test in SNAP - which expanded eligibility to households with earnings above 130 percent of the poverty line that have high deductions for shelter costs, child care and medical costs - are in need of study.

In addition, the interactions between these and other safety net programs are not well understood. Bitler and Hoynes (2015) show that in the post-welfare reform world, SNAP played a large and important role in protecting families from falling into poverty in the Great Recession. Further, they find that TANF is providing much less protection in response to economic downturns than it did prior to welfare reform (when the program was called AFDC). As a result, SNAP's role in insuring consumption in the face of economic downturns appears to be evolving and growing. Have the responses to the work disincentives of SNAP changed in the era after welfare reform, in which TANF's role in the safety net has been displaced by the EITC? How have the time limits on ABAWD participants in SNAP changed work incentives? Does SNAP play a more important role in alleviating food insecurity and other measures of material hardship because it is paid out monthly instead of the EITC's annual lump-sum payment? In a broader sense, is it optimal to have the current patchwork of programs, or would it be better to combine or streamline the programs somehow?

There is a recent and growing literature on the medium- and long-run effects of providing food and nutrition programs in utero and in early childhood. We have much more to learn about the potential benefits of these programs on health and wellbeing in the long run, and when in the life cycle is the most important time to provide these benefits.

A few recent papers focus on understanding the recent SNAP caseload dynamics, as motivated by the increase in SNAP in the Great Recession. Studies by Bitler and Hoynes (2015) and Ganong and Liebman (2014) show that a significant share of the increase in SNAP in the Great Recession can be explained by the severity of the labor market contraction. As of this writing, as the labor market is recovering, SNAP caseloads are declining. It will be of interest to understand whether these dynamics continue. Relatively little is understood about the duration and frequency of participation spells. What are the income dynamics that correlate with households' entry to and exit from the program? Given the trade-offs between incentives, protection, and the administrative costs of enrolling a household in SNAP, are the program rules set optimally? 
In addition, the Institute of Medicine (2013) set out a variety of research questions on the adequacy of SNAP benefits that have not been answered. Since a high proportion of SNAP recipients experience food insecurity at some point during the year, are there changes that could enhance the program's effectiveness in this regard? For example, are the funding formula's parameters set appropriately? Important areas of study include whether the earnings disregard is adequate, the impact of the cap on the shelter cost deduction to net income, and whether the assumptions of the amount of home production of meals implicit in the Thrifty Food Plan are reasonable in an era with higher shares of the caseload employed.

\subsection{The role of market incentives (for participants and firms)}

More work is also needed in understanding the price elasticity of demand for various goods (e.g. healthy foods). There is some recent evidence on this question from the Healthy Incentives Pilot conducted in Massachusetts (Bartlett et al. 2014). This small scale randomized controlled trial gave the treatment group a $\$ 0.30$ rebate for each dollar of SNAP benefits spent on fruits and vegetables (subject to a maximum subsidy). The evaluation shows that the price subsidy led to a $25 \%$ increase in consumption of fruits and vegetables. It would be useful to know how consumption would respond to different levels of price subsidies, and whether the results are different if they are offered at all participating retailers or limited to farmers markets only. It would also be useful to know how and for whom consumption patterns would change under targeted price subsidies compared to other policy changes with equivalent cost, such as an increase in the maximum benefit levels or an increase in the earnings disregard. Along a similar line, Just and Price (2013) find that children are more likely to eat fruits or vegetables at lunch in school if they are given a cash incentive, and impacts are more than twice as large if they are offered a quarter as a nickel.

More work is needed to understand how to design programs that are efficient and incentive-compatible for vendors. For example, SNAP and WIC benefits make use of normal channels of trade, and can be redeemed at a large number of retail stores. What are ways to promote lowest-price redemption of WIC vouchers given that WIC is a quantity voucher? How would the efficiency and effectiveness of the program be changed if the benefits were altered such that recipients could respond to the price of the goods (e.g. by turning the program into a dollar-value voucher that could be used for targeted goods)? For school meals, how have revenues responded to the new nutrition standards, and if meals are losing revenue from what sources are schools making up the shortfall? What combination of incentives and regulations improve the provision of healthy school meals, and does that vary by whether the meals service is run by the district or contracted to a private vendor?

\subsection{Insights from behavioral economics}

Another direction for research is testing whether existing economic models accurately capture participant behavior, or if models that incorporate behavioral economics insights are more appropriate. The USDA is interested in pursuing these avenues, and recently funded a Center for Behavioral Economics and Healthy Food Choice Research. 
For example, some policy advocates have suggested altering the types of goods that can be purchased with SNAP benefits, such as excluding sugar sweetened beverages or allowing purchase of hot foods. Under the canonical model, inframarginal consumers would not be predicted to alter their consumption of these goods regardless of whether SNAP benefits can be used to purchase the items. Does actual behavior adhere to the canonical model prediction, or would recipients alter their consumption of the targeted goods in response to these potential "nudges"? In 2010, New York City requested a waiver from USDA to ban the purchase of a wide range of sugar-sweetened beverages with SNAP benefits. While the waiver was rejected, a well-designed demonstration project would provide useful evidence on the matter. Even if such policies do not alter behavior, there may be scope for other well-targeted nudges to encourage healthier food consumption.

There is more to learn about the importance of the "food stamp cycle" first documented by Shapiro (2005). In particular, the data show that as the number of days pass since a family receives their (monthly) food stamp payment, food consumption, calories, nutritional intake, and food expenses decline. The decline is especially notable in the last week of the food stamp cycle. Hastings and Washington (2010) find results consistent with this using grocery store scanner data. These findings have caused some policy interest in paying out benefits more frequently, e.g. twice per month. Using a population shopping at commissaries on military bases, though, Zaki (2014) documents a similar decline in daily food purchasing patterns late in the pay period when paychecks are distributed twice per month. This suggests that more frequent payments of benefits may not be more effective at encouraging consumption smoothing. A better understanding of the interactions between the frequency of payments, self-control, and consumption smoothing would give us important insights into the economic decision-making among low-income populations that could be incorporated in our food and nutrition programs and policies.

\subsection{Final conclusions}

It is encouraging that in recent years there has been an increase in the study of food and nutrition programs using designs that attempt to isolate causal impacts of the programs. Nonetheless, many important questions remain that are unlikely to be answered by quasiexperimental analyses. To provide compelling answers on the impacts of these important programs, the USDA should be open to expanding access to administrative data and implementing well-designed social experiments. 


\section{References}

Almond, D., K. Y. Chay, and M. Greenstone. 2006. Civil rights, the war on poverty, and blackwhite convergence in infant mortality in the rural South and Mississippi. Working Paper No. 07*04. Cambridge, MA: MIT Department of Economics, December.

Almond, D., H. W. Hoynes, and D. W. Schanzenbach, D. W. 2011. Inside the war on poverty: the impact of food stamps on birth outcomes. The Review of Economics and Statistics 93 (2): 387-403.

Andreyeva, T. 2012. Effects of the revised food packages for Women, Infants, and Children (WIC) in Connecticut. Choices 27 (3).

Bailey, M. J. 2012. Reexamining the impact of family planning programs on US fertility: evidence from the War on Poverty and the early years of Title X. American Economic Journal Applied economics 4 (2): 62.

Barker, D. J. (1997). Maternal nutrition, fetal nutrition, and disease in later life. Nutrition, 13(9), 807-813.

Bartlett, S., J. Klerman, P. Wilde, L. Olsho, C. Logan, M. Blocklin, M. Beauregard, and A. Enver. 2014. Evaluation of the Healthy Incentives Pilot (HIP): Final Report. Food and Nutrition Service, U.S. Department of Agriculture. Cambridge, MA: Abt Associates, September.

Beatty, T. K., and C. Tuttle. 2012. Expenditure response to increases in in-kind transfers: Evidence from the Supplemental Nutrition Assistance Program. In AAEA/EAAE Food Environment Symposium, Boston, MA, May: 30-31.

Bernstein, L. S., J. E. McLaughlin, M. K. Crepinsek, and L. M. Daft. 2004. Evaluation of the School Breakfast Program Pilot Project: Final Report (Nutrition Assistance Program Report Series, No. CN-04-SBP). Alexandria, VA: Office of Analysis, Nutrition, and Evaluation, Food and Nutrition Service, U.S. Department of Agriculture, December.

Berry, J. M. 1984. Feeding hungry people: Rulemaking in the food stamp program. New Brunswick, NJ: Rutgers University Press.

Bhattacharya, J., J. Currie, and S. J. Haider. 2006. Breakfast of champions? The School Breakfast Program and the nutrition of children and families. Journal of Human Resources 41 (3): 445-466.

Bitler, M., and J. Currie. 2005. Does WIC Work? The effects of WIC on pregnancy and birth outcomes. Journal of Policy Analysis and Management 24 (1): 73-91.

Bitler, M., and H. W. Hoynes. 2013. Immigrants, welfare and the U.S. safety net. In Card, David and Steven Raphael (eds.), Immigration, Poverty, and Socioeconomic Inequality, New York, NY: Russell Sage Foundation. 
Bitler, M., and H. W. Hoynes. 2015. The more things change, the more they stay the same: The safety net, living arrangements, and poverty in the great recession. Forthcoming, Journal of Labor Economics.

Bitler, M. P., J. Currie, and J. K. Scholz. 2003. WIC eligibility and participation. Journal of Human Resources 1139-1179.

Blundell, R., and L Pistaferri. 2003. Income volatility and household consumption: The impact of food assistance programs. Journal of Human resources 1032-1050.

Borjas, G. J. 2004. Food insecurity and public assistance. Journal of Public Economics 88 (7): $1421-1443$

Bruich, G. 2014. The effect of SNAP benefits on expenditures: New evidence from scanner data and the November 2013 benefit cuts. Harvard University. Mimeograph, September.

Cascio, E., N. Gordon, E. Lewis, S. Reber, 2010. Paying for progress: Conditional grants and the desegregation of southern schools. Quarterly Journal of Economics 125 (1): 445-482

Coleman-Jensen, A., M. Nord, M. Andrews, and S. Carlson. 2012. Household food security in the United States in 2011. Economic Research Report no.141. Washington, D.C.: Economic Research Service, U.S. Department of Agriculture.

Coleman-Jensen, A., M. Rabbitt, C. Gregory and A. Singh. 2015. Statistical Supplement to Household Food Security in the United States in 2014. Administrative Publication Number 069. Washington, D.C.: Economic Research Service, U.S. Department of Agriculture.

Congressional Budget Office. 2012. Effective marginal tax rates for low- and moderate-income workers. Washington, D.C., November.

Congressional Budget Office. 2012. The Supplemental Nutrition Assistance Program. Washington, D.C., April.

Corsetto, L. 2012. Food and nutrition program cyclicality. University of California-Davis. Mimeograph.

Crepinsek, M. K., A. Singh, L. S. Bernstein, and J. E. McLaughlin. 2006. Dietary effects of universal-free school breakfast: findings from the evaluation of the school breakfast program pilot project. Journal of the American Dietetic Association 106 (11): 1796-1803.

Cunnyngham, K. 2002. Trends in Food Stamp Program participation rates: 1994 to 2000. Contract no. 53-3198-9-008. Washington, D.C.: Mathematica Policy Research. 
Cunnyngham, K. 2010. State trends in Supplemental Nutrition Assistance Program eligibility and participation among elderly individuals. Washington, D.C.: Mathematica Policy Research, September.

Cunnyngham, K. 2014. State Supplemental Nutrition Program participation rates in 2011. Contract no. AG-3198-K-13-0006. Washington, D.C.: Food and Nutrition Service, U.S. Department of Agriculture, February.

Cunnyngham, K, A. Sukasih, and L. Castner. 2014. Empirical Bayes shrinkage estimates of state Supplemental Nutrition Assistance Program participation rates in 2009-2011 for all eligible people and the working poor. Washington, D.C.: Mathematica Policy Research, March.

Currie, J. 2003. U.S. food and nutrition programs. In Means-tested transfer programs in the United States, Moffitt, R. A., \& Moffitt, R. (Eds.), 291-363, Chicago: University of Chicago Press.

Currie, J., and F. Gahvari. 2008. Transfers in cash and in-kind: Theory meets the data. Journal of Economic Literature 46 (2): 333-383.

Currie, J., and J. Grogger. 2001. Explaining recent declines in food stamp program participation [with comments]. Brookings-Wharton papers on urban affairs: 203-244.

Currie, J., and E. Moretti. 2008. Did the introduction of food stamps affect birth outcomes in California? In Making Americans Healthier: Social and Economic Policy as Health Policy, R. Schoeni, J. House, G. Kaplan, and H. Pollack, editors, New York, NY: Russell Sage Press.

Currie, J., and I. Rajani. 2014. Within-mother estimates of the effects of WIC on birth outcomes in New York City. Working Paper no. w20400. Cambridge, MA: National Bureau of Economic Research, August.

Davis, D. 2012. Bidding for WIC infant formula contracts: Do Non-WIC customers subsidize WIC customers? American Journal of Agricultural Economics 94 (1):80-96.

DePolt, R. A., R. A. Moffitt, and D. C. Ribar. 2009. Food stamps, temporary assistance for needy families and food hardships in three American cities. Pacific Economic Review14 (4): 445-473.

Dotter, D. 2012. Breakfast at the desk: The impact of universal breakfast programs on academic performance. Mimeograph. La Jolla, CA: University of California, San Diego.

Dunifon, R., and L. Kowaleski-Jones. 2003. The influences of participation in the national school lunch program and food insecurity on child well-being. Social Service Review 77 (1): 72 92.

East, Chloe (2015a). The effect of Food Stamps on children's health: Evidence from immigrants' changing eligibility. Mimeograph. Davis, CA: University of California, Davis. 
East, Chloe (2015b). The labor supply response to Food Stamp access. Mimeograph. Davis, CA: University of California, Davis.

Fan, M. 2010. Do food stamps contribute to obesity in low-income women? Evidence from the National Longitudinal Survey of Youth 1979. American Journal of Agricultural Economics 92 (4): 1165-1180.

Figlio, D. N., C. Gundersen, and J. P. Ziliak. 2000. The effects of the macroeconomy and welfare reform on food stamp caseloads. American Journal of Agricultural Economics 82 (3): 635-641.

Figlio, D., S. Hamersma, and J. Roth. 2009. Does prenatal WIC participation improve birth outcomes? New evidence from Florida. Journal of Public Economics 93 (1): 235-245.

Finkelstein, A., and R. McKnight. 2008. What did Medicare do? The initial impact of Medicare on mortality and out of pocket medical spending. Journal of Public Economics 92 (7): 16441668.

Frisvold, D. E. 2012. Nutrition and cognitive achievement: An evaluation of the School Breakfast Program. Discussion Paper no. 1402-12. Madison, WI: Institute for Research on Poverty, August.

Ganong, P., and J. B. Liebman. 2013. The decline, rebound, and further rise in SNAP enrollment: Disentangling business cycle fluctuations and policy changes. Working paper no. 19363. Cambridge, MA: National Bureau of Economic Research.

Gibson, D. 2003. Food Stamp Program participation is positively related to obesity in lowincome women. The Journal of Nutrition 133 (7): 2225-2231.

Gibson, D. 2004. Long-term Food Stamp Program participation is differentially related to overweight in young girls and boys. The Journal of Nutrition 134 (2): 372-379.

Gibson-Davis, C. M., and E. M. Foster. 2006. A cautionary tale: Using propensity scores to estimate the effect of food stamps on food insecurity. Social Service Review 80 (1): 93-126.

Gleason, P. M., and C. W. Suitor. 2003. Eating at school: How the National School Lunch Program affects children's diets. American Journal of Agricultural Economics 85 (4): 1047-1061.

Gluckman, P. D., and M. A. Hanson. 2004. The Fetal Matrix: Evolution, Development and Disease. Cambridge: Cambridge University Press.

Goodman-Bacon, A. J. 2014. Public insurance and mortality: Evidence from Medicaid implementation. Working paper, University of Michigan.

Gregory, C., M. Rabbitt, and D. C. Ribar. 2015. The Supplemental Nutrition Assistance Program and food insecurity. In SNAP Matters: How Food Stamps Affect Health and Well Being. J. 
Bartfeld, C. Gundersen, T. Smeeding, and J. Ziliak, (eds.), Redwood City, CA: Stanford University Press.

Griliches, Z. 1979. Sibling models and data in economics: Beginnings of a survey. The Journal of Political Economy: S37-S64.

Gundersen, C., B. Kreider, and J. Pepper. 2012. The impact of the National School Lunch Program on child health: A nonparametric bounds analysis. Journal of Econometrics 166 (1): 7991.

Gundersen, C., and J. P. Ziliak. 2003. The role of food stamps in consumption stabilization. Journal of Human Resources: 1051-1079.

Haider, S. J., R. F. Schoeni, Y. Bao, and C. Danielson. 2004. Immigrants, welfare reform, and the economy. Journal of Policy Analysis and Management 23 (4): 745-64.

Hastings, J., and E. Washington. 2010. The first of the month effect: Consumer behavior and store responses. American Economic Journal: Economic Policy 2 (2): 142-62.

Hinrichs, P. 2010. The effects of the National School Lunch Program on education and health. Journal of Policy Analysis and Management 29 (3): 479-505.

Hoynes, H. W., L. McGranahan, and D.W. Schanzenbach. 2015. SNAP and food consumption. In SNAP Matters: How Food Stamps Affect Health and Well Being. J. Bartfeld, C. Gundersen, T. Smeeding, and J. Ziliak, (eds.), Redwood City, CA: Stanford University Press. 2015.

Hoynes, H., M. Page, and A.H. Stevens. 2011. Can targeted transfers improve birth outcomes? Evidence from the introduction of the WIC program. Journal of Public Economics 95 (7): 813827.

Hoynes, H. W., and D. W. Schanzenbach. 2009. Consumption responses to in-kind transfers: Evidence from the introduction of the Food Stamp Program. American Economic Journal: Applied Economics 1 (4): 109-139.

Hoynes, H. W., and D. W. Schanzenbach. 2012. Work incentives and the Food Stamp Program. Journal of Public Economics 96 (1): 151-162.

Hoynes, H. W., D. W. Schanzenbach and D. Almond. 2015. Long run impacts of childhood access to the safety net. Forthcoming, American Economic Review.

Huang, R., and J.M. Perloff. 2014. WIC contract spillover effects. Review of Industrial Organization 44 (1): 49-71.

Imberman, S. A., and A.D. Kugler,. 2014. The effect of providing breakfast in class on student performance. Journal of Policy Analysis and Management 33 (3): 669-699. 
Institute of Medicine. 2005. WIC food packages: Time for a change. Washington, D.C.: The National Academies Press.

Institute of Medicine. 2013. Supplemental Nutrition Assistance Program: Examining the evidence to define benefit adequacy. Washington, D.C.: The National Academies Press.

Joyce, T., D. Gibson, and S. Colman. 2005. The changing association between prenatal participation in WIC and birth outcomes in New York City. Journal of Policy Analysis and Management 24 (4): 661-685.

Joyce, T., A. Racine, and C. Yunzal-Butler. 2008. Reassessing the WIC effect: Evidence from the pregnancy nutrition surveillance system. Journal of Policy Analysis and Management 27 (2): 277-303.

Just, D. R., and J. Price. 2013. Using incentives to encourage healthy eating in children. Journal of Human Resources 48 (4): 855-872.

Kabbani, N. S., and P. E. Wilde. 2003. Short recertification periods in the U.S. Food Stamp Program. Journal of Human Resources 38:1112-1138.

Kaestner, R., and N. Kaushal. 2005. Immigrant and native responses to welfare reform. Journal of Population Economics 18 (1): 69-92.

Kaushal, N. 2007. Do food stamps cause obesity? Evidence from immigrant experience. Journal of Health Economics 26 (5): 968-991.

Kim, J. 2014. Changes in Low-income Household's Spending Pattern in Response to the 2009 SNAP Benefit Increase. University of Michigan, MI.

Kreider, B., J. V. Pepper, C. Gundersen, and D. Jolliffe 2012. Identifying the effects of SNAP (Food Stamps) on child health outcomes when participation is endogenous and misreported. Journal of the American Statistical Association 107 (499): 958-975.

Leos-Urbel, J., A.E. Schwartz, M. Weinstein, and S. Corcoran. 2013. Not just for poor kids: The impact of universal free school breakfast on meal participation and student outcomes. Economics of Education Review 36: 88-107.

Levin, M., and Z. Neuberger. 2014. Improving direct certification will help more low-income children receive school meals. Washington, D.C.: Center on Budget and Policy Priorities, July.

Ludwig, J., and M. Miller. 2005. Interpreting the WIC debate. Journal of Policy Analysis and Management 24 (3): 691-701.

Ludwig, J., and D.L. Miller. 2007. Does Head Start improve children's life chances? Evidence from a regression discontinuity approach. Quarterly Journal of Economics 122 (1): 159-208. 
Macro International. 1995. The WIC dynamics study, Volume 1, Final report. U.S. Department of Agriculture, Food and Consumer Service, February.

McLaughlin, P. 2014. Incentives for non-price competition in the California WIC program. University of California-Davis. Mimeograph, May.

Meckel, K. 2014. Is the cure worse than the disease? Unintended consequences of fraud reduction in transfer programs. Columbia University. Mimeograph, November.

Meyerhoefer, C. D., and Y. Pylypchuk. 2008. Does participation in the Food Stamp Program increase the prevalence of obesity and health care spending? American Journal of Agricultural Economics 90 (2): 287-305.

Meyerhoefer, C. D., and M. Yang. 2011. The relationship between food assistance and health: A review of the literature and empirical strategies for identifying program effects. Applied Economic Perspectives and Policy: ppr023.

Millimet, D. L., R. Tchernis, and M. Husain, M. 2010. School nutrition programs and the incidence of childhood obesity. Journal of Human Resources 45 (3): 640-654.

Mirtcheva, D. M., and L. M. Powell. 2013. National School Lunch Program participation and child body weight. Eastern Economic Journal 39 (3): 328-345.

Moffitt, R. 2014. Multiple program participation and SNAP. Forthcoming in SNAP Matters: How Food Stamps Affect Health and Well Being, J. Bartfeld, C. Gundersen, T. Smeeding, and J. Ziliak, (eds.), Redwood City, CA: Stanford University Press.

Mulligan, C. B. 2012. The redistribution recession: How labor market distortions contracted the economy. New York, NY: Oxford University Press.

Mykerezi, E., and B. Mills. 2010. The impact of Food Stamp Program participation on household food insecurity. American Journal of Agricultural Economics 92 (5): 1379-1391.

Nord, M. 2009. Food insecurity in households with children: Prevalence, severity, and household characteristics. Economic Information Bulletin Number 56. Washington, D.C.: U.S. Department of Agriculture, September.

Nord, M., and K. Romig. 2006. Hunger in the summer: seasonal food insecurity and the National School Lunch and Summer Food Service programs. Journal of Children \& Poverty 12 (2): 141158.

Ogden, C.L., M. Carroll, B. Kit, and K. Flegal. 2014. Prevalence of Childhood and Adult Obesity in the United States, 2011-2012. JAMA 311(8):806-814. 
Oliveira, V., E. Frazão, and D. Smallwood. 2013. Trends in infant formula rebate contracts: Implications for the WIC program, EIB-119. Washington, D.C.: U.S. Department of Agriculture, Economic Research Service, December.

Oliveira, V., E. Racine, J. Olmsted, and L. M. Ghelfi. 2002. The WIC Program: Background, trends, and issues (Food Assistance and Nutrition Research Report No. 27). Washington, D.C.: Food and Rural Economics Division, Economic Research Service, U.S. Department of Agriculture, September.

Parrott, S., and R. Greenstein. 2014. Policymakers often overstate marginal tax rates for lowerincome workers and gloss over tough trade-offs in reducing them. Washington, D.C.: Center on Budget and Policy Priorities, December.

Peterson, A., B. McGill, B. Thorn, A. Suchman, and D. Ribar. 2014. Examining the growth of the zero-income SNAP caseload: Characteristics, circumstances, and dynamics of zero-income SNAP participants. Volume I: Cross-Sectional and Longitudinal Findings, 1993-2008. Contract No. AG-3198-C-11-0008. Alexandria, VA: Insight Policy Research, Food and Nutrition Service, U.S. Department of Agriculture.

Ratcliffe, C., S.M. McKernan, and S. Zhang. 2011. How much does the Supplemental Nutrition Assistance Program reduce food insecurity? American Journal of Agricultural Economics: aar026.

Ribar, D. C., and L. A. Haldeman. 2013. Changes in meal participation, attendance, and test scores associated with the availability of universal free school breakfasts. Social Service Review 87 (2): $354-385$.

Rossin-Slater, M. 2013. WIC in your neighborhood: New evidence on the impacts of geographic access to clinics. Journal of Public Economics 102: 51-69.

Schanzenbach, D. W. 2009. Do school lunches contribute to childhood obesity? Journal of Human Resources 44 (3): 684-709.

Schanzenbach, D. W. 2007. What are food stamps worth? Working paper, University of Chicago.

Schanzenbach, D. W., and M. Zaki. 2014. Expanding the School Breakfast Program: Impacts on children's consumption, nutrition and health. Working Paper no. 20308. Cambridge, MA:

National Bureau of Economic Research, July.

Schmeiser, M. D. 2012. The impact of long-term participation in the Supplemental Nutrition Assistance Program on child obesity. Health Economics 21 (4): 386-404.

Schmidt, L., L. Shore-Sheppard, and T. Watson. 2015. The effect of safety net programs on food insecurity. Journal of Human Resources (forthcoming). 
Shaefer, H. L., and I. A. Gutierrez. 2013. The Supplemental Nutrition Assistance Program and material hardships among low-income households with children. Social Service Review 87 (4): 753-779.

Shapiro, J. M. 2005. Is there a daily discount rate? Evidence from the food stamp nutrition cycle. Journal of Public Economics 89 (2): 303-325.

Short, K. 2011. The research supplemental poverty measure: 2010. Current Population Reports, (P60-241). Washington, D.C.: U.S. Department of Commerce, Economics and Statistics Administration, U.S. Census Bureau, November.

Short, K. 2014. The research supplemental poverty measure: 2014. Current Population Reports, (P60-254). Washington, D.C.: U.S. Department of Commerce, Economics and Statistics Administration, U.S. Census Bureau.

Smeeding, T., D. Jolliffe, and L. Tiehen. 2013. The Effect of SNAP on poverty. Discussion Paper Series no. DP2013-06. Lexington, KY: University of Kentucky Center for Poverty Research, October.

Southworth, H. M. 1945. The economics of public measures to subsidize food consumption. Journal of Farm Economics 27 (1): 38-66.

U.S. Department of Agriculture (USDA). 2013. Special Supplemental Nutrition Program for Women, Infants and Children food package cost report, fiscal year 2010. Washington, D.C.: Food and Nutrition Service, U.S. Department of Agriculture, August.

U.S. Government Accountability Office (GAO). 2007. Food Stamp Program: FNS could improve guidance and monitoring to help ensure appropriate use of non-cash categorical eligibility. GAO-07-465. Washington, D.C., March.

Vartanian, T. P., and L. Houser. 2012. The effects of childhood SNAP use and neighborhood conditions on adult body mass index. Demography 49 (3): 1127-1154.

Ver Ploeg, M., and D. Betson. 2003. Estimating eligibility and participation for the WIC program. Washington, D.C.: The National Academies Press.

Wang, D. D., et al. (2014). Trends in Dietary Quality Among Adults in the United States, 1999 Through 2010, JAMA Internal Medicine 174(10):1587-1595.

Wilde, P., and M. Nord. 2005. The effect of food stamps on food security: a panel data approach. Applied Economic Perspectives and Policy 27 (3): 425-432.

Yen, S. T., M. Andrews, Z. Chen, and D.B. Eastwood. 2008. Food Stamp Program participation and food insecurity: an instrumental variables approach. American Journal of Agricultural Economics 90 (1): 117-132. 
Zaki, M. 2014. Access to short-term credit and consumption smoothing within the paycycle. Department of Economics, Northwestern University.

Ziliak, J. 2008. Effective tax rates and guarantees in the Food Stamp Program. A report to the Food and Nutrition Research Program, Economic Research Service, U.S. Department of Agriculture, April.

Ziliak, J. P. 2015. Why are so many Americans on food stamps? The role of the economy, policy, and demographics. In SNAP Matters: How Food Stamps Affect Health and Well Being. J. Bartfeld, C. Gundersen, T. Smeeding, and J. Ziliak, (eds.), Redwood City, CA: Stanford University Press. 2015.

Ziliak, J. P., C. Gundersen, and D.N. Figlio. 2003. Food stamp caseloads over the business cycle. Southern Economic Journal: 903-919. 
Figure 1.1 Stylized Representation of SNAP Benefit Formula

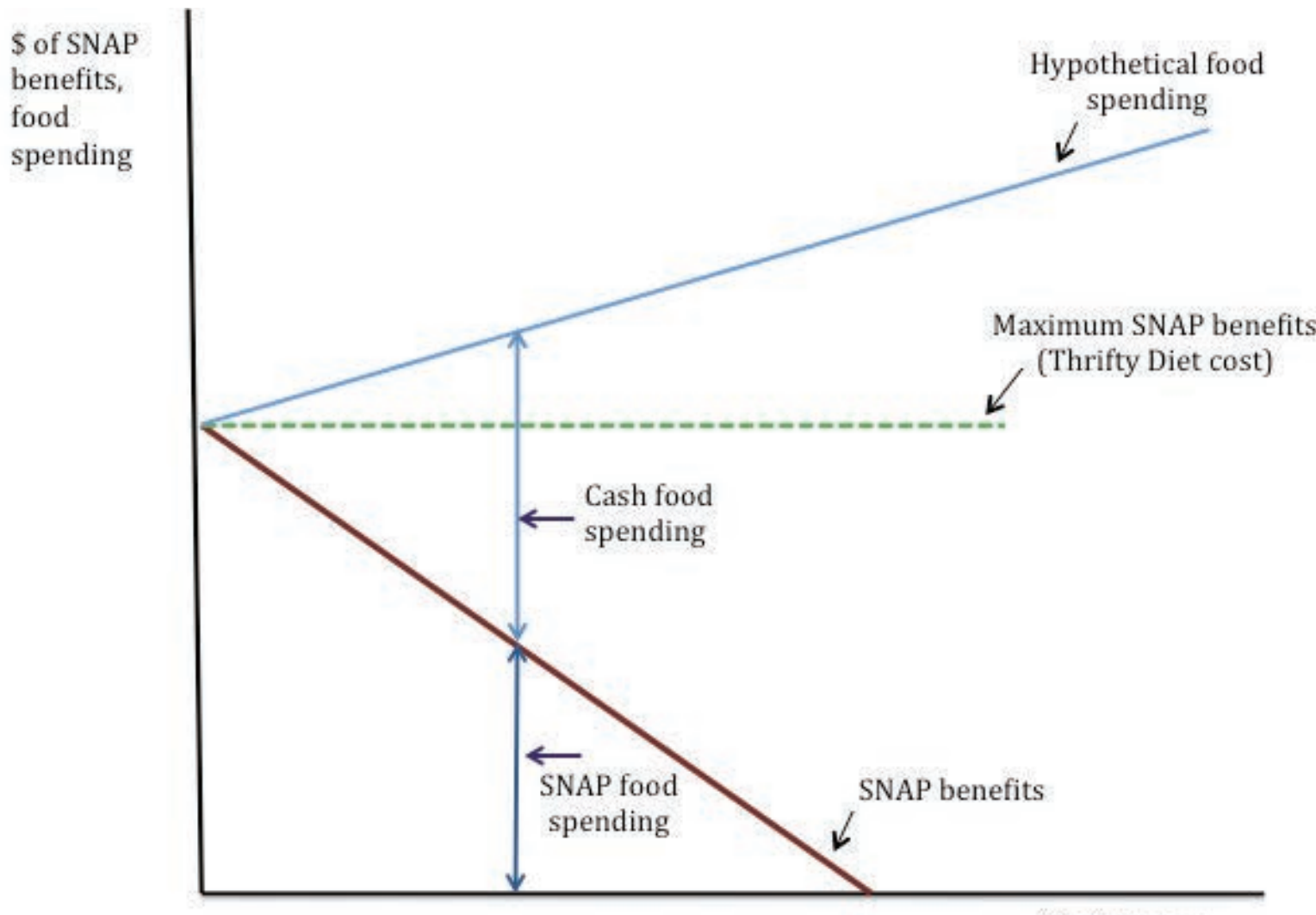

(Net) income

Source: Hoynes, McGranahan and Schanzenbach (2015)

Figure 1.2 Cumulative Percent of Counties with Food Stamp Program, 1960-1975

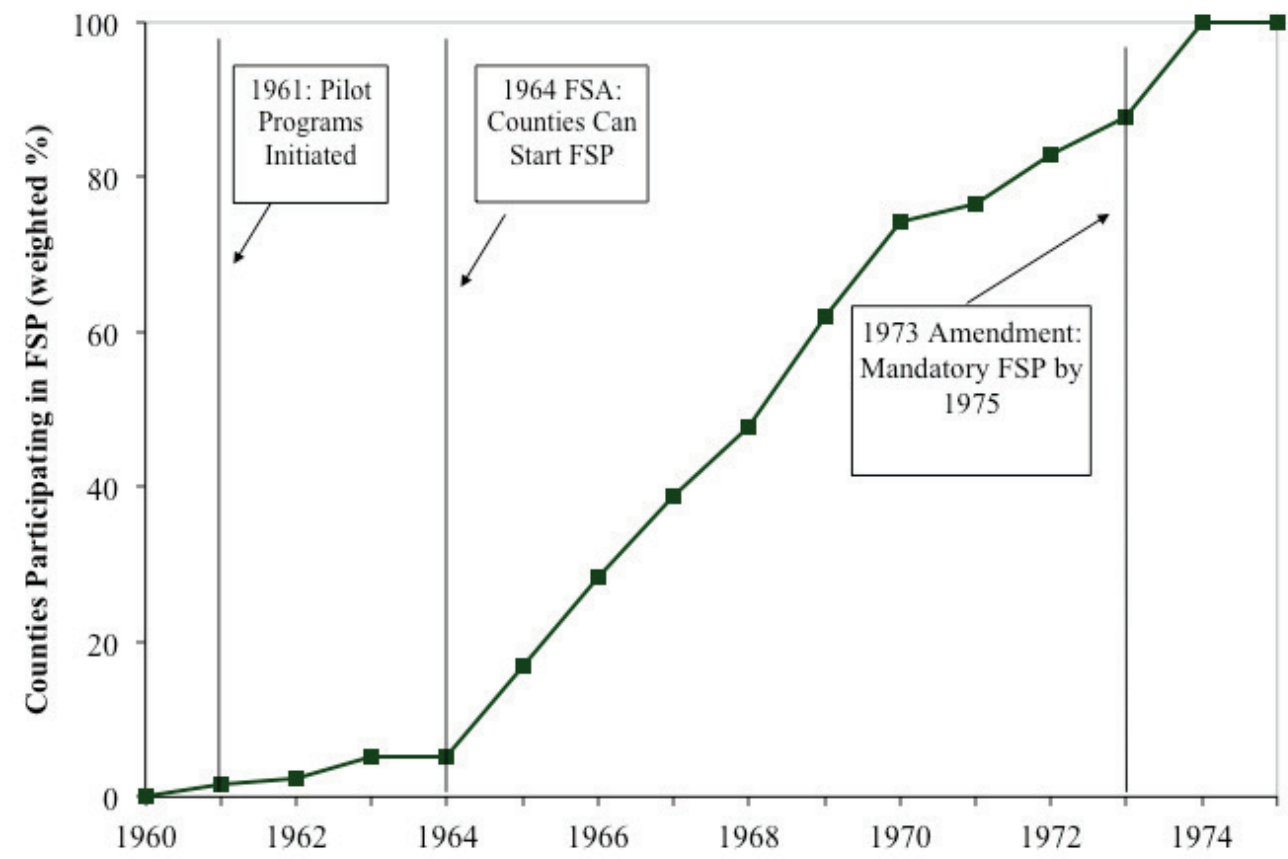

Source: Hoynes and Schanzenbach 2009. Weighted by 1970 county population. 
Figure 1.3 Food Stamp Start Date, by County

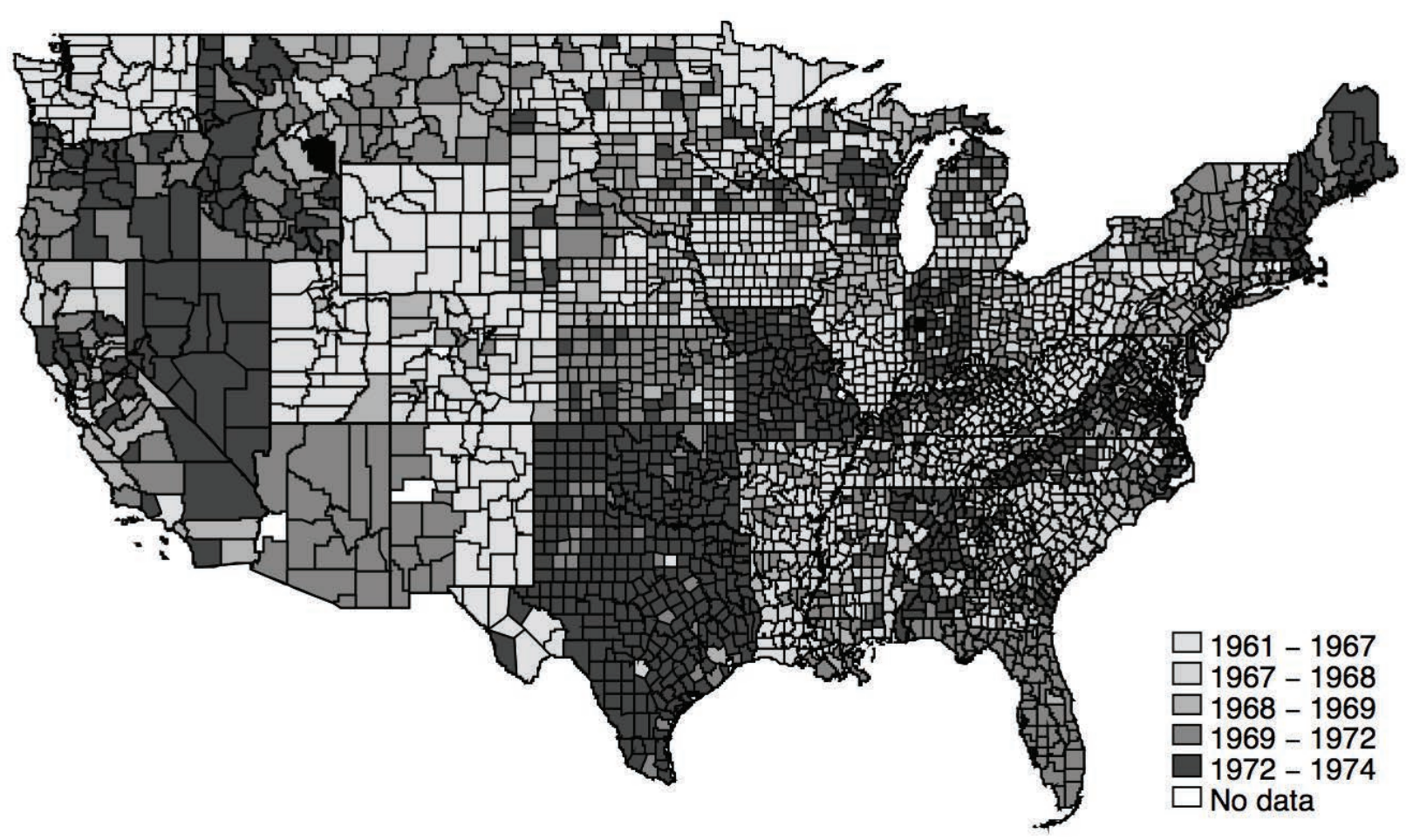

Source: Hoynes and Schanzenbach (2009).

Figure 1.4 Cumulative Percent of Counties with WIC Programs, 1970-1981

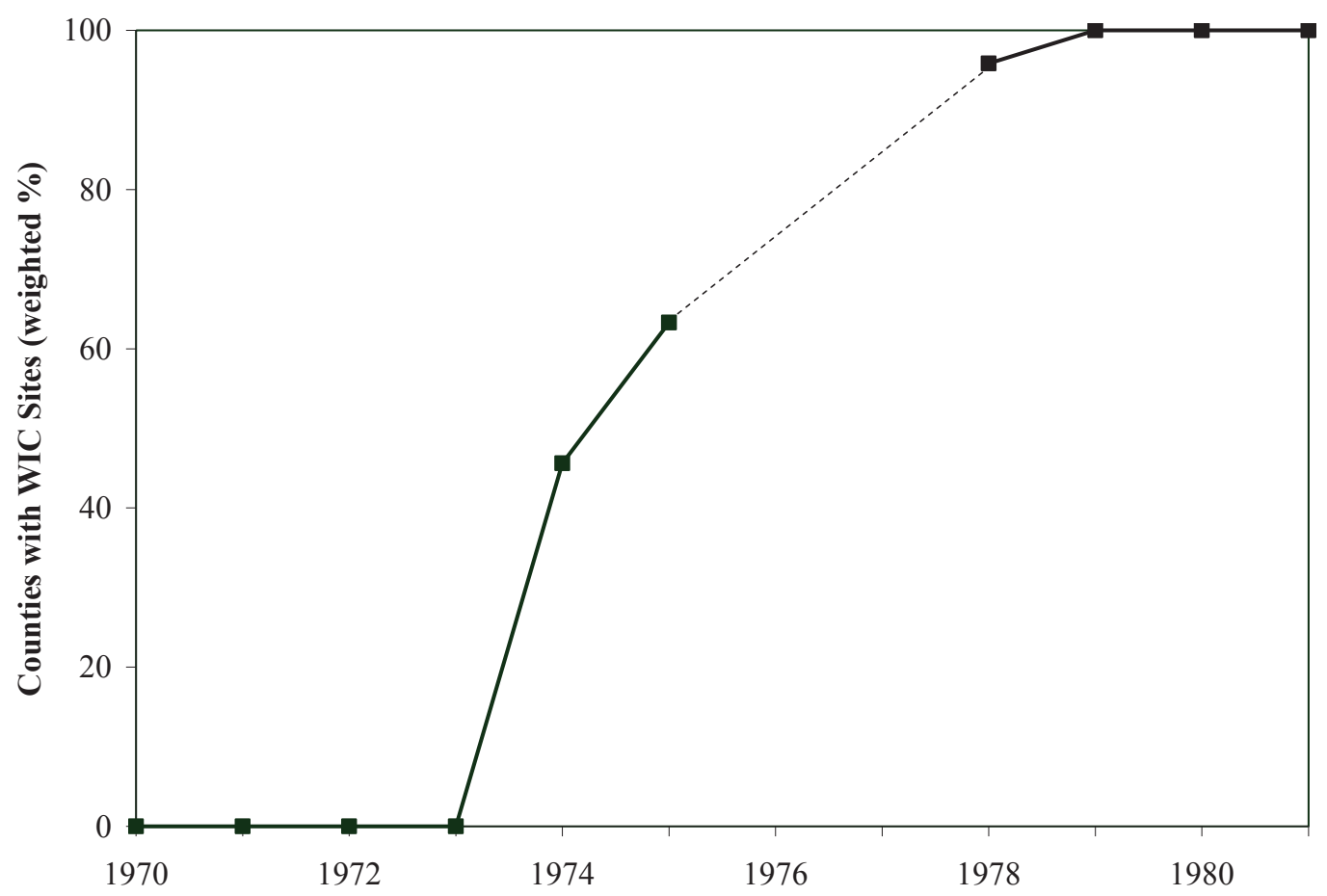

Source: Hoynes, Page, and Stevens (2011). Weighted by 1970 county population. Missing Data for 1976, 1977. 
Figure 2.1 Real per capita expenditures for SNAP, 1980-2014 (Real 2014 dollars), with U.S. Unemployment Rate

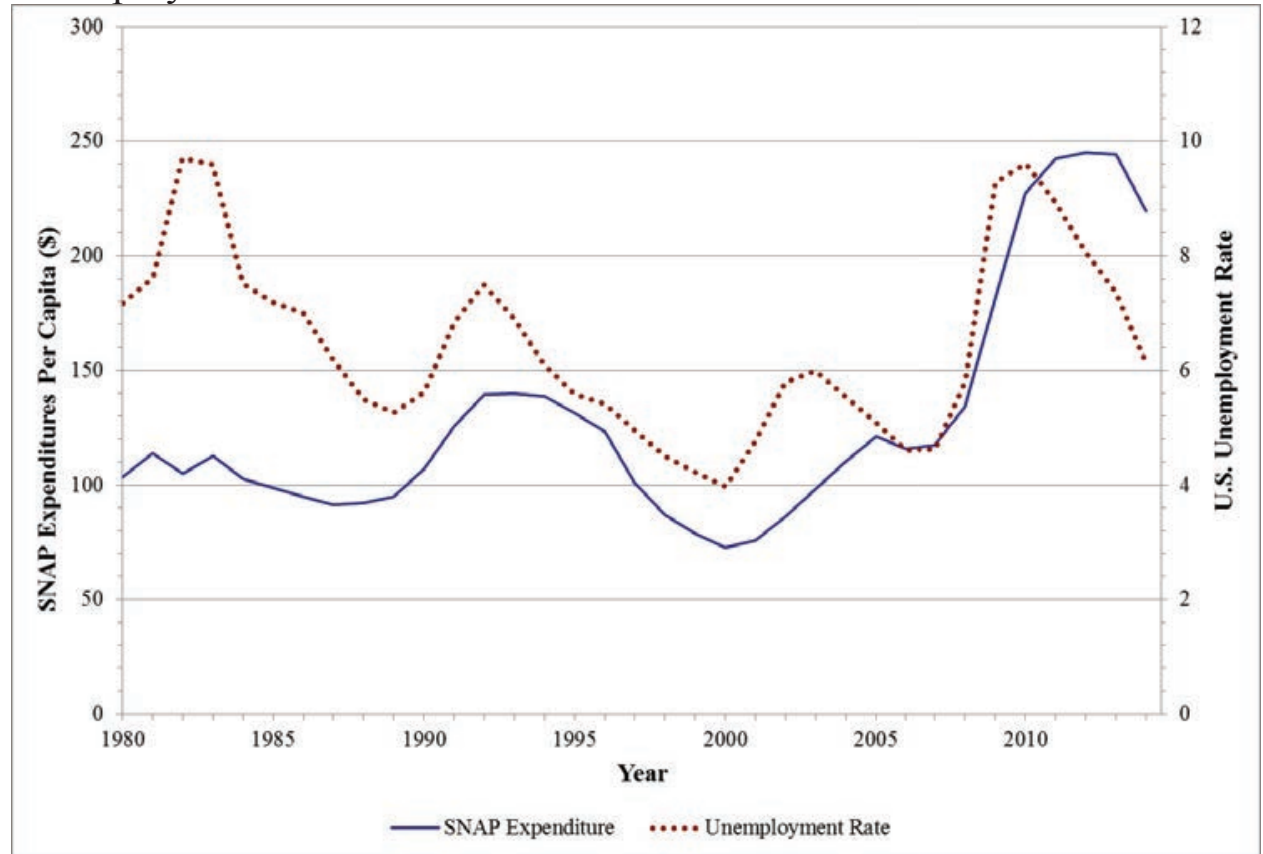

Source: USDA SNAP Program Data, http://www.fns.usda.gov/pd/supplemental-nutrition-assistance-program-snap.

Unemployment rates from http://data.bls.gov/pdq/SurveyOutputServlet. For definitions of recessionary periods see Bitler and Hoynes 2014. Note: Per capita SNAP expenditures are calculated using the U.S. population as the denominator (not per SNAP recipient) and inflation adjusted using the U.S. Bureau of Labor Statistics' CPI inflation calculator.

Figure 2.2 Real per capita expenditures for WIC, NSLP and SBP, 1980-2014 (real 2014 dollars)

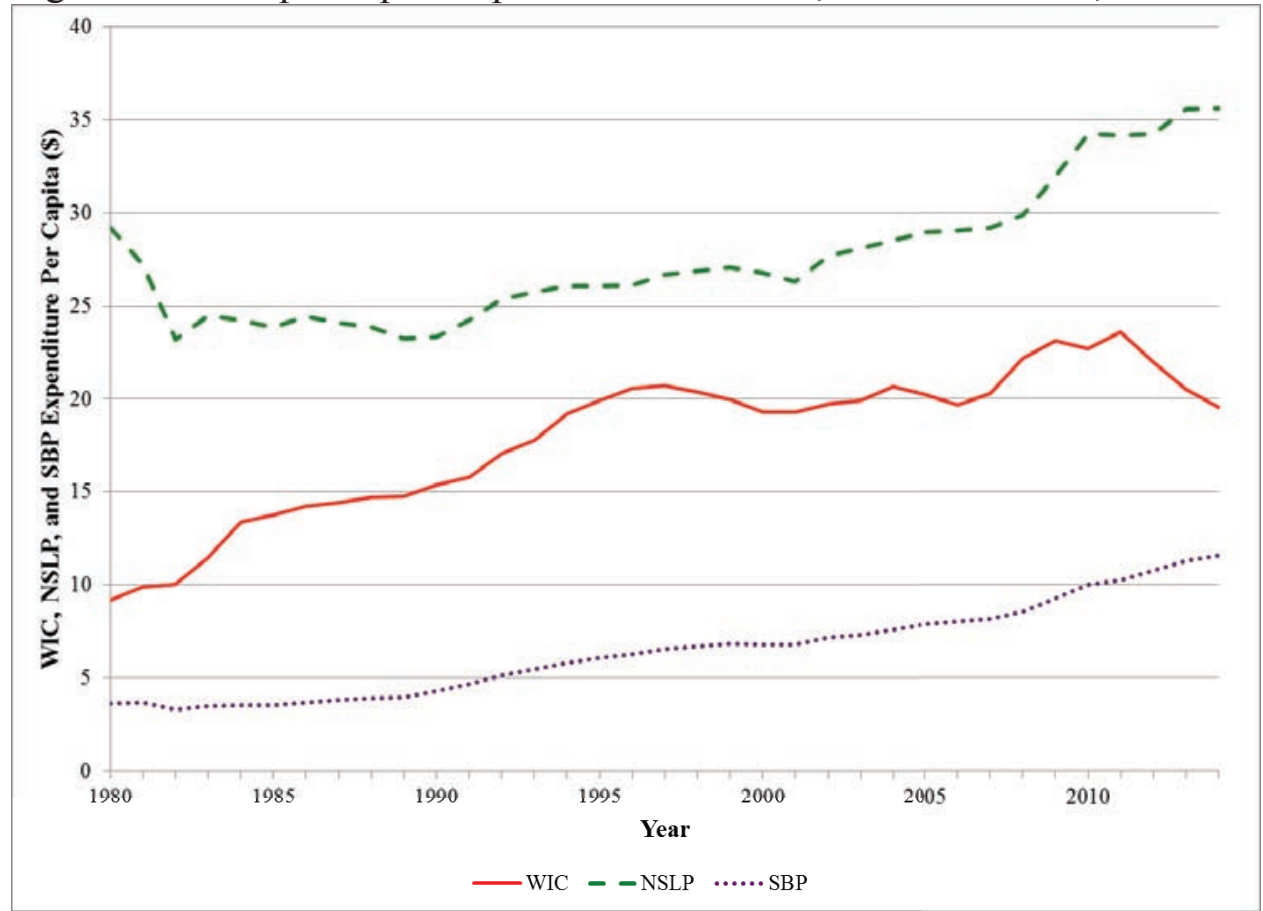

Source: USDA WIC, NSLP, and SBP program data, http://www.fns.usda.gov/pd/wic-program, http://www.fns.usda.gov/pd/child-nutrition-tables. Note: Per capita expenditures are calculated using the U.S. population as the denominator (not per program recipient) and inflation adjusted using the U.S. Bureau of Labor Statistics' CPI inflation calculator. 
Figure 2.3 Federal expenditures and number of recipients by program (2014)

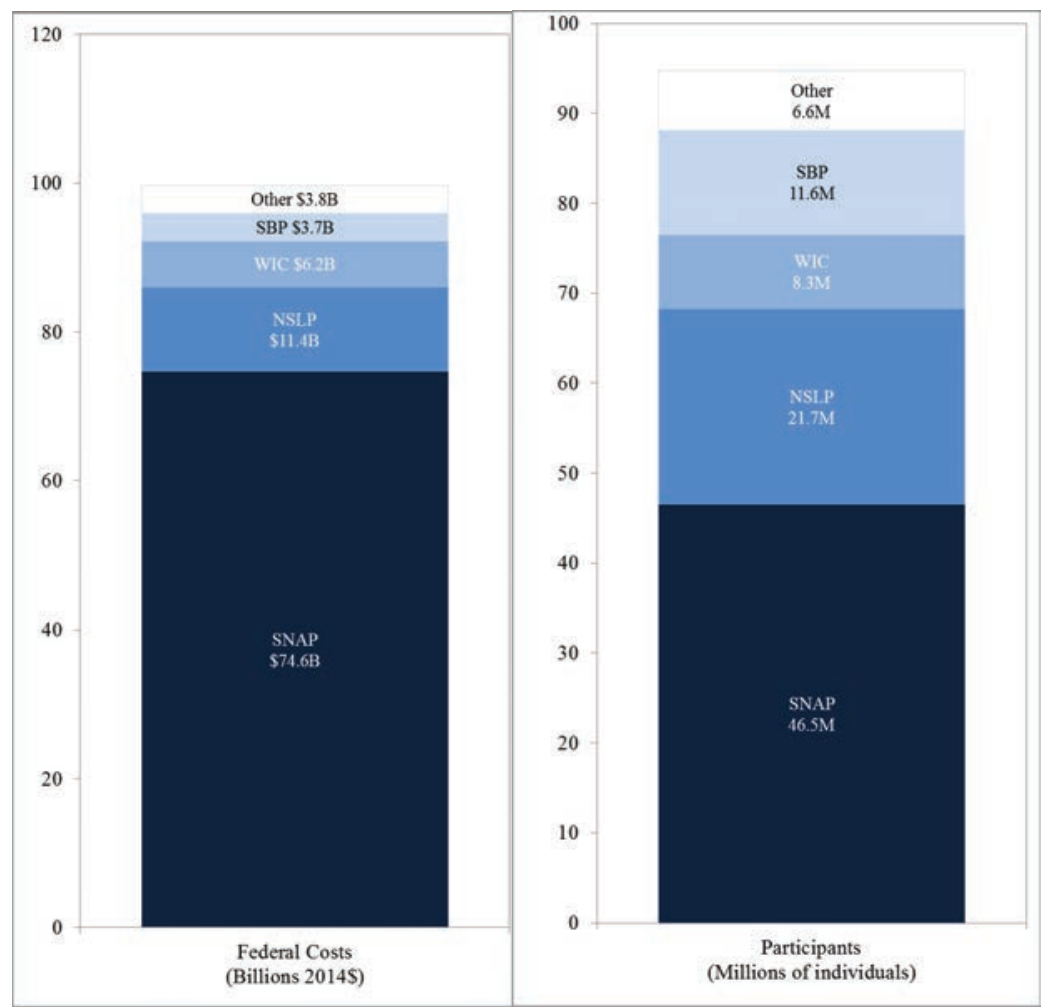

Note: "Other" includes the Child and Adult Care Food Program (CACFP), the Summer Food Service Program (SFSP), the Special Milk Program (SMP), and the Fresh Fruit and Vegetable Program (FFVP). Participation for NSLP and SBP only includes free and reduced-price lunch participants. Participation data is missing from SMP and FFVP and is not included in this graph. 
Figure 2.4 Household Participation in Food and Nutrition Programs by Household Income to Poverty, Households with Children headed by Nonelderly Individual (2013)

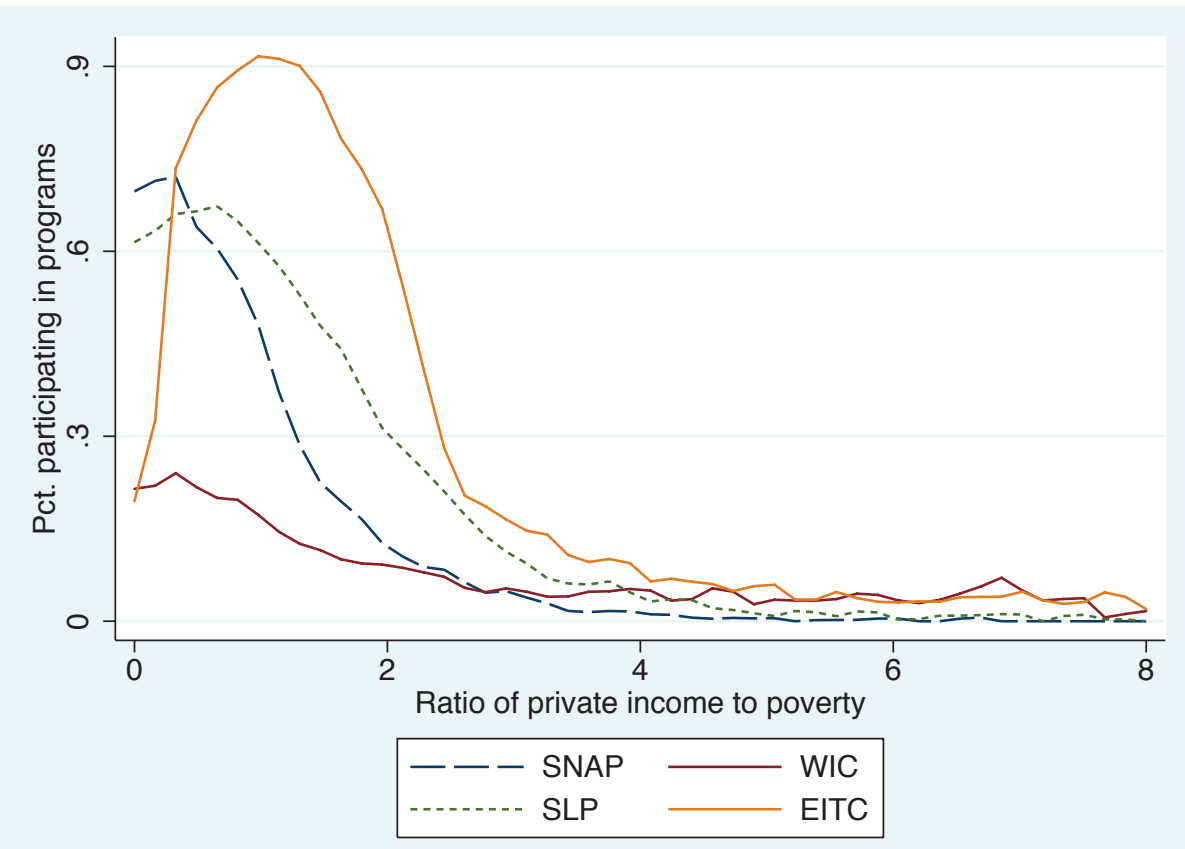

Source: Adapted from Bitler and Hoynes (2015). Author's tabulations of 2014 Current Population Survey capturing data for 2013 calendar year. Kernel density plot of household program participation, by ratio of household private income to poverty. Sample includes non-elderly household heads in households with children.

Figure 2.5 Millions of Children Removed from Poverty by Program, 2014

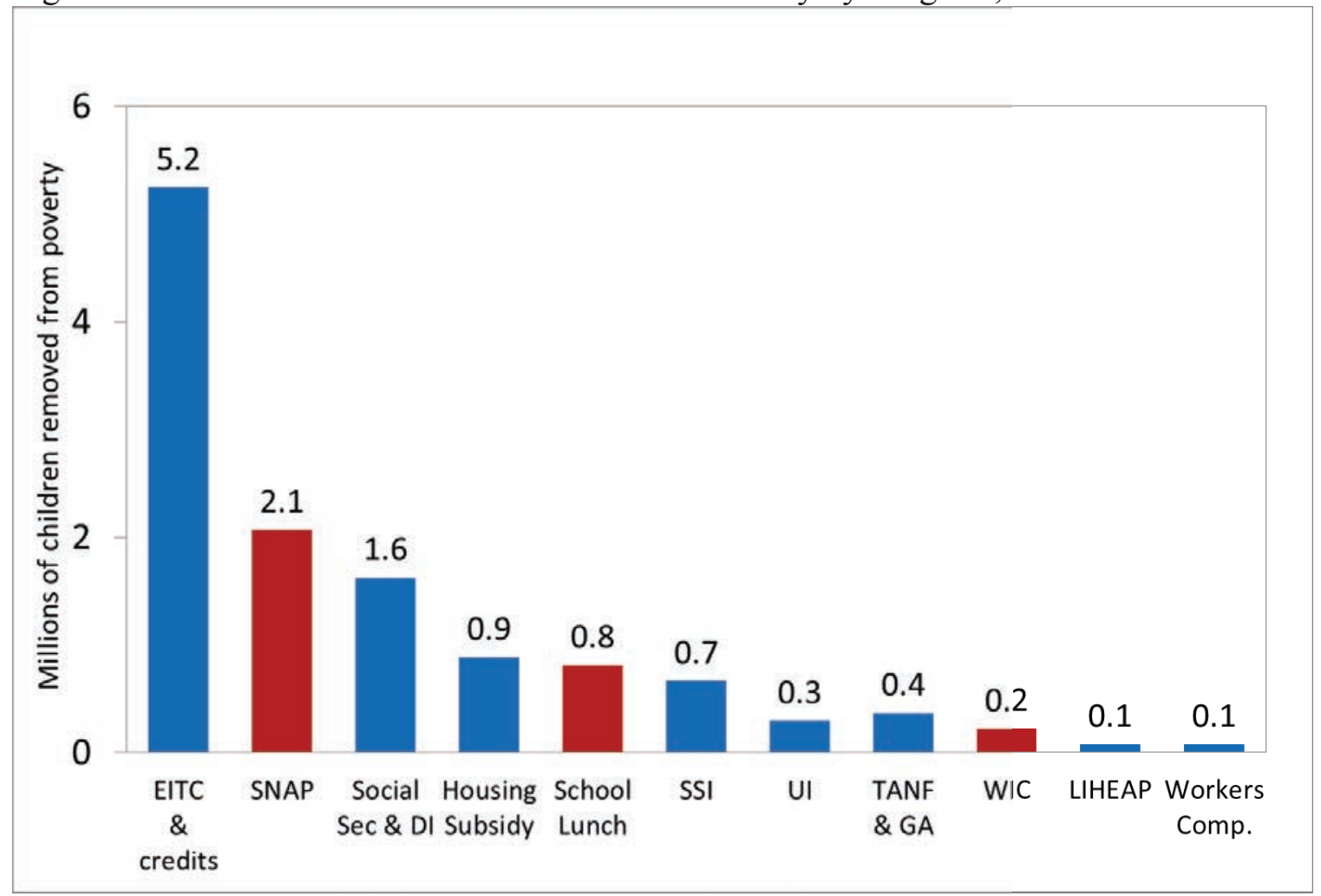

Source: Authors' tabulation of Short (2015). 
Figure 3.1 Effects of SNAP on consumption

Panel A: Budget Set Shift

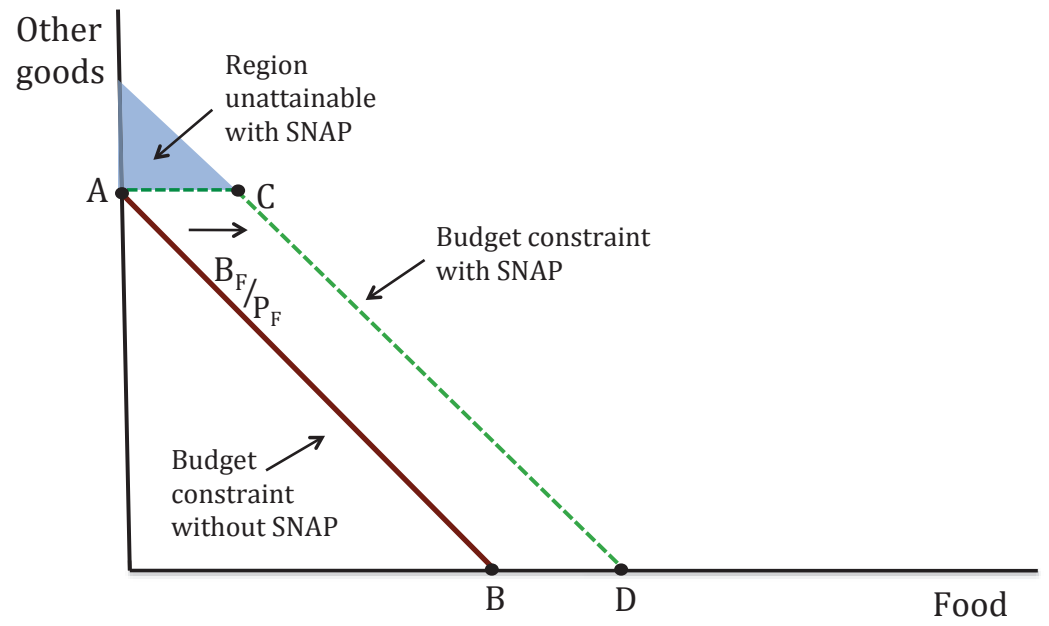

Panel B: Consumer's Utility Maximization Response to SNAP

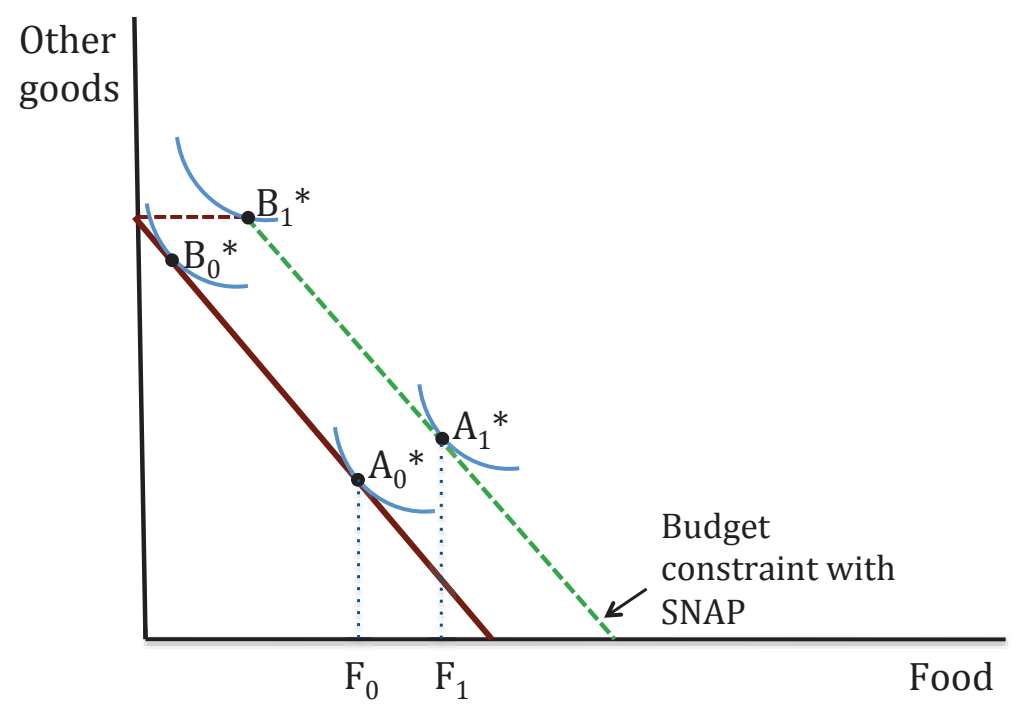


Figure 3.2 Effects of WIC on consumption

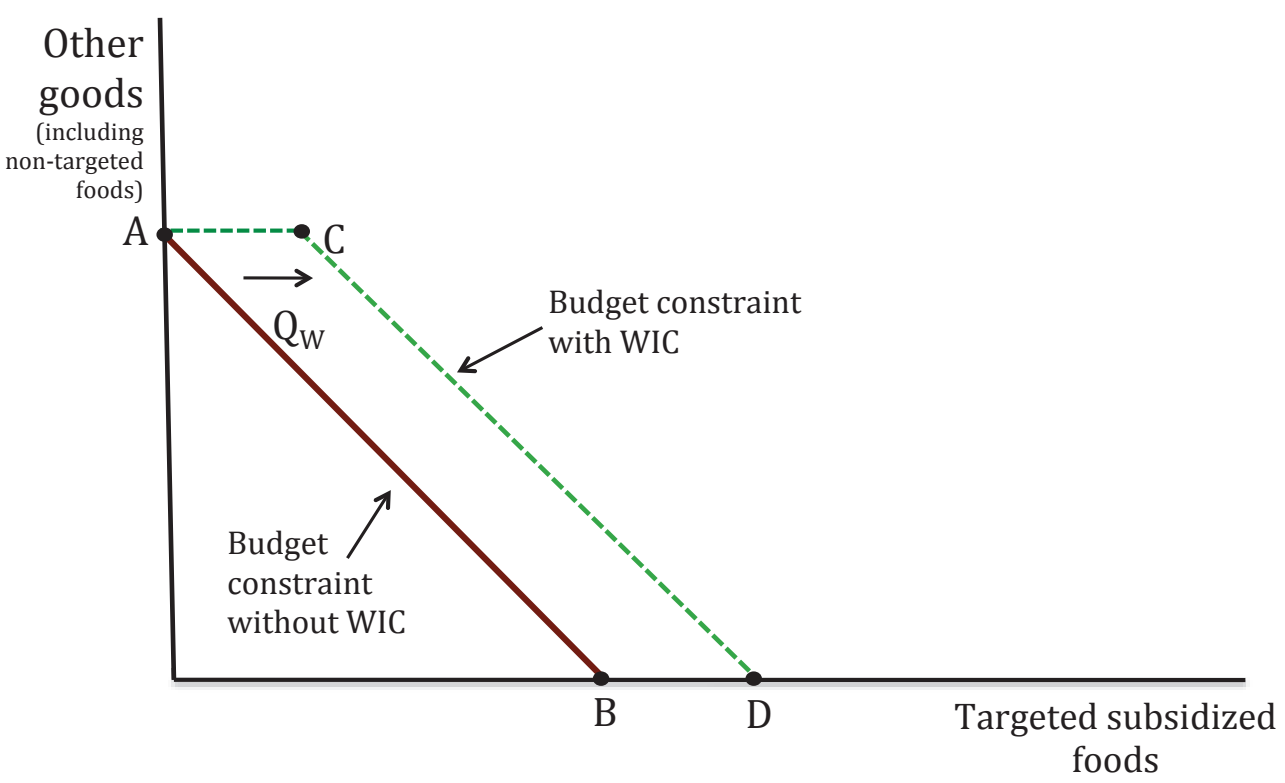

Figure 3.3 Effects of NSLP on consumption

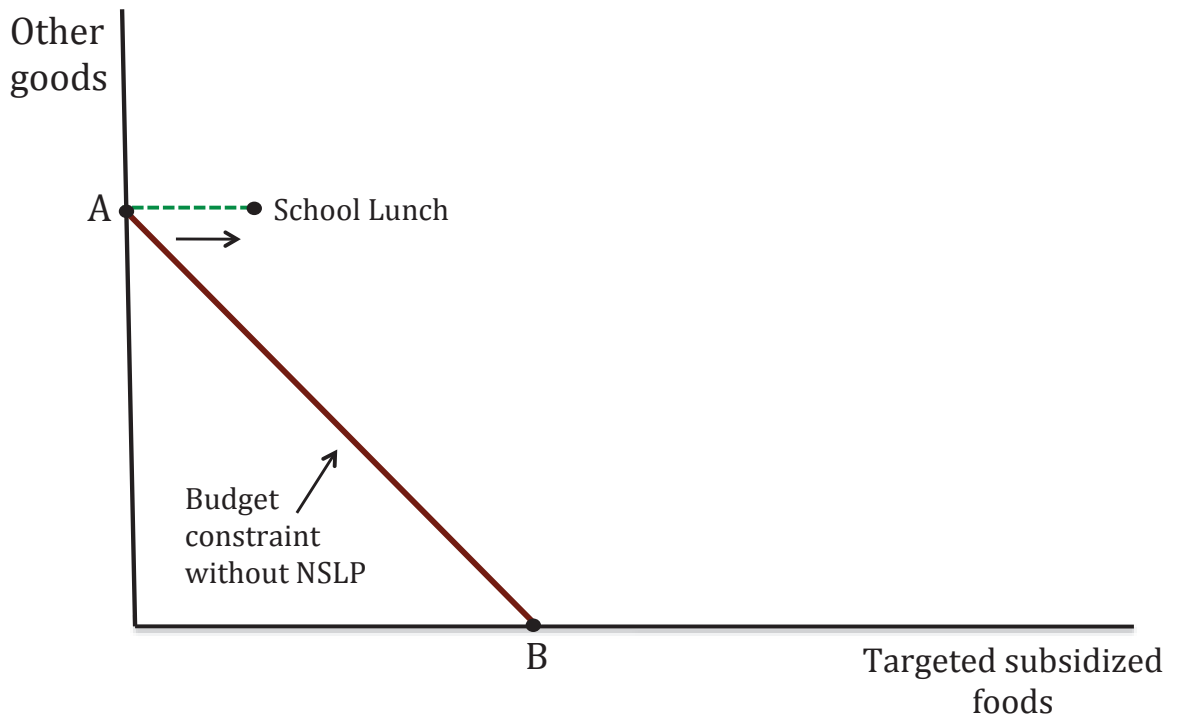


Figure 3.4 Income-Leisure Tradeoffs and SNAP

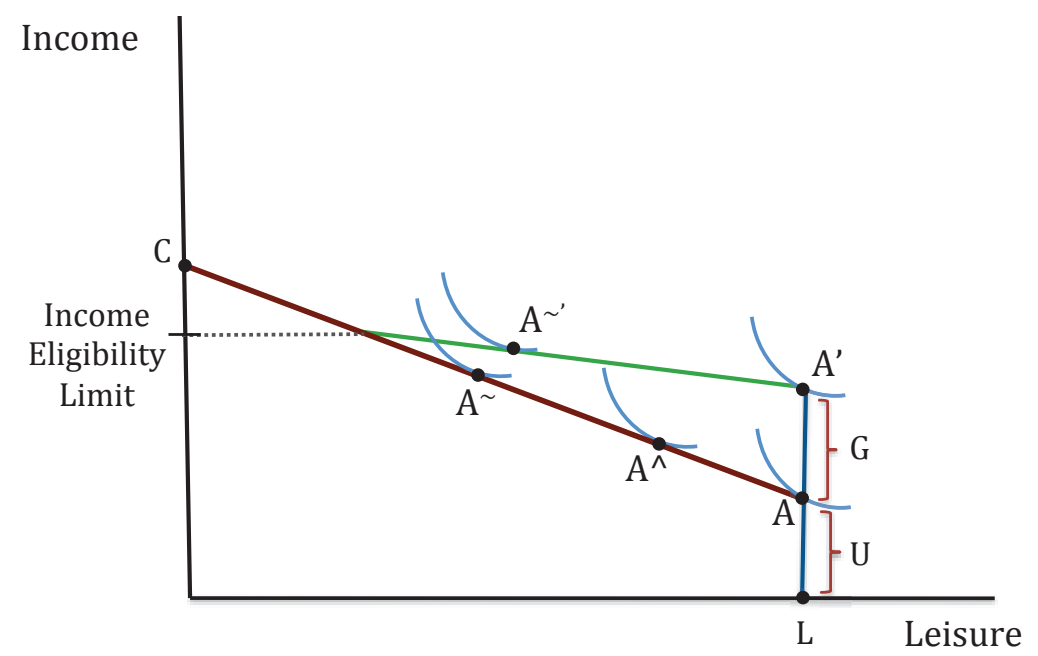

Source: Hoynes and Schanzenbach (2012).

Figure 3.5 Income-Leisure Tradeoffs and WIC / NSLP

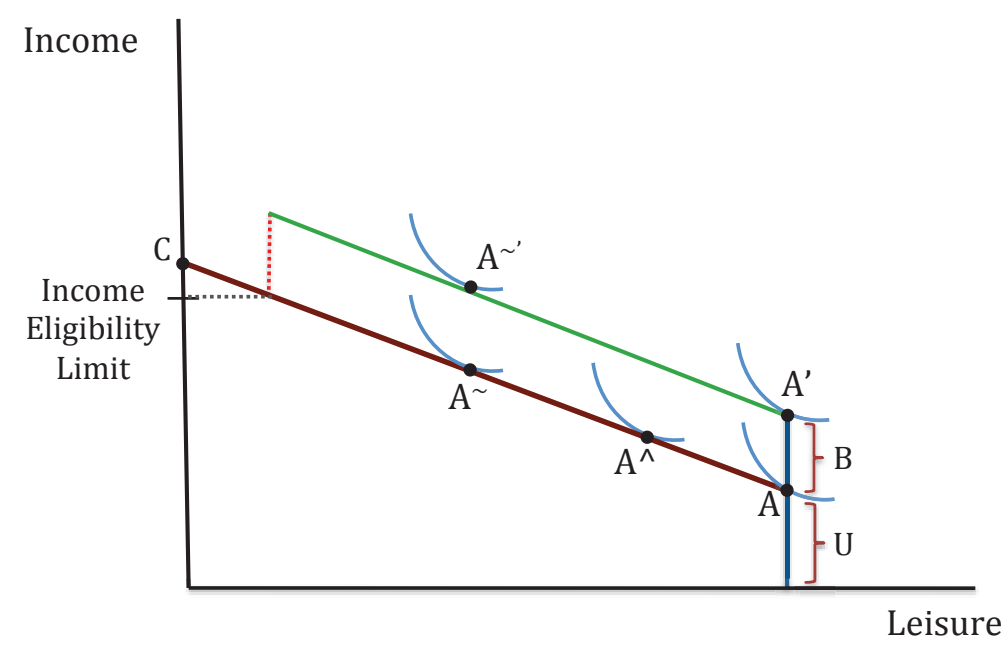




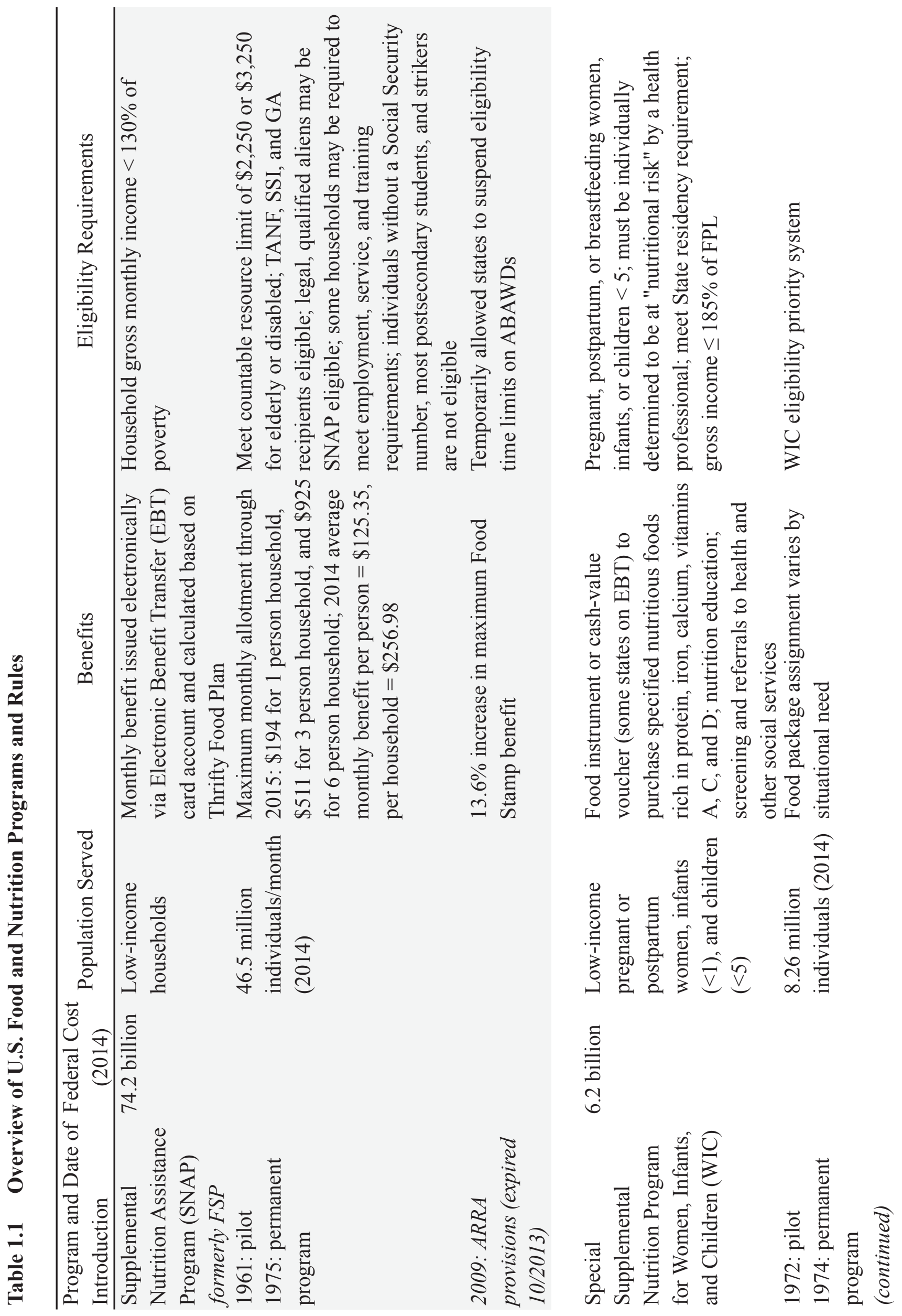




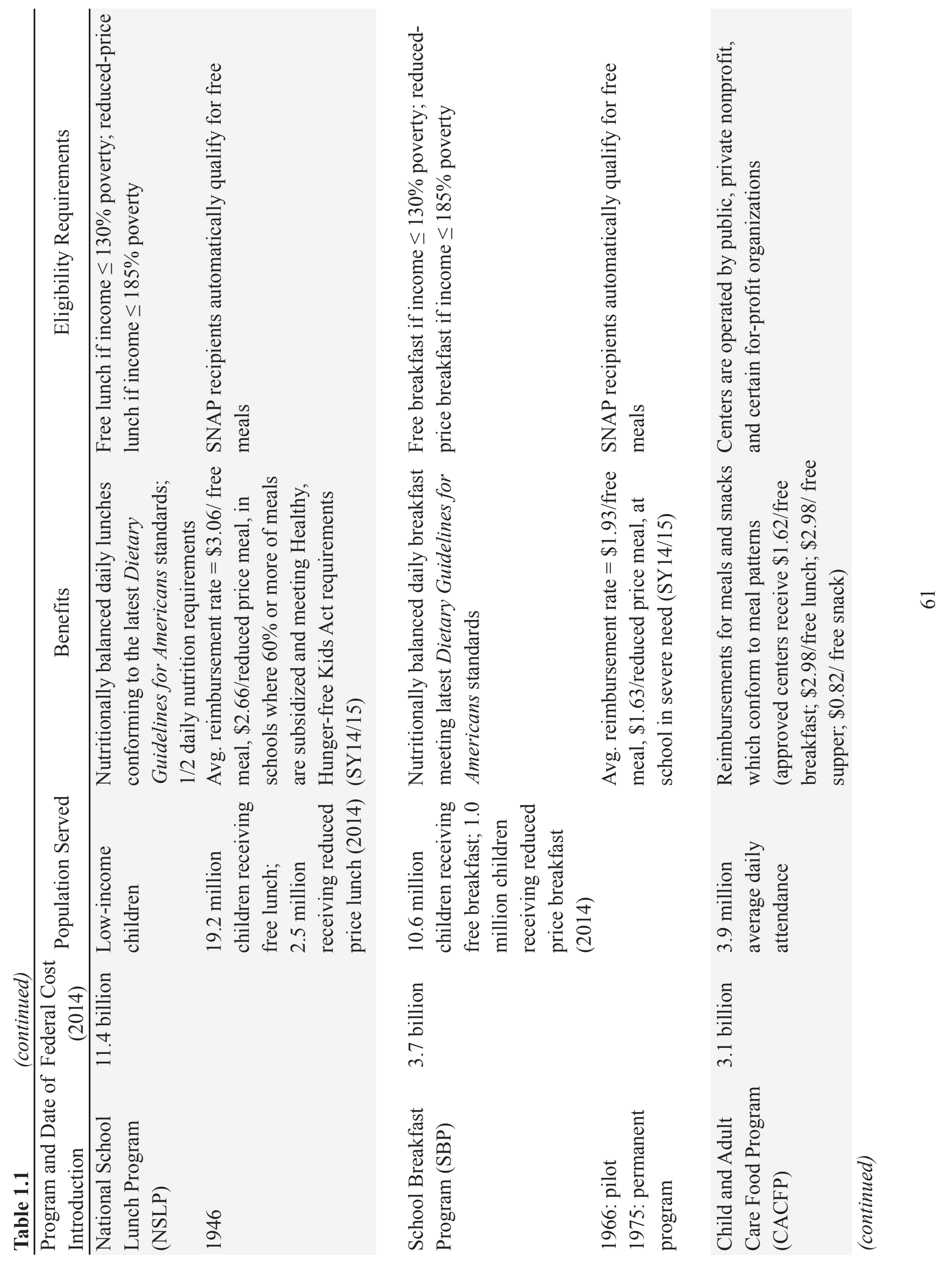




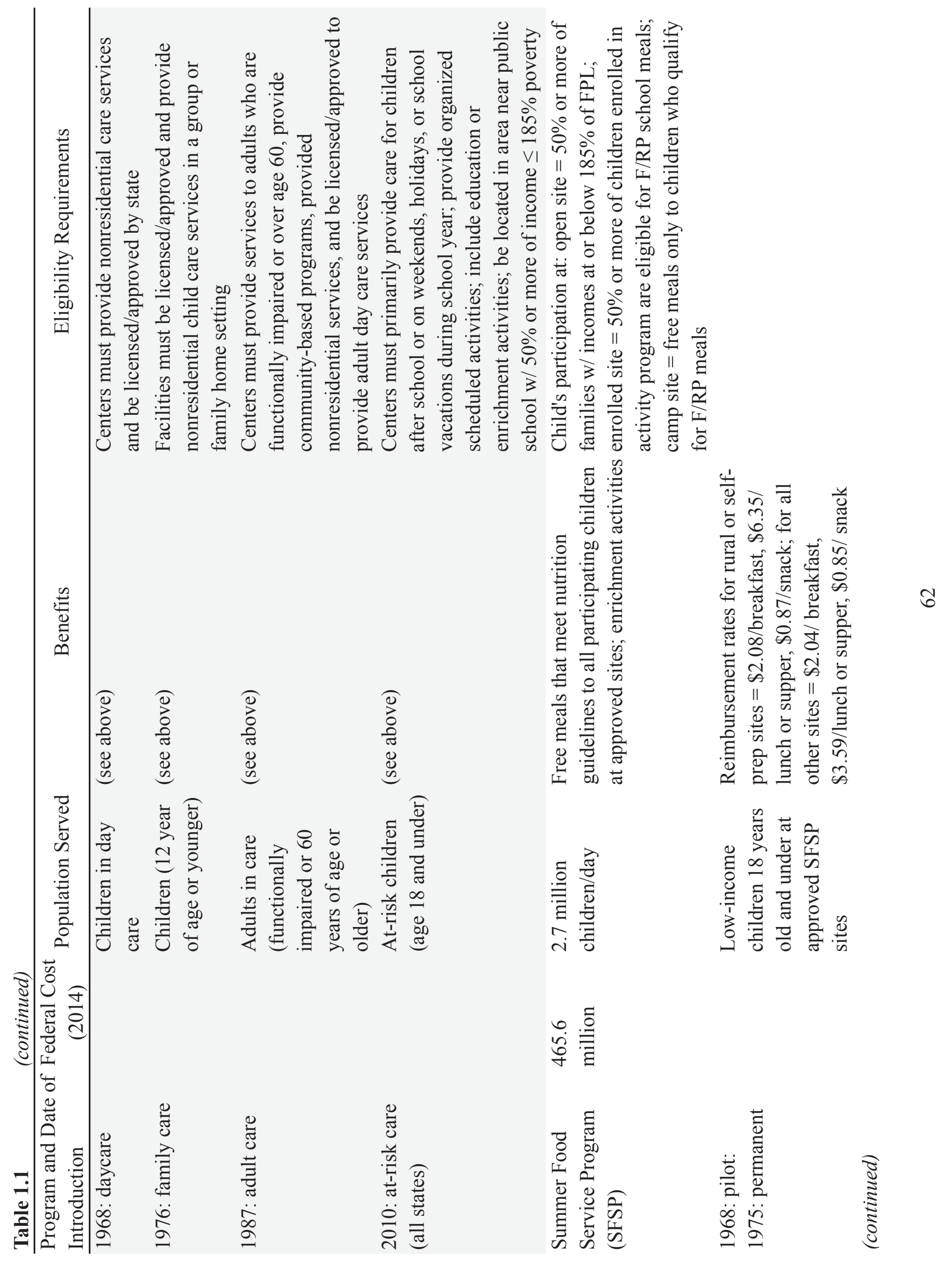




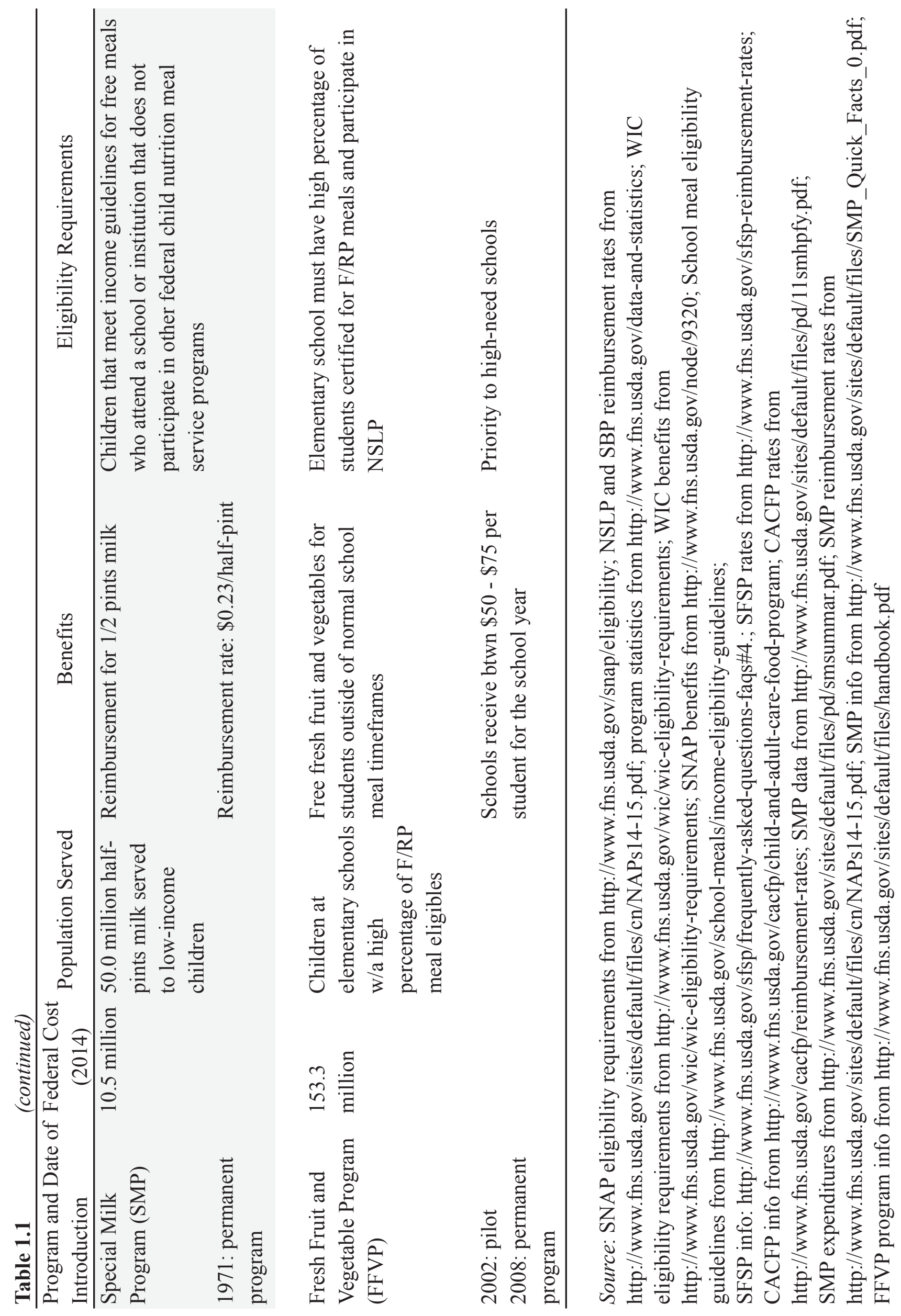


Table 1.2 WIC Food Packages - Maximum Monthly Allowances

\begin{tabular}{ll}
\hline Food Package & \multicolumn{1}{c}{ Recipient } \\
\hline I & $\begin{array}{l}\text { Infants, fully formula fed } \\
(0-5 \text { months })\end{array}$ \\
& \\
& $\begin{array}{l}\text { Infants, partially breastfed } \\
(0-5 \text { months })\end{array}$
\end{tabular}

II

III

Infants, fully formula fed (0-11 months)

Infants, partially breastfed (0-11 months)
Food

WIC formula: $823 \mathrm{fl} \mathrm{oz}$ reconstituted liquid concentrate (0-3 months)

WIC formula: $896 \mathrm{fl} \mathrm{oz} \mathrm{reconstituted} \mathrm{liquid}$ concentrate (4-5 months)

WIC formula: $104 \mathrm{fl} \mathrm{oz} \mathrm{reconstituted} \mathrm{powder} \mathrm{(0-1}$ month)

WIC formula: $388 \mathrm{fl}$ oz reconstituted liquid concentrate (1-3 months)

WIC formula: $460 \mathrm{fl} \mathrm{oz} \mathrm{reconstituted} \mathrm{liquid}$ concentrate (4-5 months)

WIC formula: $630 \mathrm{fl} \mathrm{oz} \mathrm{reconstituted} \mathrm{liquid}$ concentrate

Infant cereal: $24 \mathrm{oz}$

Baby food fruits \& vegetables: $128 \mathrm{oz}$

WIC formula: $315 \mathrm{fl} \mathrm{oz} \mathrm{reconstituted} \mathrm{liquid}$ concentrate

Infant cereal: $24 \mathrm{oz}$

Baby food fruits \& vegetables: $128 \mathrm{oz}$

Infant cereal: $24 \mathrm{oz}$

Baby food fruits \& vegetables: $256 \mathrm{oz}$

Baby food meat: $77.5 \mathrm{oz}$

WIC formula: $823 \mathrm{fl} \mathrm{oz} \mathrm{reconstituted} \mathrm{liquid}$

concentrate (0-3 months)

WIC formula: $896 \mathrm{fl} \mathrm{oz} \mathrm{reconstituted} \mathrm{liquid}$

concentrate (4-5 months)

WIC formula: $630 \mathrm{fl} \mathrm{oz} \mathrm{reconstituted} \mathrm{liquid}$ concentrate (6-11 months)

Infant cereal: $24 \mathrm{oz}$ (6-11 months)

Baby food fruits \& vegetables: 128 oz (6-11 months) WIC formula: $104 \mathrm{fl} \mathrm{oz} \mathrm{reconstituted} \mathrm{powder} \mathrm{(0-1}$ month)

WIC formula: $388 \mathrm{fl} \mathrm{oz} \mathrm{reconstituted} \mathrm{liquid}$ concentrate (1-3 months)

WIC formula: $460 \mathrm{fl} \mathrm{oz} \mathrm{reconstituted} \mathrm{liquid}$ concentrate (4-5 months)

WIC formula: $315 \mathrm{fl} \mathrm{oz} \mathrm{reconstituted} \mathrm{liquid}$ concentrate (6-11 months)

Infant cereal: $24 \mathrm{oz}$ (6-11 months)

Baby food fruits \& vegetables: 128 oz (6-11 months)

(continued) 
Table 1.2 (continued)

\begin{tabular}{lc}
\hline Food Package & Recipient \\
\hline IV & Children: 1 - 4 years old \\
V & Pregnant and partially breastfeeding \\
& women (up to 1 year postpartum)
\end{tabular}

Juice, single strength: $144 \mathrm{fl} \mathrm{oz}$

Milk: 22 qt*

Breakfast cereal: $36 \mathrm{oz}$

Eggs: 1 dozen

Fruits \& vegetables: $\$ 10.00$ in cash value voucher Whole wheat bread: $1 \mathrm{lb}^{* *}$

Legumes, $1 \mathrm{lb}$ dry or $64 \mathrm{oz}$ canned AND peanut butter, $18 \mathrm{oz}$

VI Postpartum women (not breastfeeding, up to 6 months postpartum) Juice, single strength: $96 \mathrm{fl} \mathrm{oz}$

Milk: 16 qt*

Breakfast cereal: $36 \mathrm{oz}$

Eggs: 1 dozen

Fruits \& vegetables: $\$ 10.00$ in cash value voucher Legumes, $1 \mathrm{lb}$ dry or $64 \mathrm{oz}$ canned OR peanut butter, $18 \mathrm{oz}$

VII Fully breastfeeding women (up to 1 year postpartum)

Juice, single strength: $144 \mathrm{fl} \mathrm{oz}$

Milk: $24 \mathrm{qt}^{*}$

Breakfast cereal: $36 \mathrm{oz}$

Cheese: $1 \mathrm{lb}$

Eggs: 2 dozen

Fruits \& vegetables: $\$ 10.00$ in cash value voucher Whole wheat bread: $1 \mathrm{lb}^{* *}$

Fish, canned: $30 \mathrm{oz}^{* * *}$

Legumes, $1 \mathrm{lb}$ dry or $64 \mathrm{oz}$ canned AND peanut butter, $18 \mathrm{oz}$

\footnotetext{
* Allowable options for milk alternatives are cheese, soy beverage, tofu, and yogurt (partially). No whole milk for $>2$ years. ** Allowable options for whole wheat bread are whole grain bread, brown rice, bulgur, oatmeal, whole-grain barley, soft corn, or whole wheat tortillas.

*** Allowable options for canned fish are light tuna, salmon, sardines, mackerel, and Jack mackerel. Source: USDA Federal Register/

Vol. 79, No. 42/March 2014/; Rules and Regulations accessed http://www.fns.usda.gov/sites/default/files/03-04-14_WIC-Food-Packages-

Final-Rule.pdf
} 


\section{Table 1.3 NSLP and SBP History}

1946 National School Lunch Act

Congress passes to make school lunch program permanent

A. Serve lunches meeting the minimum nutritional requirements prescribed by Secretary of Agriculture

B. Serve meals without cost or at reduced cost to children of need

C. Operate program on a non-profit basis

D. Utilize commodities declared by the Secretary to be in abundance

E. Utilize commodities donated by the Secretary

F. Maintain proper records of all receipts and expenditures to be reported to State agency

1952 1st Amendment to change appropriations in AK, HI, P.R., V.I.., and Guam

1962 Amended fund to be apportioned on basis of participation rate and assistance need rate

1966 Child Nutrition Act

A. Program expanded and strengthened

B. Special Milk Program added

C. School Breakfast Program 2-year pilot begins

1971 Congress specifies SBP to target schools in which there are children of working mothers and from low-income families

1973 SBP restructured reimbursement from grant to a specific per-meal reimbursement

1975 SBP becomes permanent with emphasis on schools in severe need

1998 Child Nutrition Reauthorization Act increases federal subsidies for child nutrition programs

2004 Child Nutrition and WIC Reauthorization Act of 2004

A. Required all school districts receiving federal funds for meal programs to create wellness policies

2010 Healthy, Hunger-Free Kids Act

A. Improves nutrition with a focus on childhood obesity reduction

B. Increases access

C. Increases program monitoring

D. Increases funding

Source: NSLP history from http://www.fns.usda.gov/sites/default/files/NSLP-Program\%20

History.pdf; SBP history from http://www.fns.usda.gov/sbp/program-history 
Table 1.4 Current NSLP and SBP Rules (Post Healthy, Hunger-Free Kids Act Implementation)

I. New Dietary Guidelines established by USDA

A. Fluid milk restrictions: unflavored milk can be $1 \%$ or fat-free; flavored milk must be fat-free

B. No added trans fat or zero trans fat

C. Avg. saturated fat content per meal (averaged across week) must be less than $10 \%$ of total calories

D. Fruits and vegetables minimum requirement increase

E. Avg. calories per meal (averaged across week) must fall within defined ranges for each age/grade group

F. Serve a variety of vegetables from each of these groups every week: dark green, red/orange, legumes, starchy and 'all other'

G. Half of grain items offered must be 'whole grain rich'

H. Number of servings of grain items and meat/meat alternates offered must be within the weekly ranges for each age/grade group

I. Minimum daily portion sizes and minimum weekly serving requirements for each food group

J. Reduce sodium content

II. Simplifications to direct certification process and increased access

A. Foster children automatically eligible

B. Community eligibility: areas of high poverty qualify for universal free

III. Payments and Reimbursement changes

A. Increased lunch reimbursement rate by 6 cents for meals that meet nutrition standards

B. Requires school districts to gradually increase price of paid lunches to offset new costs

IV. Increased authority to USDA

A. Regulation of competitive foods

B. Nutritional standards applicable to all food sold in schools

V. Requires schools to make free potable water where meals are served

VI. Increased program monitoring

VII. Privacy protection for individual completing application

Source: USDA Comparison of Previous and Current Regulatory Requirements under Final Rule, http://www.fns.usda.gov/ sites/default/files/comparison.pdf; Summary of the Healthy, Hunger-Free Kids Act of 2010 from http://www.fns.usda.gov/ sites/default/files/PL111-296_Summary.pdf 


\section{Table 1.5 Previous and Current School Meal Caloric Standards}

\begin{tabular}{|c|c|}
\hline Previous (pre HHFKA) & Current (post HHFKA) \\
\hline \multicolumn{2}{|c|}{ Lunch } \\
\hline grades K-3 & grades K-5 \\
\hline Min: 633 & Min: 550 \\
\hline Max: none & Max: 650 \\
\hline grades $4-12$ & grades $6-8$ \\
\hline Min: 785 & Min: 600 \\
\hline Max: none & Max: 700 \\
\hline grades 7-12 (optional) & grades $9-12$ \\
\hline Min: 825 & Min: 750 \\
\hline Max: none & Max: 850 \\
\hline \multicolumn{2}{|c|}{ Breakfast } \\
\hline grades K-12 & grades K-5 \\
\hline Min: 554 & Min: 350 \\
\hline \multirow[t]{7}{*}{ Max: none } & Max: 500 \\
\hline & grades $6-8$ \\
\hline & Min: 400 \\
\hline & Max: 550 \\
\hline & grades $9-12$ \\
\hline & Min: 450 \\
\hline & Max: 600 \\
\hline
\end{tabular}

Source: Comparison of Previous and Current Regulatory Requirements under Final Rule from Nutrition Standards in the National School Lunch and School Breakfast

Programs (published January 26, 2012) 


\begin{tabular}{|c|c|c|c|c|c|c|c|c|}
\hline & 1990 & 1995 & 2000 & 2005 & 2010 & 2012 & 2013 & 2014 \\
\hline \multicolumn{9}{|c|}{ Expenditures (billions \$2014) } \\
\hline SNAP & 28.0 & 38.2 & 23.4 & 37.7 & 74.1 & 80.9 & 81.2 & 74.2 \\
\hline WIC & 3.8 & 5.3 & 5.4 & 6.0 & 7.0 & 6.9 & 6.5 & 6.2 \\
\hline NSLP & 5.8 & 6.9 & 7.6 & 8.6 & 10.6 & 10.7 & 11.2 & 11.4 \\
\hline SBP & 1.1 & 1.6 & 1.9 & 2.3 & 3.1 & 3.4 & 3.6 & 3.7 \\
\hline \multicolumn{9}{|c|}{ Average Monthly Participation (millions persons) } \\
\hline SNAP & 20.0 & 26.6 & 17.2 & 25.6 & 40.3 & 46.6 & 47.6 & 46.5 \\
\hline \multicolumn{9}{|c|}{ Annual Participation (millions persons) } \\
\hline WIC (total) & 4.5 & 6.9 & 7.2 & 8.0 & 9.2 & 8.9 & 8.7 & 8.3 \\
\hline Women & 1.0 & 1.6 & 1.7 & 2.0 & 2.1 & 2.1 & 2.0 & 2.0 \\
\hline Infants & 1.4 & 1.8 & 1.9 & 2.0 & 2.2 & 2.1 & 2.0 & 2.0 \\
\hline Children & 2.1 & 3.5 & 3.6 & 4.0 & 4.9 & 4.7 & 4.6 & 4.3 \\
\hline NSLP (total free, reduced, and full paid meals) & 24.1 & 25.7 & 27.3 & 29.6 & 31.8 & 31.7 & 30.7 & 30.5 \\
\hline Free meals & 9.8 & 12.4 & 13.0 & 14.6 & 17.6 & 18.7 & 18.9 & 19.2 \\
\hline Reduced price meals & 1.7 & 1.9 & 2.5 & 2.9 & 3.0 & 2.7 & 2.6 & 2.5 \\
\hline SBP (total free, reduced, and full paid meals) & 4.1 & 6.3 & 7.6 & 9.4 & 11.7 & 12.9 & 13.2 & 13.6 \\
\hline Free meals & 3.3 & 5.1 & 5.7 & 6.8 & 8.7 & 9.8 & 10.2 & 10.6 \\
\hline Reduced price meals & 0.22 & 0.37 & 0.61 & 0.86 & 1.0 & 1.0 & 1.0 & 1.0 \\
\hline
\end{tabular}

\begin{tabular}{lcccccccc} 
SNAP & 8.1 & 10.1 & 6.2 & 8.7 & 13.2 & 15.0 & 15.2 & 14.8 \\
WIC & & & & & & & & \\
$\quad$ Women (as \% of all women aged 18-44) & 1.9 & 2.9 & 3.1 & 3.6 & 3.9 & 3.7 & 3.6 & 3.5 \\
$\quad$ Children 1-4 & 13.5 & 21.7 & 23.0 & 24.6 & 28.3 & 29.6 & 28.5 & 26.9 \\
$\quad$ Infants $<1$ & 35.3 & 46.5 & 48.5 & 50.5 & 52.9 & 53.4 & 53.8 & 51.9 \\
NSLP (as \% of children aged 5-17) & & & & & & & & \\
$\quad$ Free and reduced price meals & 25.0 & 28.0 & 29.1 & 32.6 & 38.4 & 39.5 & 39.7 & 40.0 \\
$\quad$ Free meals & 21.4 & 24.4 & 24.5 & 22.7 & 32.8 & 34.5 & 35.0 & 35.4 \\
$\quad$ All meals & 52.5 & 50.2 & 51.5 & 55.3 & 59.2 & 58.3 & 56.6 & 56.2 \\
SBP (as \% of children aged 5-17) & & & & & & & & \\
$\quad$ Free and reduced price meals & 7.6 & 10.7 & 12.0 & 14.3 & 18.1 & 19.9 & 20.6 & 21.3 \\
$\quad$ Free meals & 7.2 & 10.0 & 10.8 & 12.7 & 16.2 & 18.0 & 18.8 & 19.5 \\
$\quad$ All meals & 8.8 & 12.4 & 14.3 & 17.4 & 21.7 & 23.7 & 24.4 & 25.2 \\
\hline \hline
\end{tabular}

Source: http://www.fns.usda.gov/sites/default/files/pd/SNAPsummary.xls; CPI is from EROP http://www.gpoaccess.gov/eop/tables10.html population is from EROP http://www.gpoaccess.gov/eop/2010/B34.xls and Census Department http://www.fns.usda.gov/sites/default/files/pd/17SNAPfyBEN\$.xls; http://www.fns.usda.gov/sites/default/files/pd/SNAPsummary.xls Additional Spreadsheets provided by Candy Mountjoy (Candy.Mountjoy@fns.usda.gov), Maeve Myers (maeve.myers@fns.usda.gov) and Gene Austin (Gene.Austin@fns.usda.gov); http://www.fns.usda.gov/sites/default/files/pd/10sbcash.xls http://www.fns.usda.gov/sites/default/files/pd/16SNAPpartHH.xls; http://www.fns.usda.gov/sites/default/files/pd/34SNAPmonthly.xls http://www.fns.usda.gov/sites/default/files/pd/15SNAPpartPP.xls; http://www.fns.usda.gov/sites/default/files/pd/06slcash.xls 
Table 2.2 Characteristics of SNAP Recipients

\begin{tabular}{|c|c|c|c|c|c|}
\hline & 1996 & 2000 & 2005 & 2010 & 2012 \\
\hline \multicolumn{6}{|c|}{ All Food Stamp Households } \\
\hline Share with children & 60 & 54 & 54 & 49 & 45 \\
\hline Share female heads with children & 39 & 35 & 32 & 26 & 24 \\
\hline Share with elderly members & 16 & 21 & 17 & 16 & 17 \\
\hline Share of individuals $<18$ & 47 & 47 & 47 & 44 & 43 \\
\hline Share of individuals $>=65$ & 9 & 10 & 7 & 5 & 6 \\
\hline Share no elderly, no kids, no disabled & 15 & 11 & 16 & 24 & 25 \\
\hline Share with gross monthly income below poverty & 91 & 89 & 88 & 85 & 82 \\
\hline Share with no cash income & 10 & 8 & 14 & 20 & 20 \\
\hline Share with any earnings & 23 & 27 & 29 & 30 & 31 \\
\hline Share with no net income & 25 & 20 & 30 & 38 & 38 \\
\hline \multicolumn{6}{|l|}{ Multiple program participation; share with income from: } \\
\hline AFDC/TANF & 37 & 26 & 15 & 8 & 7 \\
\hline General Assistance & 6 & 5 & 6 & 4 & 3 \\
\hline SSI & 24 & 32 & 26 & 21 & 20 \\
\hline Social Security & 19 & 25 & 23 & 21 & 23 \\
\hline Unemployment Insurance & 2 & 2 & 2 & 7 & 5 \\
\hline Veterans Benefits & 1 & 1 & 1 & 1 & 1 \\
\hline \multicolumn{6}{|c|}{ Food Stamp Households without Elderly Members } \\
\hline Share with children & 70 & 67 & 64 & 57 & 54 \\
\hline Share female heads with children & 46 & 43 & 38 & 30 & 29 \\
\hline Share with elderly members & 0 & 0 & 0 & 0 & 0 \\
\hline Share with gross monthly income below poverty & 92 & 89 & 89 & 87 & 85 \\
\hline Share with no cash income & 12 & 10 & 16 & 22 & 23 \\
\hline Share with any earnings & 26 & 33 & 35 & 34 & 37 \\
\hline \multicolumn{6}{|l|}{ Multiple program participation; share with income from: } \\
\hline AFDC/TANF & 43 & 32 & 17 & 9 & 8 \\
\hline General Assistance & 7 & 5 & 6 & 4 & 3 \\
\hline SSI & 17 & 24 & 20 & 16 & 16 \\
\hline Social Security & 9 & 14 & 14 & 13 & 14 \\
\hline Unemployment Insurance & 2 & 2 & 2 & 8 & 6 \\
\hline Veterans Benefits & 1 & 1 & 1 & 1 & 0 \\
\hline \multicolumn{6}{|l|}{ Effective tax rate on: } \\
\hline Earned Income & 18 & 15 & 16 & 15 & 15 \\
\hline Unearned Income & 19 & 17 & 17 & 17 & 16 \\
\hline
\end{tabular}

Source: Authors' tabulations of SNAP Quality Control Data. Available at http://hostm142.mathematicampr.com/fns/ 
Table 2.3 Food Stamps Maximum Benefits by Household Size (2014)

\begin{tabular}{cccc}
\hline Household Size & $\begin{array}{c}\text { Net Income }(100 \% \\
\text { of poverty) }\end{array}$ & $\begin{array}{c}\text { Gross Income } \\
(130 \% \text { of poverty })\end{array}$ & Maximum Benefit \\
1 & $\$ 973$ & $\$ 1,265$ & $\$ 194$ \\
2 & $\$ 1,311$ & $\$ 1,705$ & $\$ 357$ \\
3 & $\$ 1,650$ & $\$ 2,144$ & $\$ 511$ \\
4 & $\$ 1,988$ & $\$ 2,584$ & $\$ 649$ \\
5 & $\$ 2,326$ & $\$ 3,024$ & $\$ 771$ \\
6 & $\$ 2,665$ & $\$ 3,464$ & $\$ 925$ \\
7 & $\$ 3,003$ & $\$ 3,904$ & $\$ 1,022$ \\
8 & $\$ 3,341$ & $\$ 4,344$ & $\$ 1,169$ \\
Each additional & $(+) \$ 339$ & $(+) \$ 440$ & $(+) \$ 146$ \\
person & & & \\
\hline
\end{tabular}

Notes: Includes Contiguous States, District of Columbia, Guam, and the Virgin Islands.

Does not include Hawaii or Alaska.

Source: Income eligibility standards from http://www.fns.usda.gov/sites/default/files/FY15 Income_Standards.pdf; Maximum allotments from http://www.fns.usda.gov/sites/default/ files/FY15_Allot_Deduct.pdf 


\section{Table 2.4 Characteristics of WIC Recipients}

\begin{tabular}{lcc}
\hline & 1994 & 2012 \\
\hline Income below 50\% FPL & 42 & 37 \\
Income below 100\% FPL & 74 & 73 \\
Income below 150\% FPL & 91 & 92 \\
& & \\
Percent of women participants who are & 52 & 43 \\
$\quad$ Pregnant & 17 & 29 \\
Breastfeeding & $\underline{31}$ & $\underline{28}$ \\
Postpartum & 100 & 100 \\
& & \\
Multiple program participation; percent with income from: & 29 & 9 \\
TANF & 40 & 37 \\
SNAP & 58 & 72 \\
Medicaid & 35 & 33 \\
SNAP and Medicaid & 36 & 24 \\
No TANF/SNAP or Medicaid & & \\
\hline
\end{tabular}

Source: "WIC Participant and Program Characteristics 2012: Final Report" FNS, USDA, December 2013 and "WIC Participant and Program Characteristics 1994" FNS, USDA.

Observations with missing data are excluded from the tabulations. 


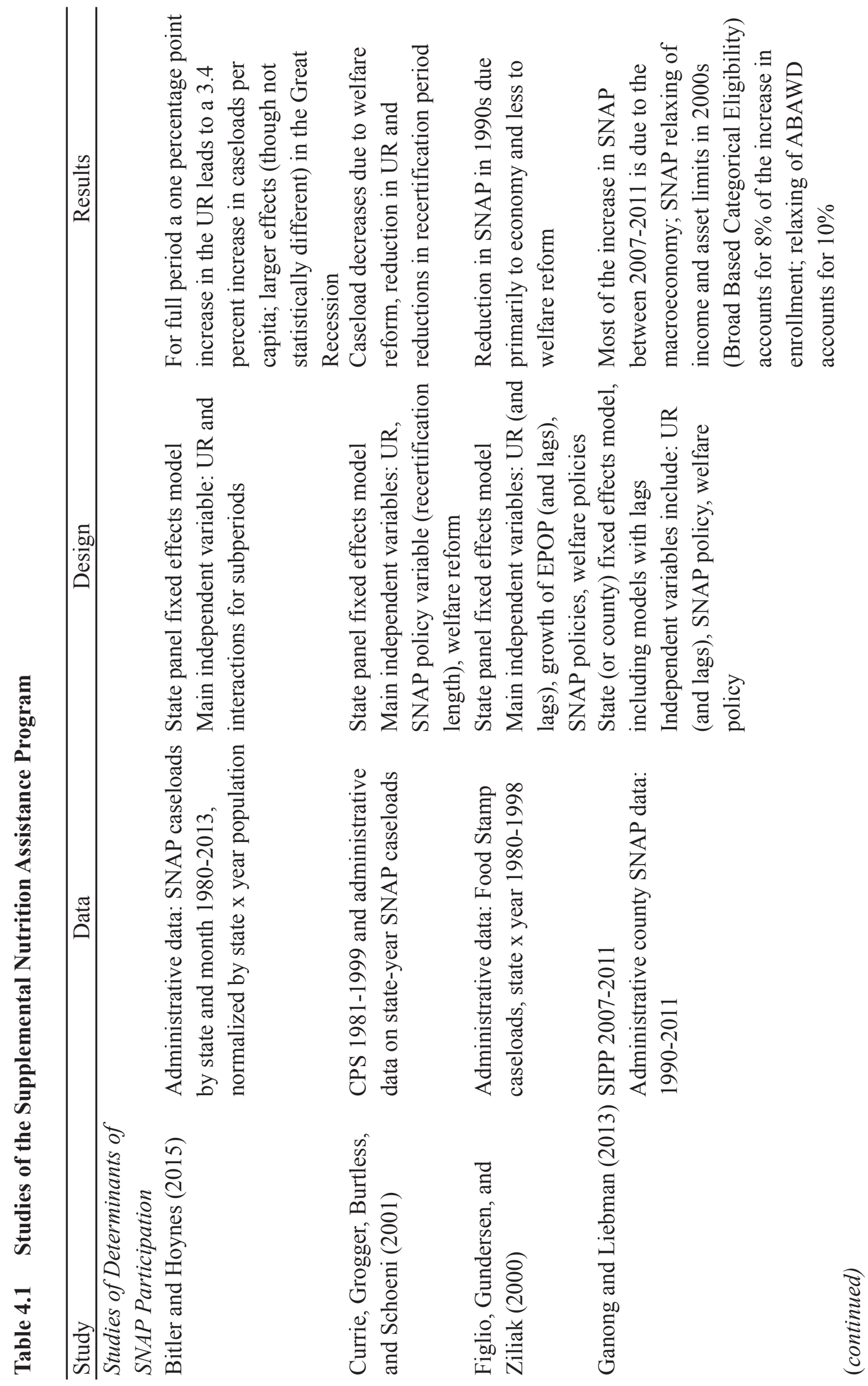




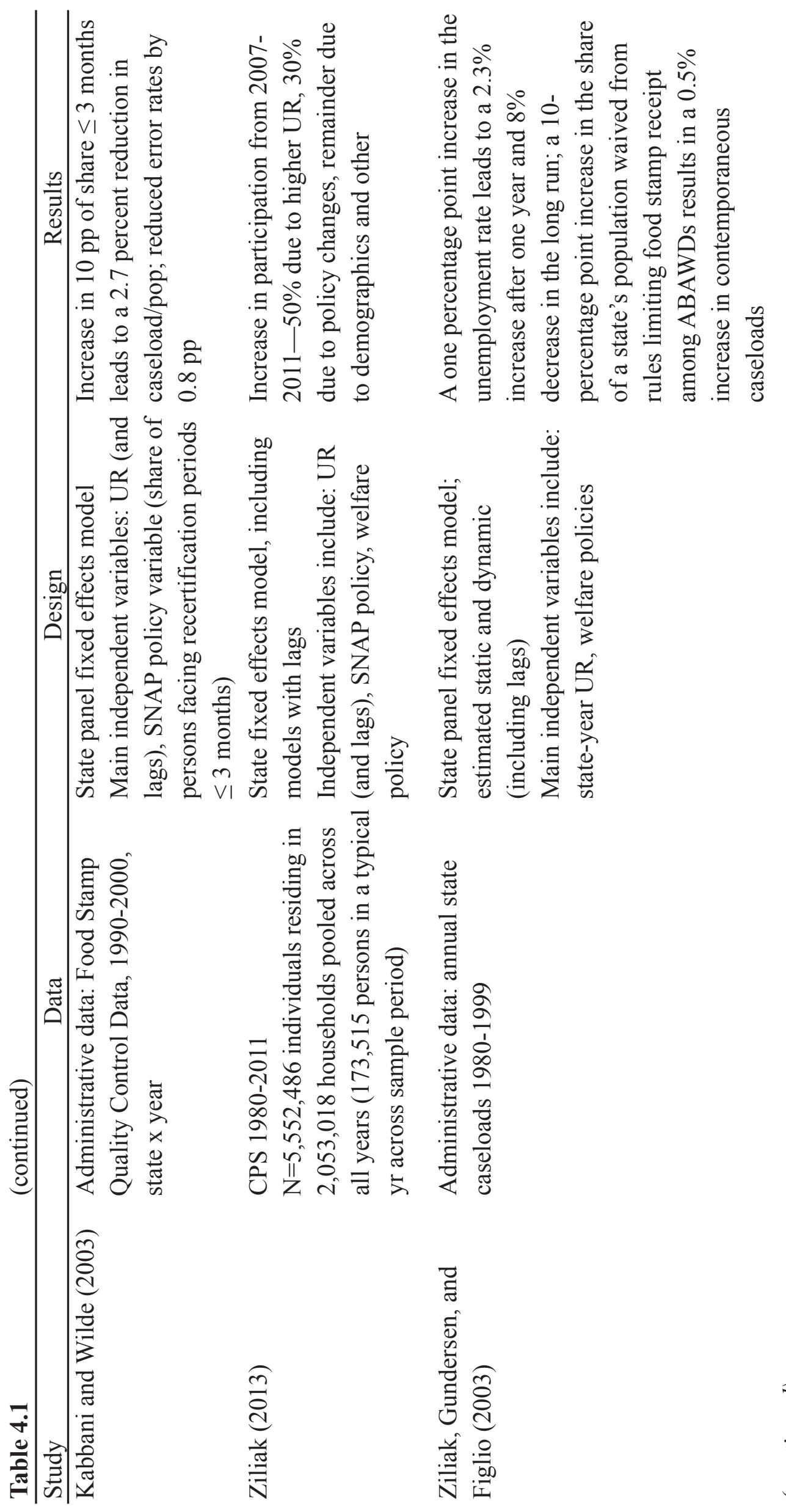




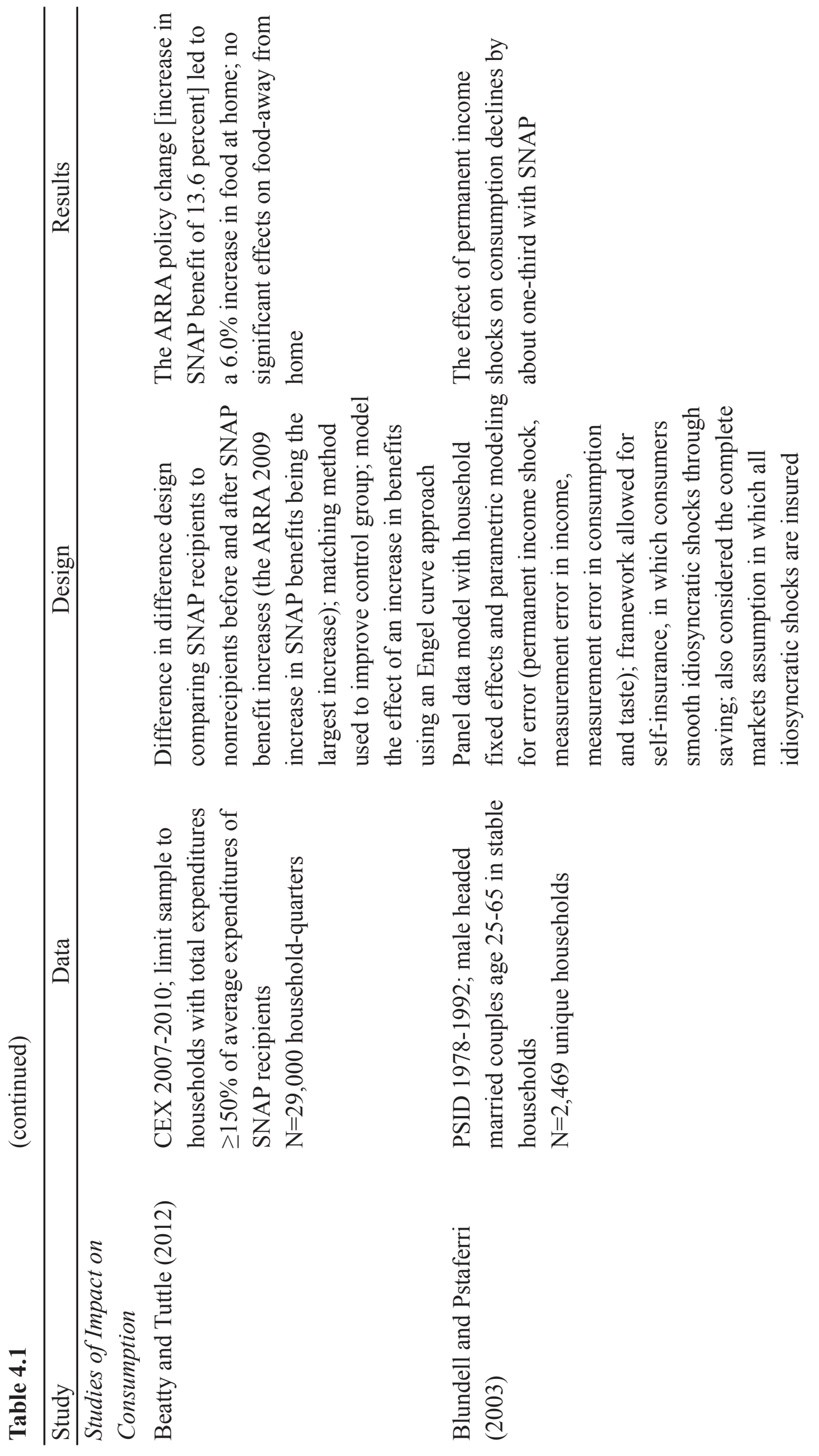




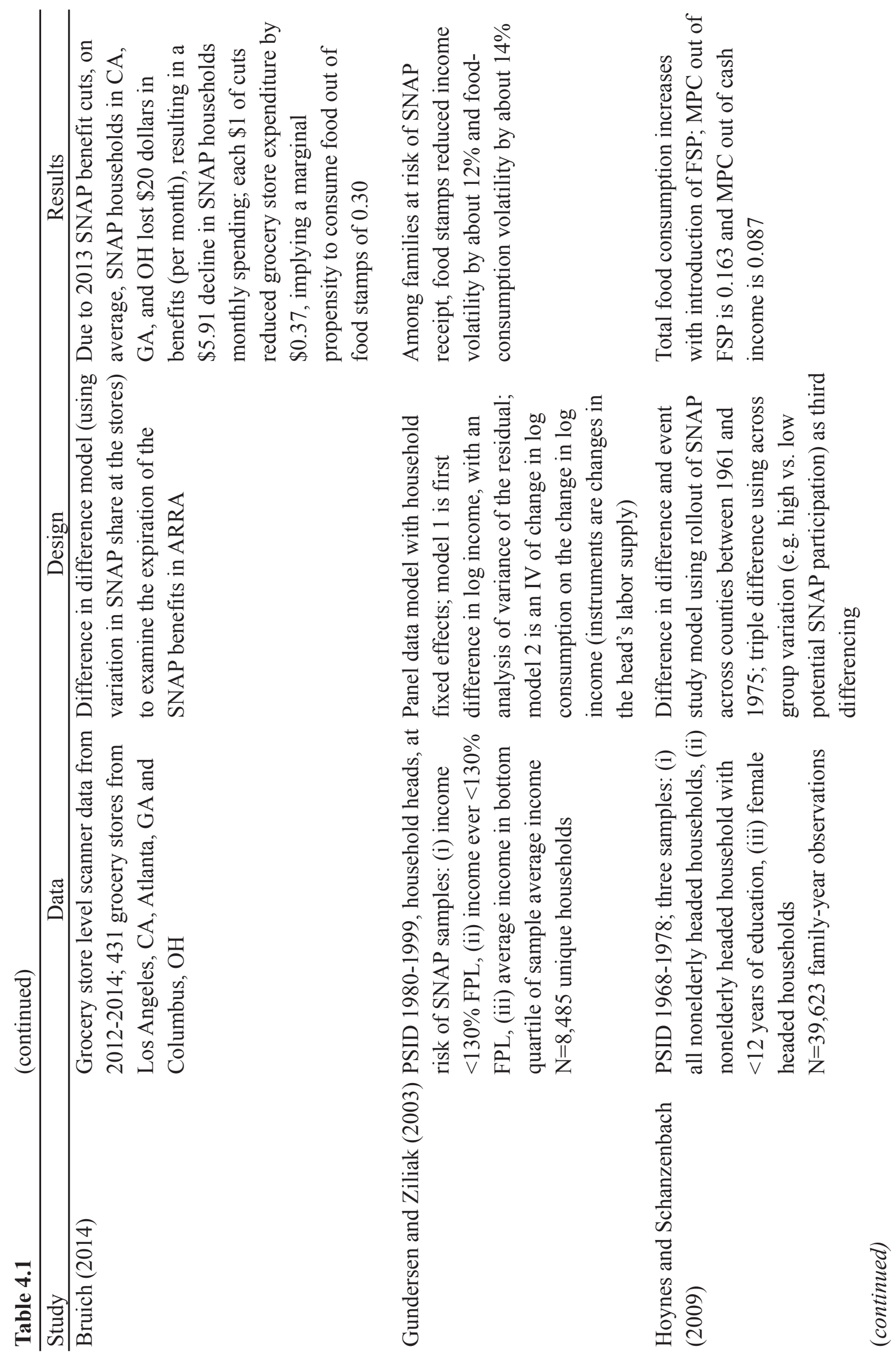




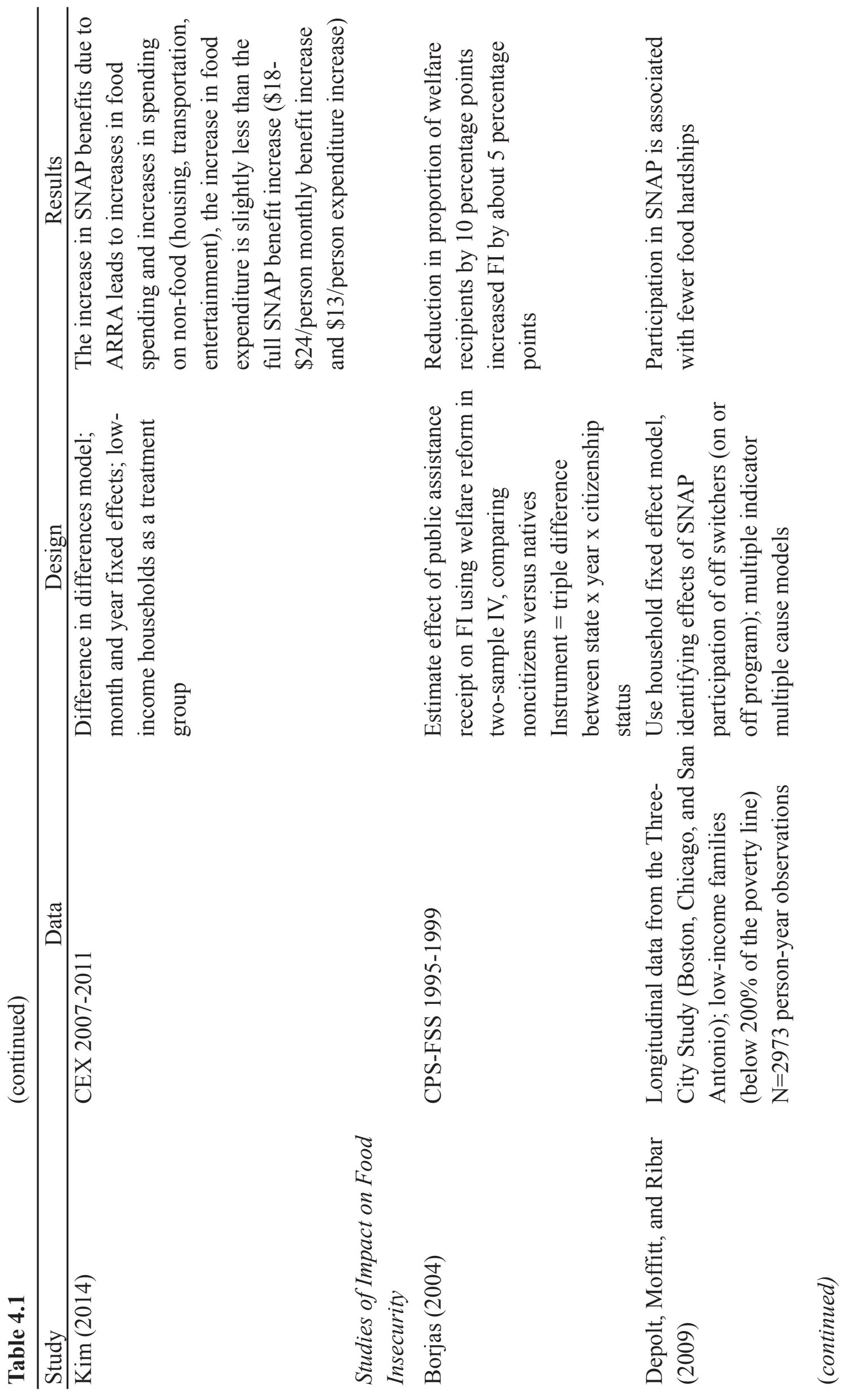




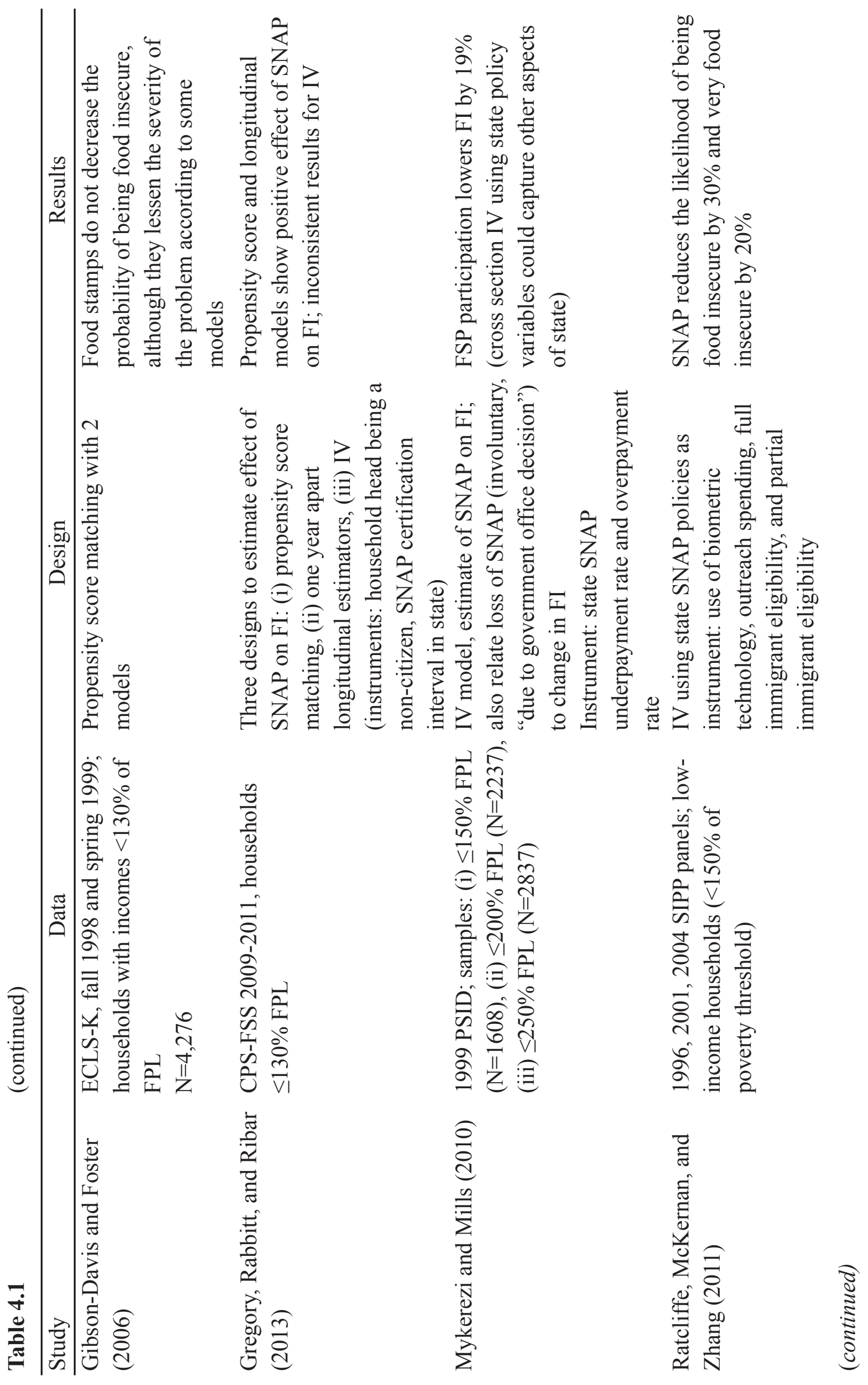




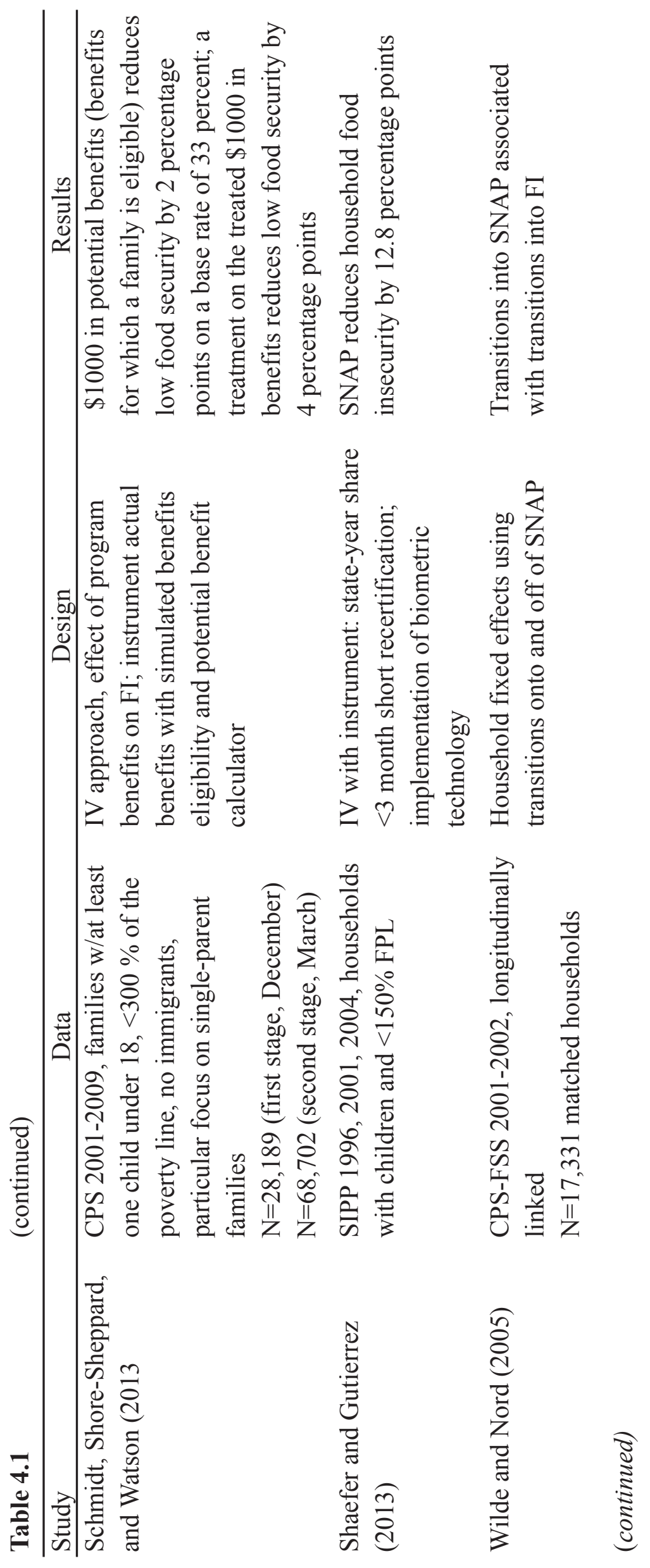




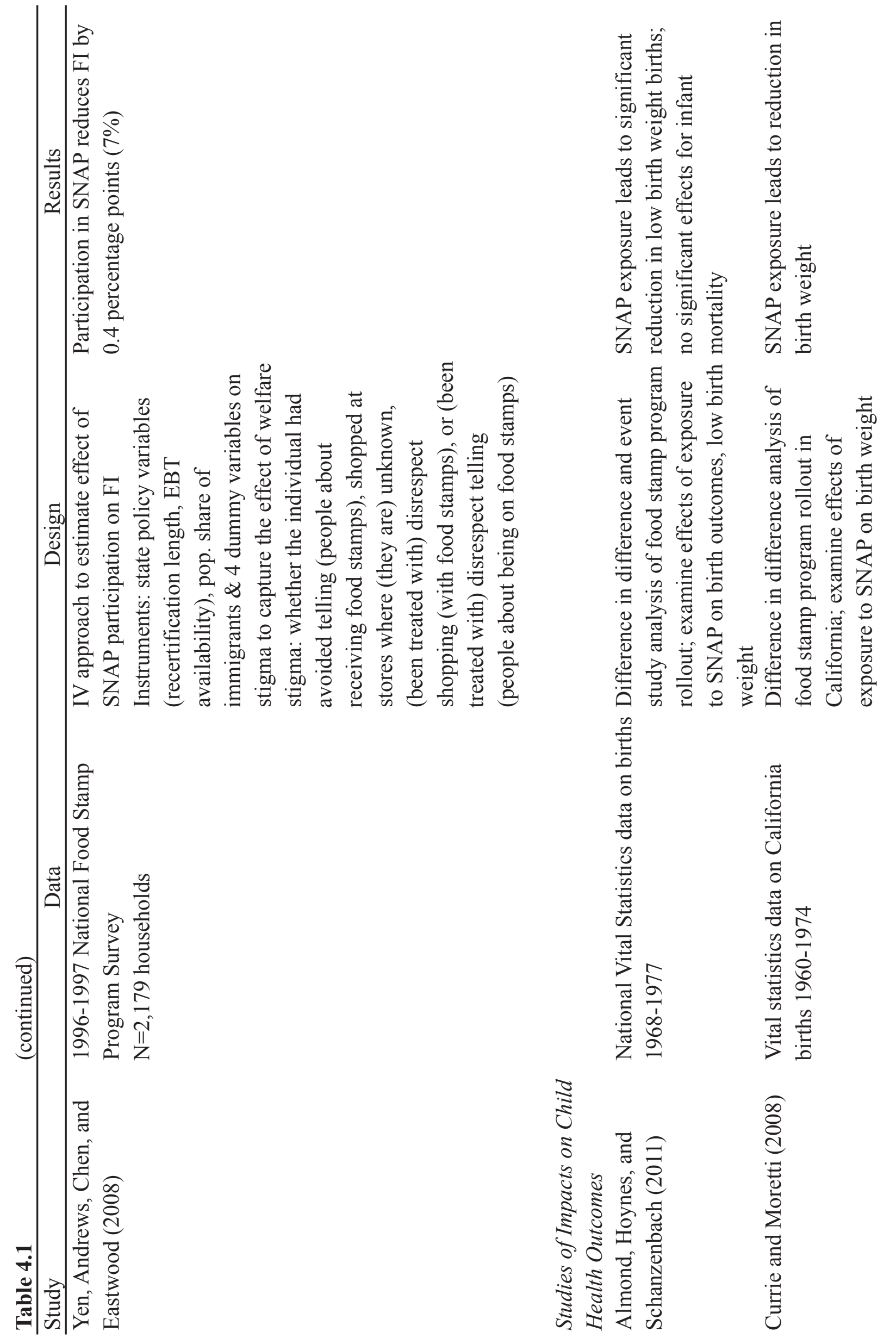




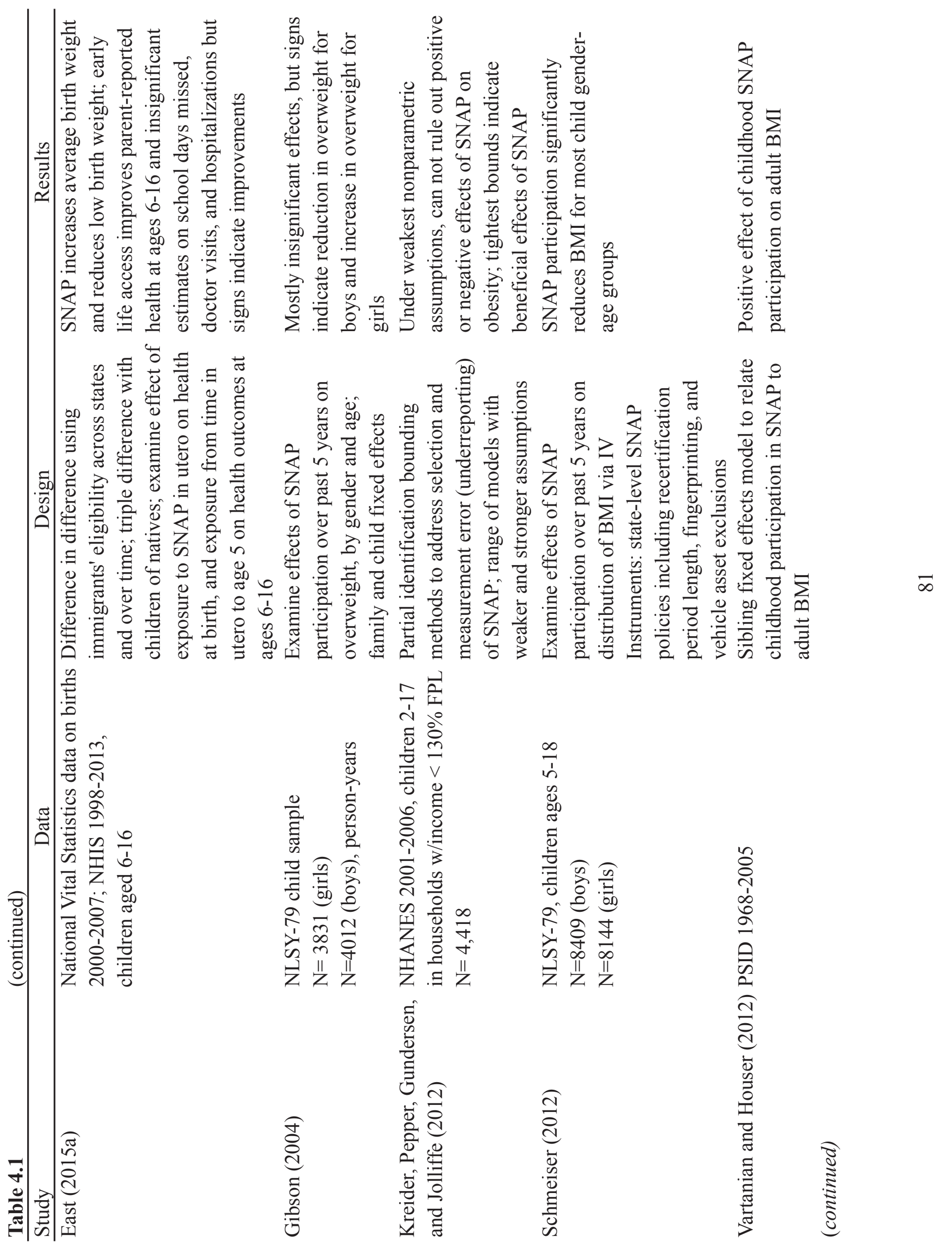




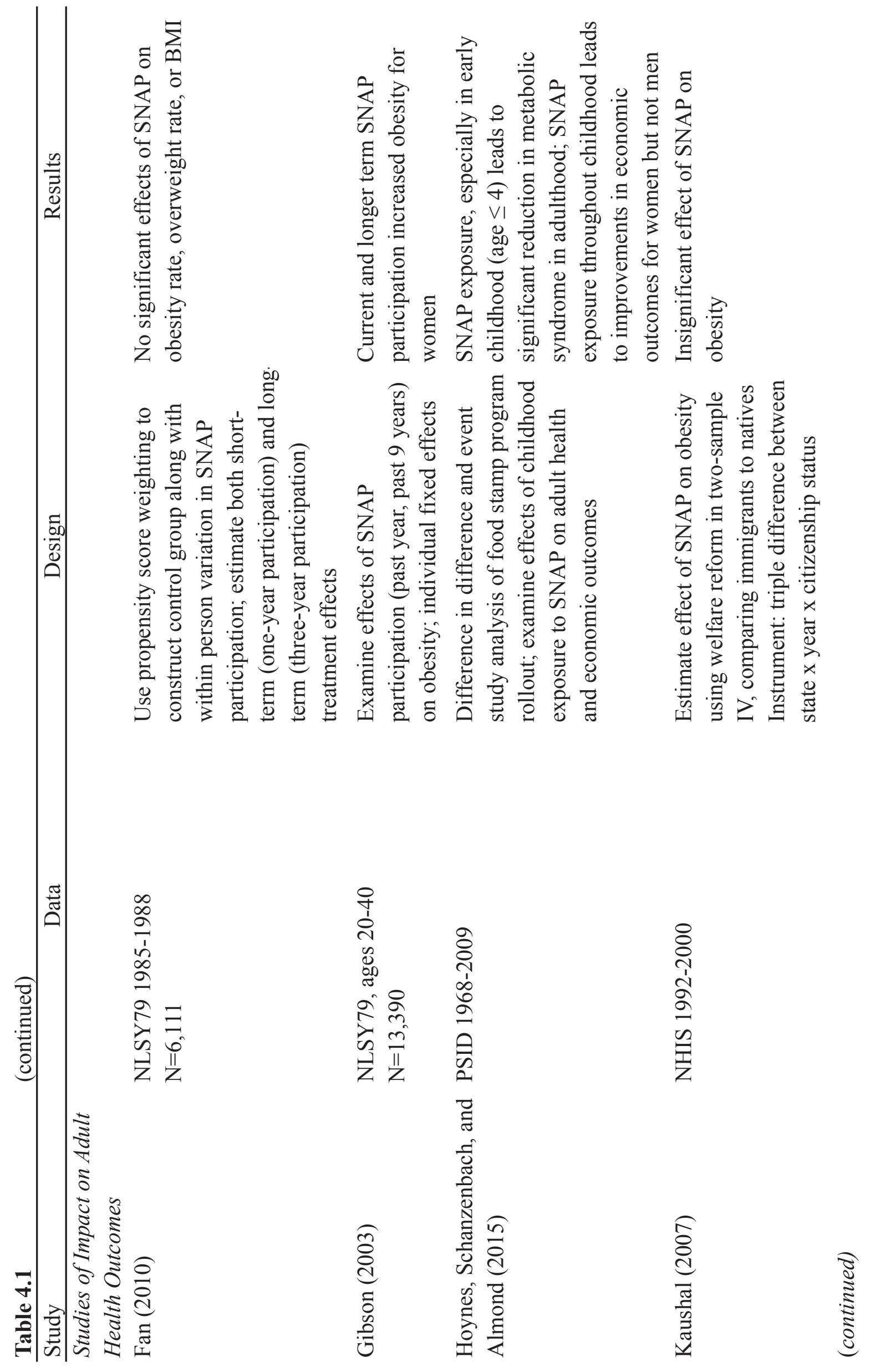




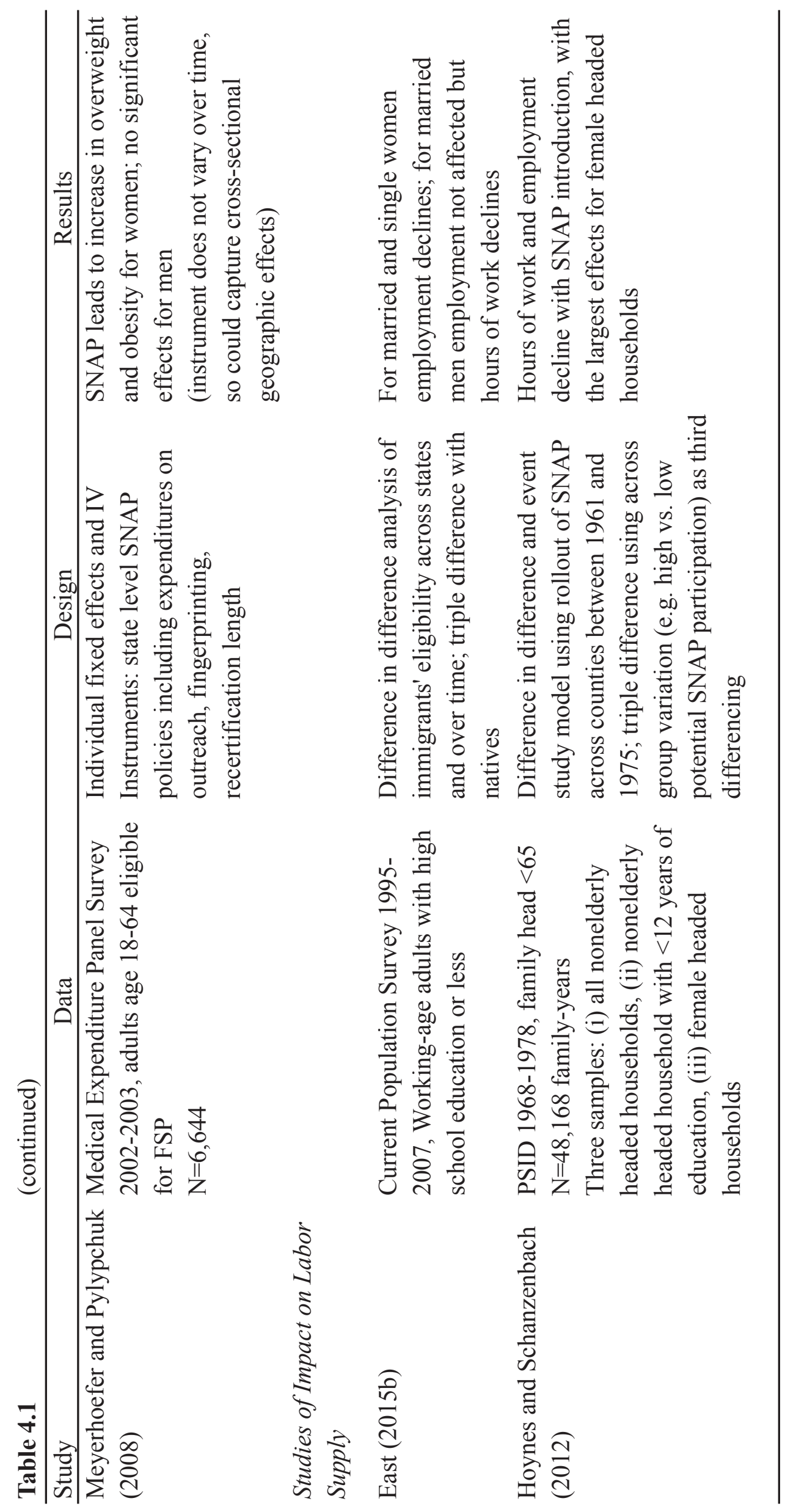




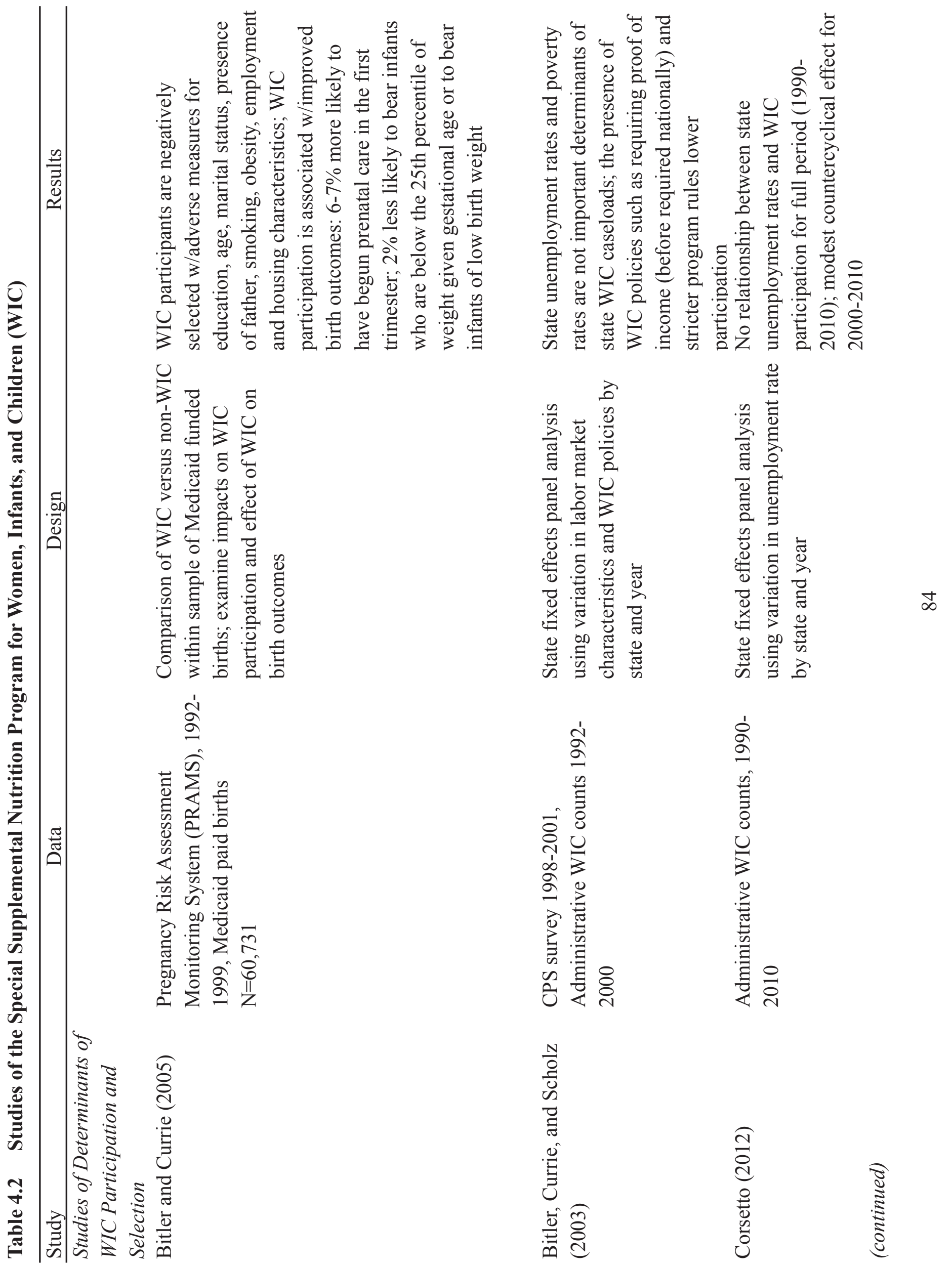




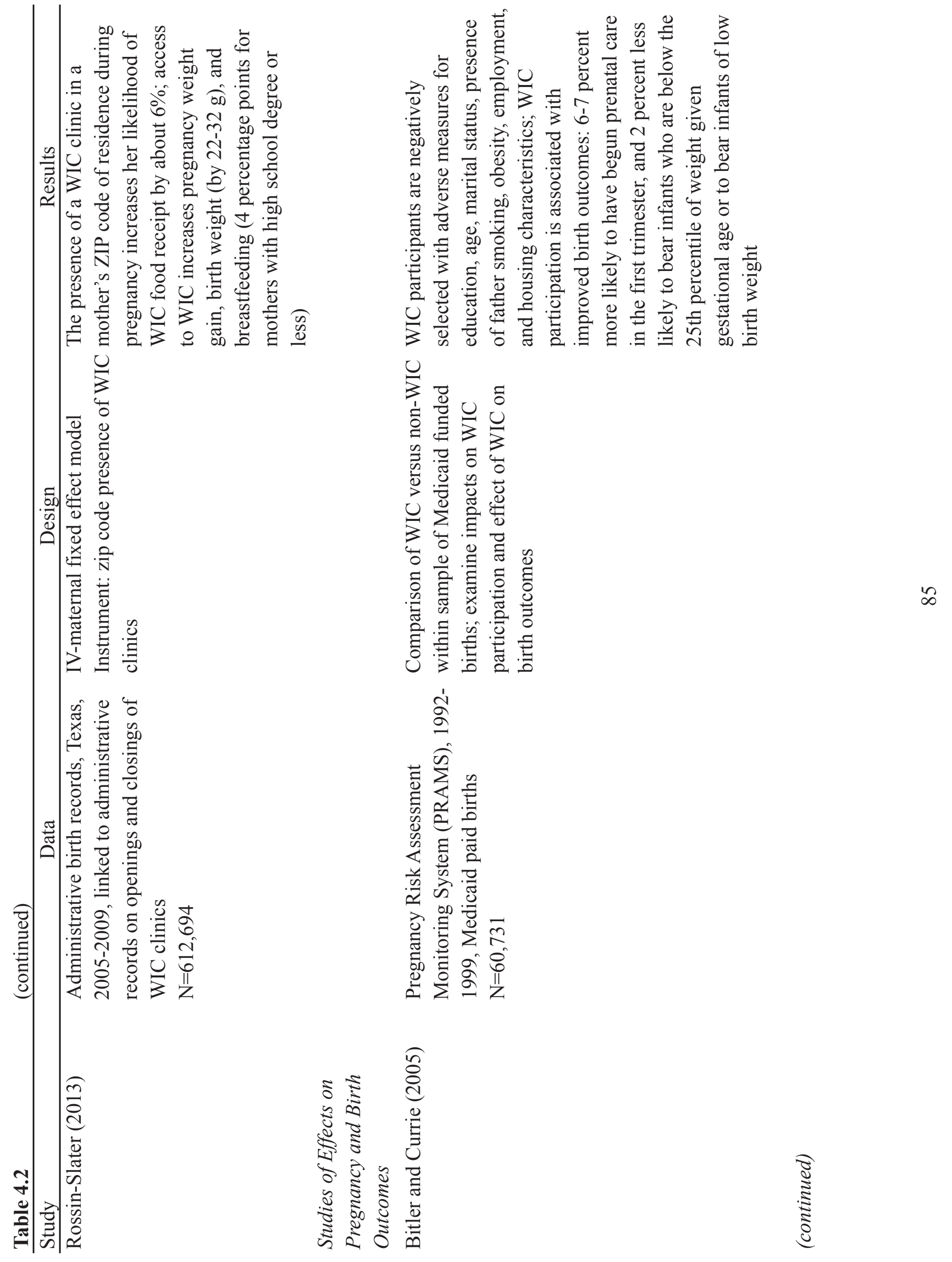




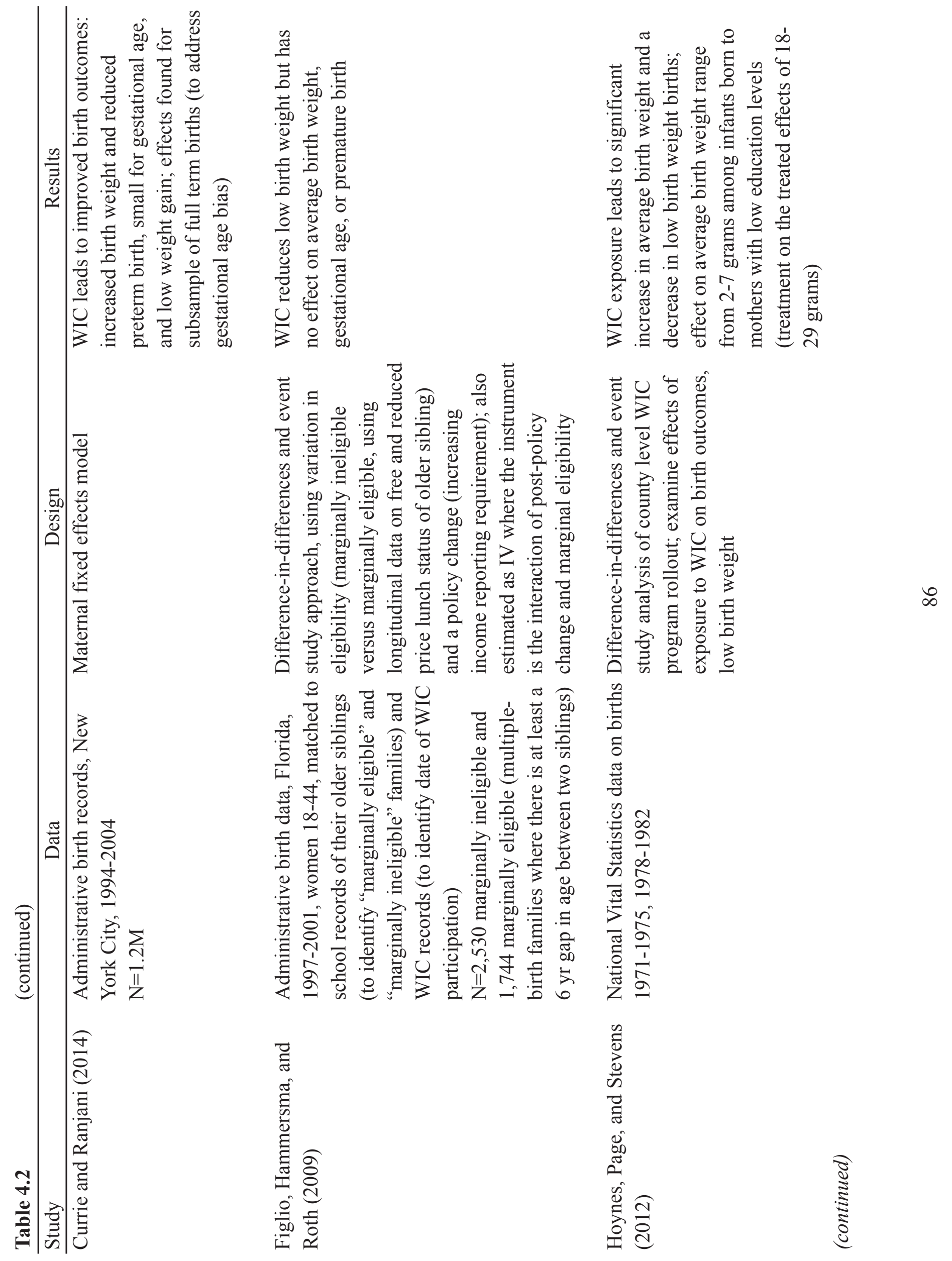




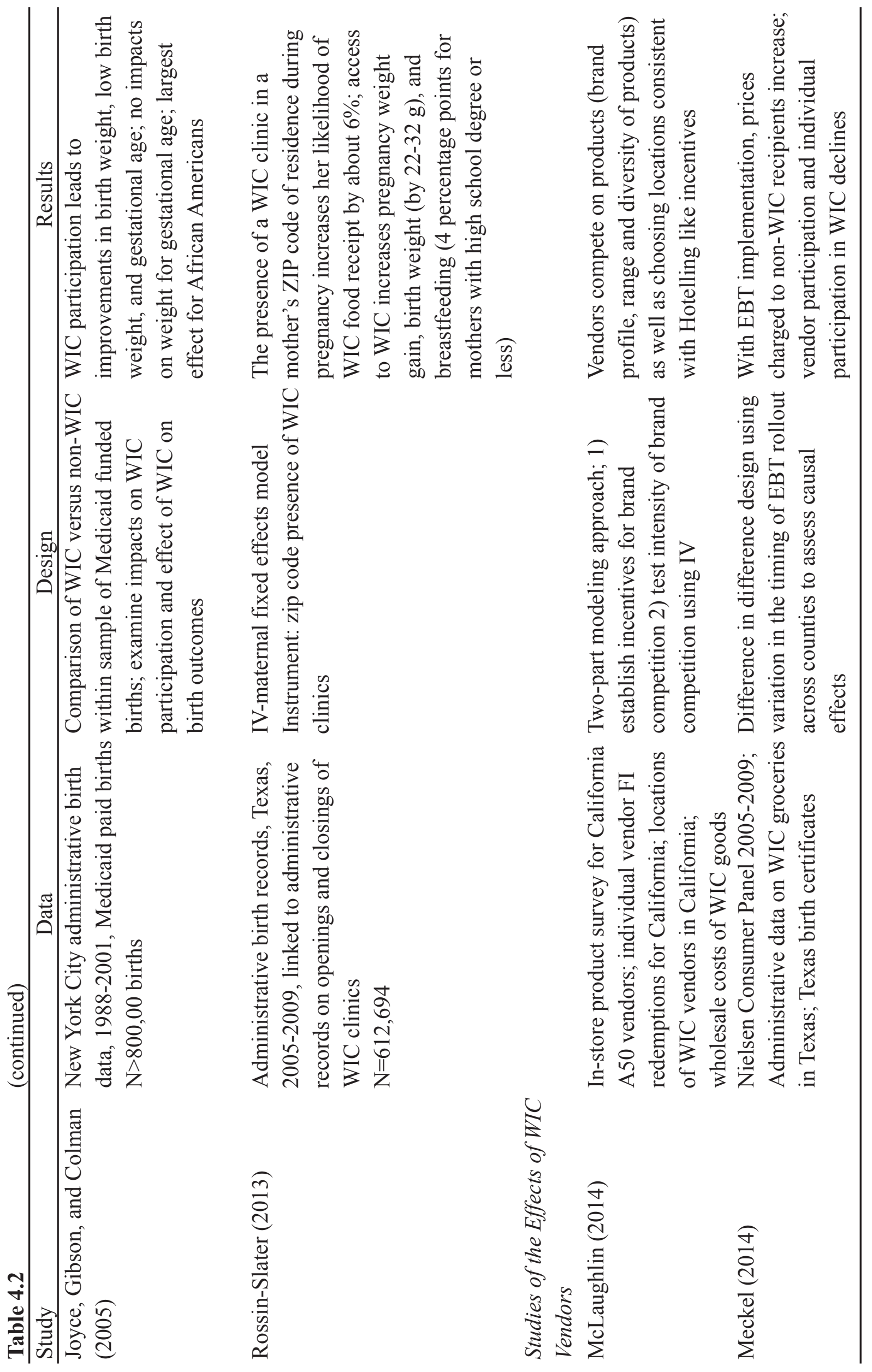




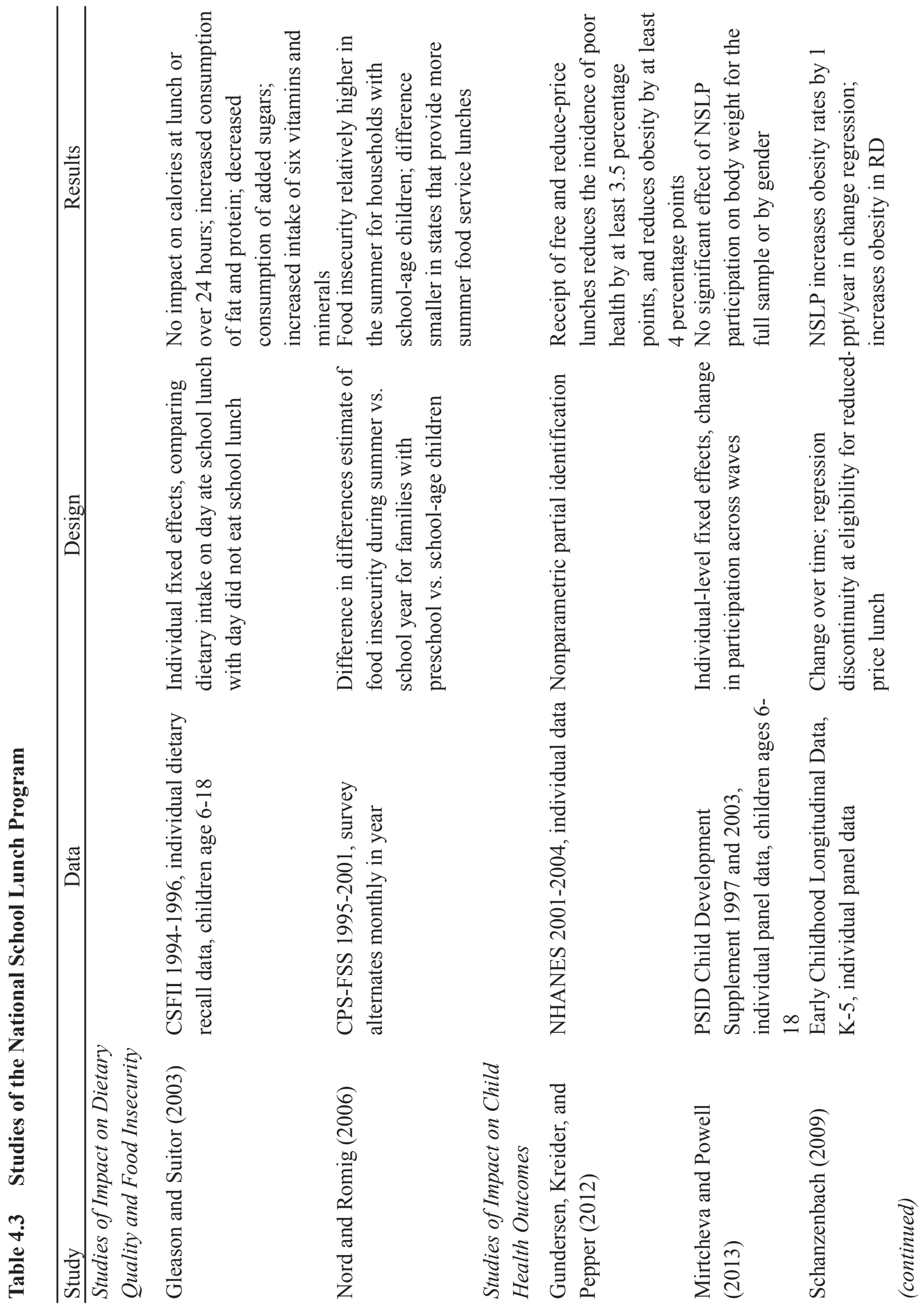




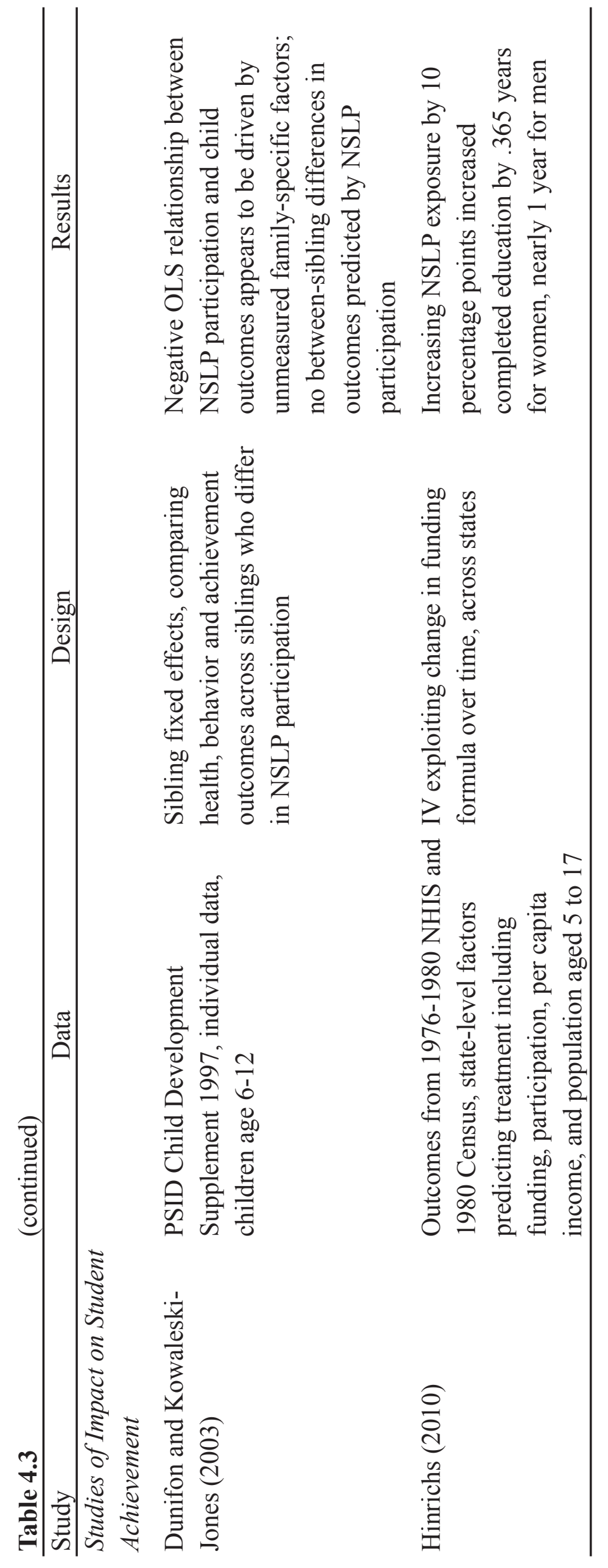




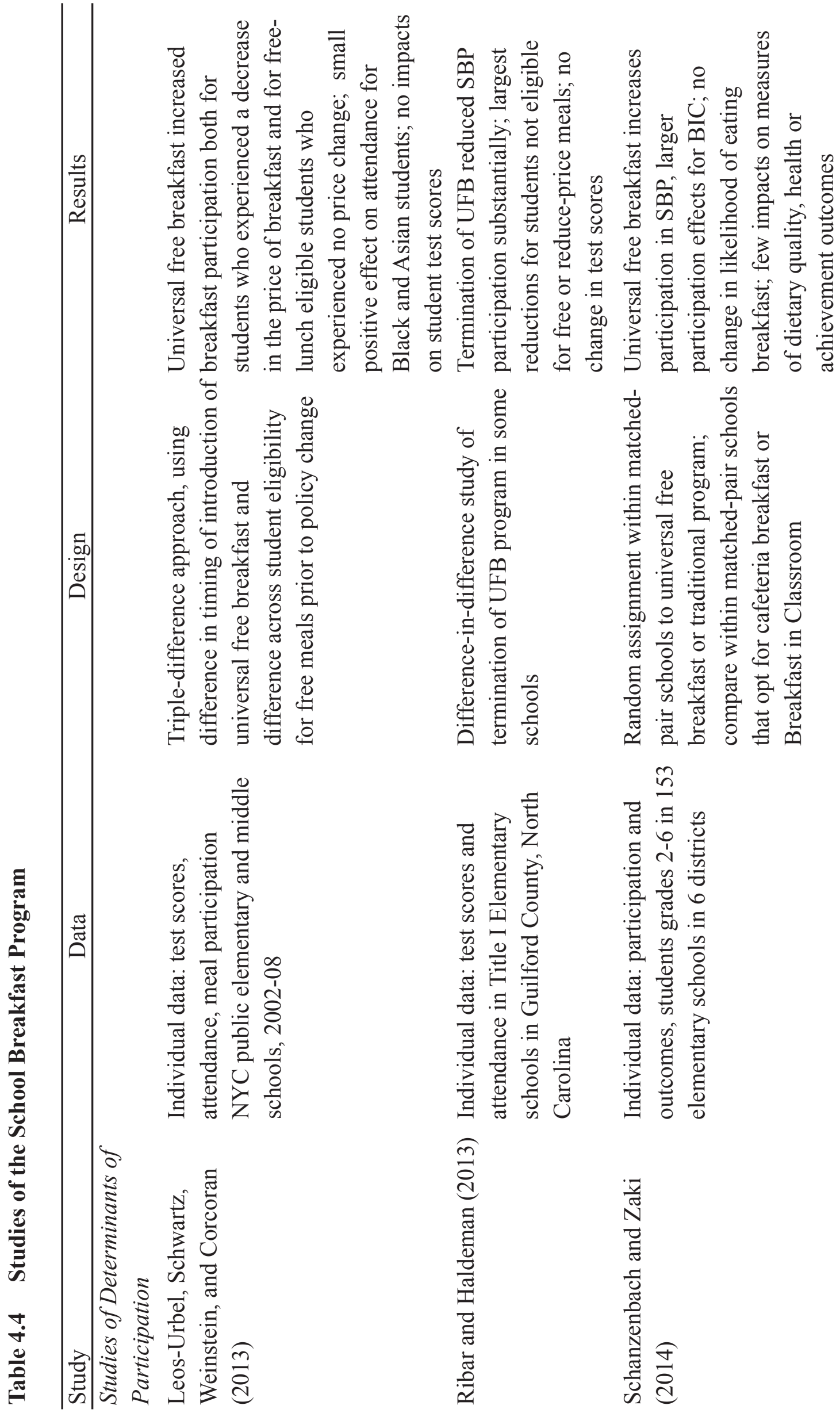




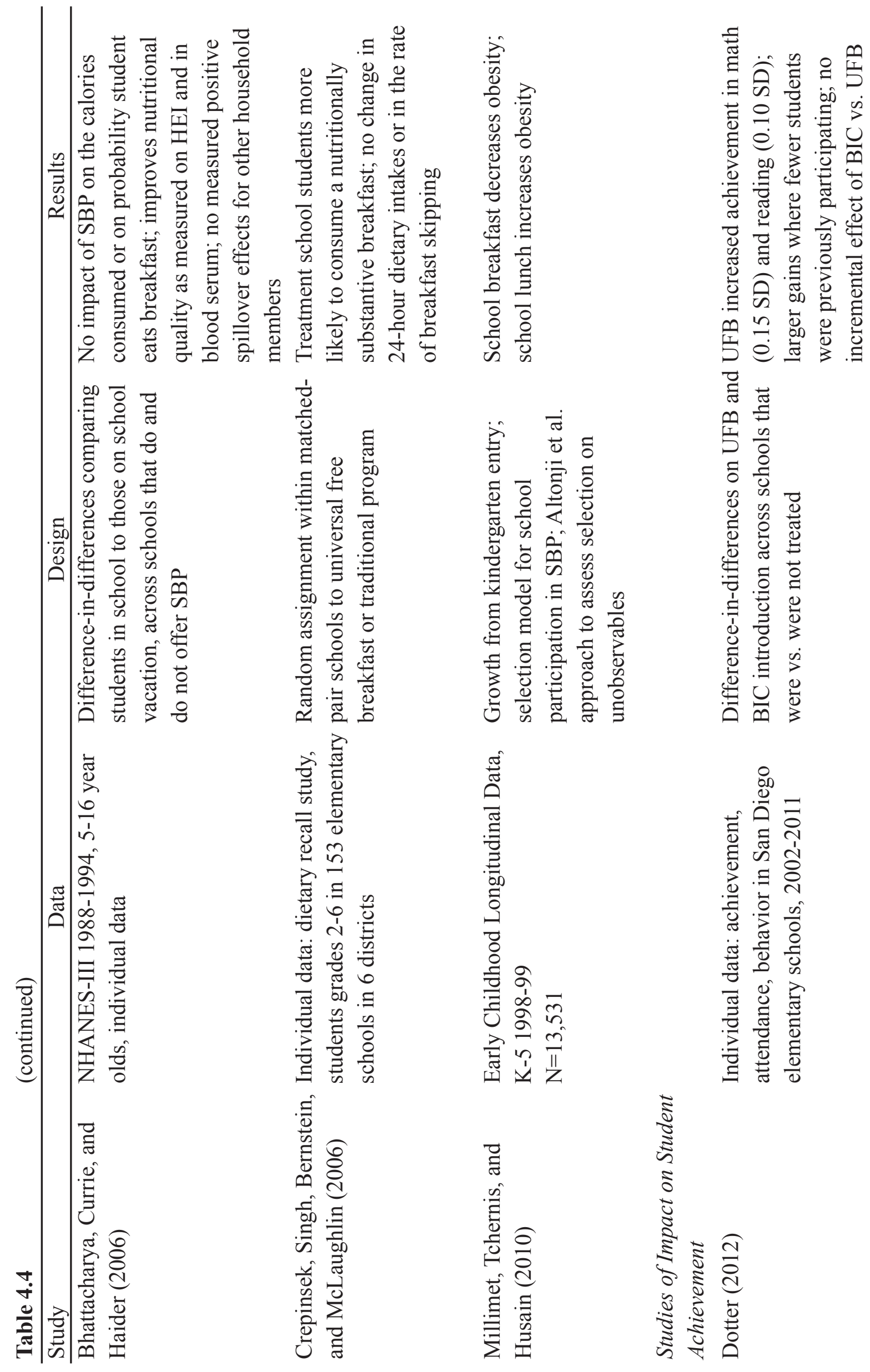




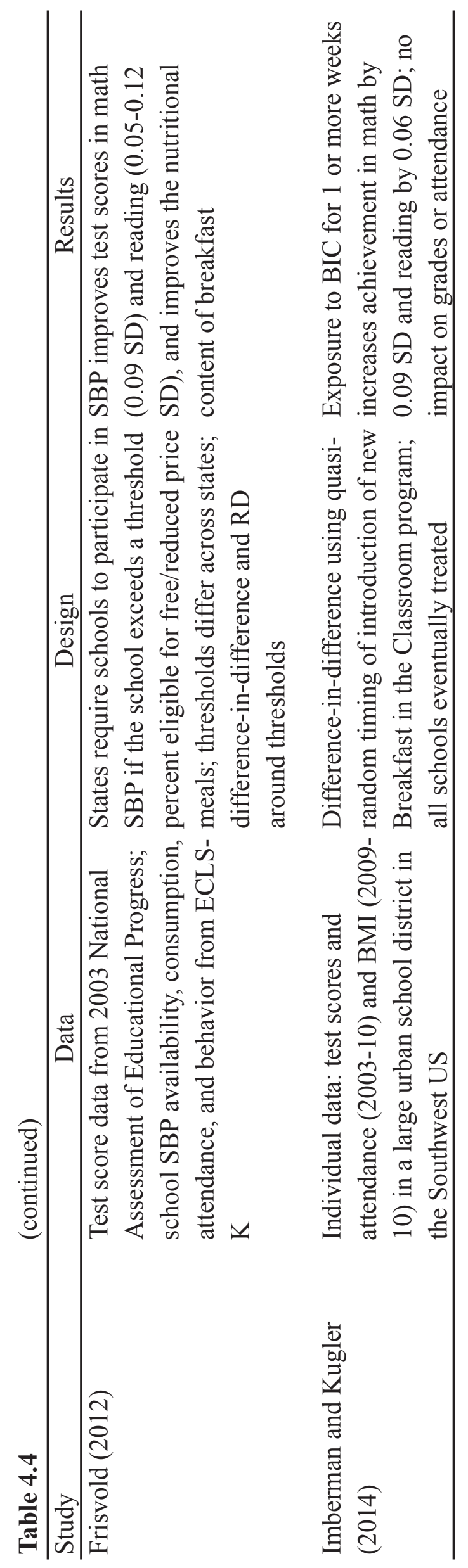

